Aus der Klinik für

Gastroenterologie und Endokrinologie

(Prof. Dr. Tilman Sauerbruch)

im Zentrum Innere Medizin

der Medizinischen Fakultät der Universität Göttingen

\title{
Zytokinabhängige Expression von EGF und VEGF und inrer Rezeptoren EGFR und VEGFR-1 im Tumormikromilieu des kolorektalen Karzinoms
}

\author{
INAUGURAL - DISSERTATION \\ zur Erlangung des Doktorgrades \\ der Medizinischen Fakultät der \\ Georg-August-Universität zu Göttingen
}

vorgelegt von

Florentine Sattler

aus Suhl

Göttingen 2014 
Dekan:

I. Berichterstatterin:

II. Berichterstatter:

III. Berichterstatter:

Tag der mündlichen Prüfung:
Prof. Dr. rer. nat. H. K. Kroemer

Prof. Dr. rer. nat. S. Mihm

PD Dr. Jochen Gaedcke

Prof. Dr. Martin Oppermann 



\section{Inhaltsverzeichnis}

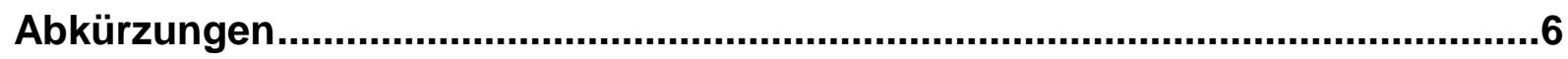

1) Einleitung: Entzündung und Tumorwachstum ................................................9

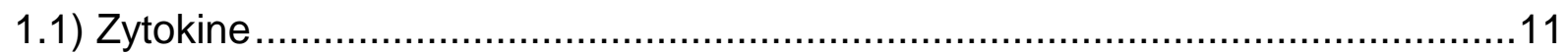

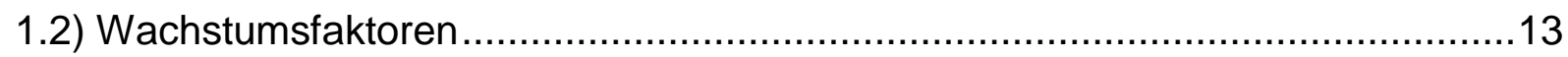

1.2.1) Epidermaler Wachstumsfaktor (EGF) und sein Rezeptor (EGFR) ....... 13

1.2.2) Der vaskuläre endotheliale Wachstumsfaktor (VEGF) und seine

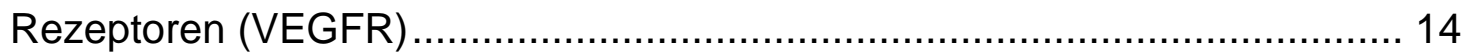

1.3) Monoklonale Antikörper in der Therapie des kolorektalen Karzinoms ...............18

1.3.1) EGFR-Blockade .................................................................... 18

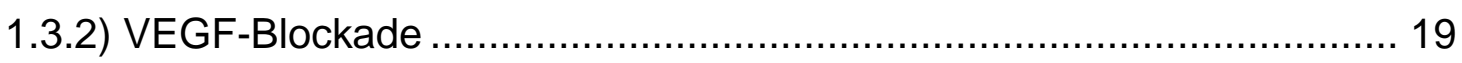

1.4) Antikörpertherapie entzündlicher Erkrankungen: Infliximab............................20

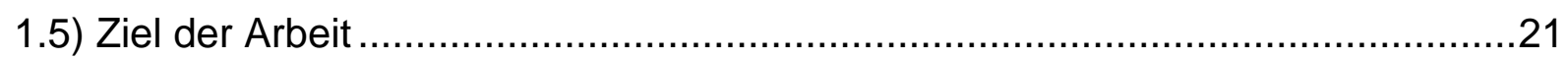

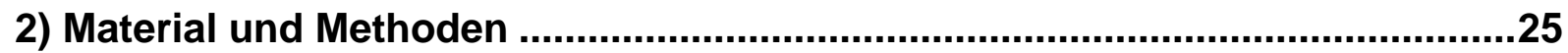

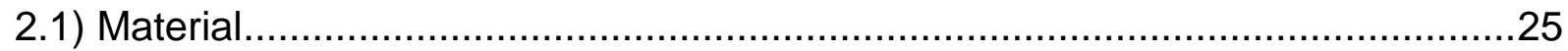

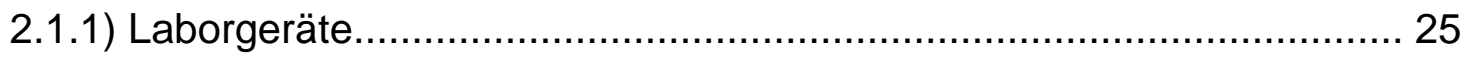

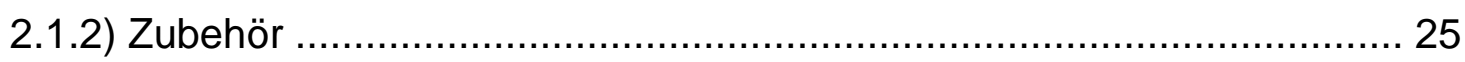

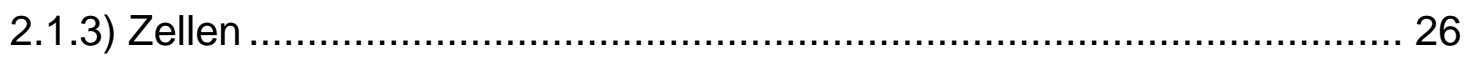

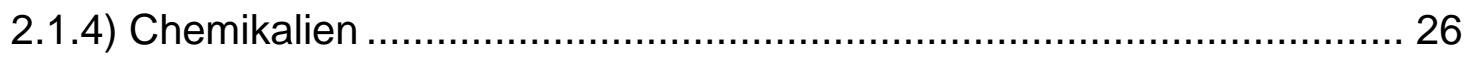

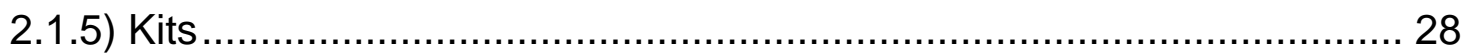

2.1.6) Primer-Sequenzen Real-Time-PCR ........................................... 28

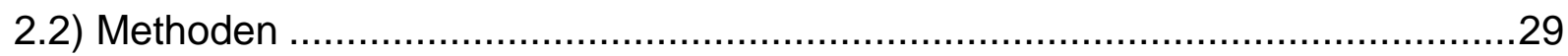

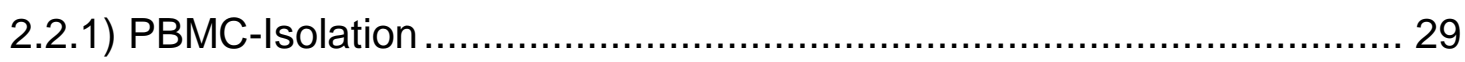

2.2.2) Stimulation und Inkubation der Zellen und Zellernte .......................... 30

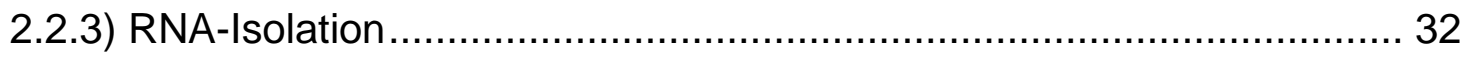

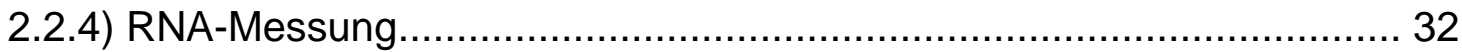

2.2.5) Reverse Transkription (RT) und Polymerasekettenreaktion (PCR)...... 32

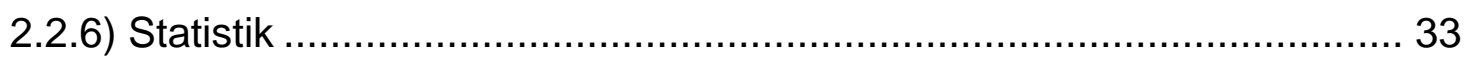

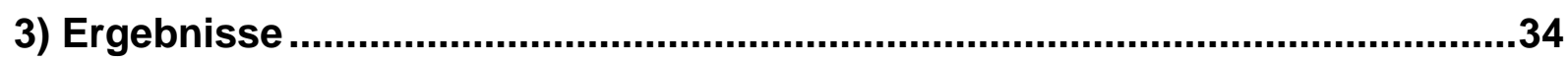

3.1) Regulation der Expression der Wachstumsfaktoren und ihres Rezeptors in PBMCs 
3.1.1) Regulation der EGF- und EGFR-mRNA-Expression in PBMCs.......... 34

3.1.2) Regulation der VEGF mRNA-Expression in PBMCs.......................... 35

3.1.3) Regulation der VEGFR-1 mRNA-Expression in PBMCs ..................... 42 3.2) Regulation der Expression der Wachstumsfaktoren EGF und VEGF und ihrer

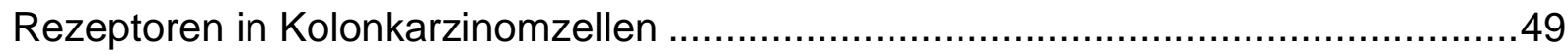

3.2.1) Regulation der EGF mRNA-Expression in DLD-1-Zellen.................... 50

3.2.2) Regulation der EGFR mRNA-Expression in DLD-1-Zellen ................. 54

3.2.3) Regulation der VEGF mRNA-Expression in DLD-1-Zellen ................ 58

3.2.4) Regulation der VEGFR-1 mRNA-Expression in DLD-1-Zellen............. 62

3.2.5) Regulation der EGF mRNA-Expression in HT-29-Zellen .................... 66

3.2.6) Regulation der EGFR mRNA-Expression in HT-29-Zellen.................. 70

3.2.7) Regulation der VEGF-mRNA-Expression in HT-29-Zellen.................. 74

3.2.8) Regulation der VEGFR-1 mRNA-Expression in HT-29-Zellen ............. 78

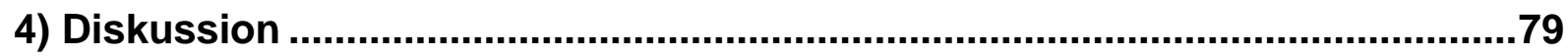

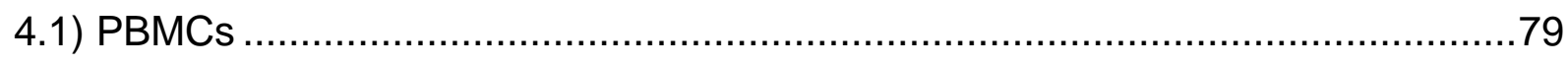

4.1.1) Expression von EGF und seinem Rezeptor EGFR-1 in PBMCs ......... 79

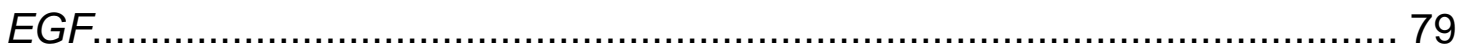

4.1.2) Expression von VEGF und seinem Rezeptor VEGFR-1 in PBMCs ..... 80

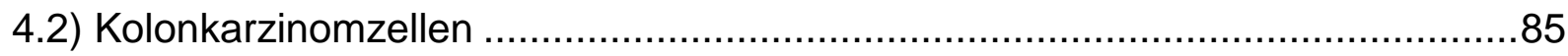

4.2.1) Expression von EGF und seinem Rezeptor EGFR-1 in unstimulierten

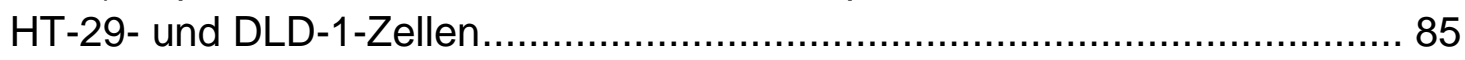

4.2.2) Expression von VEGF und seinem Rezeptor VEGFR-1 in unstimulierten

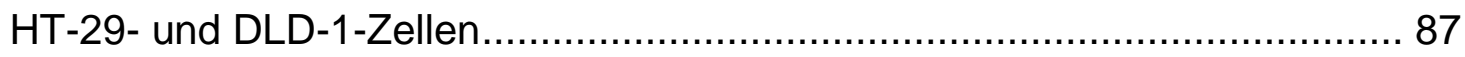

4.2.3) Regulation der Expression von EGF und VEGF sowie ihrer Rezeptoren in Kolonkarzinomzellen durch die Zytokine IL-1 $\beta$, TNF- $\alpha$ und IFN- $\gamma \ldots \ldots \ldots \ldots . . . . .89$

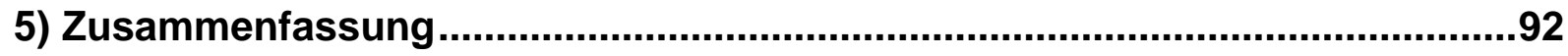

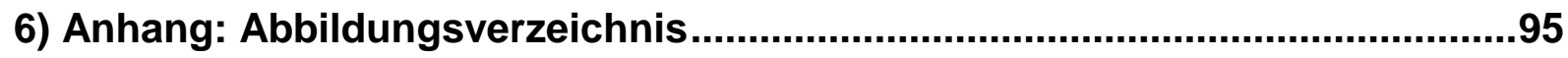

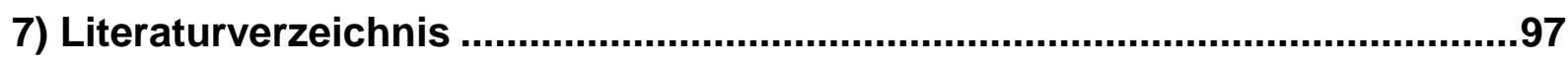




\section{Abkürzungen}

\begin{tabular}{|c|c|}
\hline AK & Antikörper \\
\hline Akt & Akt-Onkogen, das für Protein Kinase B kodiert \\
\hline ATP & Adenosintriphosphat \\
\hline bFGF & Fibroblastenwachstumsfaktor - basic fibroblast growth factor \\
\hline BRAF & Protoonkogen/ Proteinkinase BRAF \\
\hline CD14 & Opsonin-Rezeptor CD14 - cluster of differentiation 14 \\
\hline CDNA & komplementäre DNA - complementary DNA \\
\hline CED & chronisch entzündliche Darmerkrankungen \\
\hline CSF-1 & $\begin{array}{l}\text { Granulozyten-Kolonie stimulierender Faktor-1 - colony stimulating } \\
\text { factor-1 }\end{array}$ \\
\hline CT & comparative threshold \\
\hline $\begin{array}{l}\text { CXCL-10, } \\
12\end{array}$ & Chemokin CXCL-10 (Syn. IP-10, s. u.), -12 \\
\hline CXCR-4 & Chemokinrezeptor CXCR-4 (Syn. CD184) \\
\hline EDTA & Ethylendiamintetraacetat \\
\hline EGF & epidermaler Wachstumsfaktor - epidermal growth factor \\
\hline EGFR & $\begin{array}{l}\text { epidermaler Wachstumsfaktor-Rezeptor - epidermal growth factor } \\
\text { receptor }\end{array}$ \\
\hline ERK & extracellular signal regulated kinase (eine MAPK, s.u.) \\
\hline Flt-1 & Syn. VEGFR-1, s. u. \\
\hline GIST & gastrointestinaler Stromatumor \\
\hline GRB-2 & growth factor receptor-bound protein-2 \\
\hline HER2/neu & Syn. EGFR, s. o. \\
\hline HB-EGF & $\begin{array}{l}\text { heparinbindender Epidermaler Wachstumsfaktor - heparin binding } \\
\text { epidermal growth factor }\end{array}$ \\
\hline $\mathrm{HIF}-1(\alpha)$ & Hypoxie-induzierter Faktor-1 (alpha) \\
\hline ICAM-1 & $\begin{array}{l}\text { interzelluläres Adhäsionsmolekül-1, Syn. CD54 - intercellular } \\
\text { adhesion molecule-1 }\end{array}$ \\
\hline IFN-ץ & Interferon- $\mathrm{Y}$ \\
\hline $\mathrm{IL}-1 \beta,-6,-8$ & Interleukin-1 $\beta,-6,-8$ \\
\hline ILR-1 & Interleukinrezeptor-1 \\
\hline IP-10 & Interferon- $\gamma$-induziertes Protein -10 (Syn. CXCL-10, s. o.) \\
\hline IRF-1 & Transkriptionsfaktor IRF-1- interferon regulatory factor-1 \\
\hline $\mathrm{kDa}$ & Kilodalton \\
\hline KRAS & "kirsten rat sarcoma”-Onkogen bzw. -Protein \\
\hline LOF & loss of function \\
\hline
\end{tabular}




\begin{tabular}{|l|l|}
\hline LPS & Lipopolysaccharid \\
\hline mAb & monoklonaler Antikörper - monoclonal antibody \\
\hline $\begin{array}{l}\text { (p38) MAPK } \\
\text { (-KK) }\end{array}$ & (p38) mitogen-aktivierte Proteinkinase (-Kinase-Kinase) \\
\hline MCP-1 & Makrophagen-Chemoattraktorprotein-1 \\
\hline MEK & mitogen-aktivierte ERK-Kinase (s. o.) \\
\hline MMP-9 & Matrix-Metalloproteinase-9 \\
\hline mRNA & Boten-RNA - messenger RNA \\
\hline mTOR & Protein “mammalian Target Of Rapamycin" \\
\hline NF-kB & nukleärer Faktor kappa B \\
\hline NK-Zellen & natürliche Killerzellen \\
\hline P & Phosphat \\
\hline PBMCs & Periphere Blutmonozyten - peripheral blood mononuclear cells \\
\hline PBS & phosphatgepufferte Salzlösung - phosphate buffered saline \\
\hline PCR & Polymerase-Kettenreaktion - polymerase chain reaction \\
\hline PHA & Phytohämagglutinin \\
\hline PI3(-)K & Phosphoinositid-3-Kinase \\
\hline PIGF & plazentarer Wachstumsfaktor - plazenta growth factor \\
\hline PTEN & phosphatase and tensin homologue \\
\hline RA & Rheumatoide Arthritis \\
\hline RAS & G-Protein RAS \\
\hline RT & reverse Transkription \\
\hline SD & Standardabweichung - standard deviation \\
\hline SOS & Guanin-Nukleotid-Austauschfaktor SOS \\
\hline Src & Tyrosinkinase Src \\
\hline STAT & $\begin{array}{l}\text { Transkriptionsfaktoren der STAT(signal transducers and activators of } \\
\text { transcription )-Gruppe }\end{array}$ \\
\hline s-VEGFR-1 & $\begin{array}{l}\text { lösliche Form des vaskulären Wachstumsfaktorrezeptors-1 - soluble } \\
\text { vascular endothelial growth factor receptor-1 }\end{array}$ \\
\hline transforming growth factor-alpha/beta \\
\hline s/mTNF- $\alpha$ & $\begin{array}{l}\text { löslicher / membrangebundener Tumor-Nekrose-Faktor alpha - } \\
\text { soluble/ membrane-bound Tumor Necrosis Factor-alpha }\end{array}$ \\
\hline TNFR 1/2 & Tumor-Nekrose-Faktor-Rezeptor 1/2 \\
\hline TKI & Tyrosinkinase-Inhibitor \\
\hline tPA & $\begin{array}{l}\text { gewebsspezifischer Plasminogenaktivator - tissue plasminogen } \\
\text { activator }\end{array}$ \\
\hline uPA & Urokinase-Typ Plasminogen Aktivator \\
\hline VEGF(-A/B) & $\begin{array}{l}\text { vaskulärer endothelialer Wachstumsfaktor (-A/B) - vascular } \\
\text { endothelial growth factor (-A/B) }\end{array}$ \\
\hline
\end{tabular}




\begin{tabular}{|l|l|}
\hline VEGFR(-1/2) & $\begin{array}{l}\text { vaskulärer endothelialer Wachstumsfaktor-Rezeptor (-1/2)- vascular } \\
\text { endothelial growth factor receptor (-1/2) }\end{array}$ \\
\hline VCAM-1 & $\begin{array}{l}\text { endotheliales Adhäsionsmolekül VCAM-1 - vascular cell adhesion } \\
\text { molecule-1 }\end{array}$ \\
\hline$\overline{\mathrm{x}}$ & Mittelwert \\
\hline
\end{tabular}




\section{1) Einleitung: Entzündung und Tumorwachstum}

Bereits Rudolf Virchow postulierte, dass sich maligne Tumoren aus entarteten organbzw. gewebseigenen Zellen und einem leukozytären Infiltrat zusammensetzen (Virchow 1867) und stellte die Theorie auf, dass das entzündliche Infiltrat Voraussetzung für die maligne Entartung ortsständiger Zellen ist. Dieser Zusammenhang von Entzündung und Karzinogenese wurde seitdem beispielsweise durch das Ösophaguskarzinom bei gastroösophagealem Reflux, das Magenkarzinom bei Helicobacter pylori-assoziierter Gastritis oder das kolorektale Karzinom auf dem Boden chronisch entzündlicher Darmerkrankungen (CED) untermauert. Dabei führt ein lokaler Reiz zum Zelluntergang im ortsständigen Gewebe, und es kommt zur Rekrutierung aktivierter Immunzellen aus dem Blut an den Ort der Reizeinwirkung. Folge ist eine lokale Entzündungsreaktion. Dieses Milieu kann auf die darin enthaltenen Zellen mutagen wirken und dadurch Tumorentstehung begünstigen: ortsständige Zellen gehen zugrunde, gefolgt von erneuter Teilung und Entstehung von Zellen mit fehlerhaftem Erbgut. Man spricht hier von der Tumorinitiation (Karin und Greten 2005).

Unter Einfluss verschiedener Entzündungsmediatoren werden eingewanderte Immunzellen zur Bildung einer Vielzahl von Chemokinen und Wachstumsfaktoren, Zytokinen - wie z. B. Interferon gamma (IFN- $\mathrm{y})$ - und Proteasen angeregt. Diese Faktoren wirken modulierend auf Angiogenese und Immunsystem im betroffenen Gewebe und es kommt zur sogenannten Tumorpromotion. Als wichtiger Faktor in diesem Stadium der Tumorentwicklung hat sich der Tumor-Nekrose-Faktor alpha (TNF- $\alpha$ ) erwiesen. Er bewirkt die Produktion sogenannter tumor survival factors durch Immun- und Tumorzellen. Seine Wirkung wird durch das Zytokin Interleukin-1 beta (IL-1ß) und durch den vaskulären endothelialen Wachstumsfaktor (vascular endothelial growth factor, VEGF) ergänzt (Karin und Greten 2005). Letzterer bewirkt in erster Linie die Tumorangiogenese und sichert dadurch die Versorgung des expandierenden Gewebes mit Sauerstoff und Nährstoffen. Auch der Rezeptor für den epidermalen Wachstumsfaktor (epidermal growth factor receptor, EGFR) hat sich als für das Tumorwachstum entscheidend erwiesen, er vermittelt Zellüberleben und Zellproliferation (Yarden und Sliwkoski 2001). 
In der weiteren Entwicklung des Tumoren verschiebt sich das Gleichgewicht innerhalb des Immunzellinfiltrats von vorwiegend entzündlich aktivierten Immunzellen in Richtung immunsuppressiver, phagozytierender Zellen (Qian und Pollard 2010). Durch ihre Phagozytoseaktivität ermöglichen Immunzellen letztlich die Dissemination und Migration von Tumorzellen und ihre Invasion an anderer Stelle. In dieser Phase der Metastasierung wirkt - z. B. im Mammakarzinom - durch Makrophagen gebildeter epidermaler Wachstumsfaktor (EGF) (Wyckoff et al. 2004), aber auch TNF- $\alpha$, IL-1 $\beta$, VEGF (Vendramini-Costa und Cavalho 2012) und sein Rezeptor (VEGFR) (Kaplan et al. 2005) sind an diesem Prozess beteiligt.

Parallel zur Schaffung eines tumorgerechten Milieus vor Ort durch die Immunzellen tragen die Tumorzellen selbst zu ihrem Überleben bei. Mit der steigenden Anzahl an entarteten Zellen steigt die Menge der von innen gebildeten tumor survival factors (Tab. 1) und deren Abgabe ins Blut. Die anfänglich entzündliche Immunlage des Organismus verschiebt sich unter Einfluss dieser Faktoren - wie in der lokalen Immunreaktion - in Richtung Unterbindung einer adäquaten Immunantwort auf den Tumor (Balkwill und Mantovani 2001). Die veränderten Plasmaspiegel der beteiligten Proteine lassen sich teilweise klinisch zur Abschätzung der Prognose des erkrankten Patienten nutzen. Zudem bieten die tumor survial factors einen Angriffspunkt zur zielgerichteten Tumortherapie.

Tab. 1: tumor survival factors - Auswahl (Vendramini-Costa und Cavalho 2012)

\begin{tabular}{|c|c|}
\hline Zytokine & Chemokine \\
\hline Tumor-Nekrose-Faktor alpha (TNF- $\alpha)$ & CXCL-10, -12 \\
Interleukin-1 $\beta,-6$ (IL1- $\beta$, IL-6) & CXCR-4 \\
Interferon-y (IFN- $\gamma$ ) & Interleukin-8 (IL-8) \\
Epidermal growth factor (EGF) \\
Vascular endothelial growth factor \\
(VEGF)
\end{tabular}




\section{1) Zytokine}

\section{TNF- $\alpha$ und $I L-1 \beta$}

Sowohl TNF- $\alpha$ als auch IL-1 $\beta$ werden vorwiegend von entzündlich aktivierten Makrophagen sezerniert.

TNF- $\alpha$ liegt in einer löslichen - $s$ (oluble) TNF- $\alpha$ - und in einer membrangebundenen $m$ (embrane) TNF- $\alpha$ - Form vor. Dabei bindet die lösliche Form bevorzugt an den TNF- $\alpha$-Rezeptor 1 (TNFR1) und bewirkt so die Apoptose von Tumorzellen. Die membrangebundene Form bewirkt über Bindung an den TNF-a-Rezeptor 2 (TNFR2) und Aktivierung des nukleären Faktor $\mathrm{kB}$ (NF-kB) andererseits Zellproliferation, Zelldifferenzierung, Chemotaxis und Ausschüttung weiterer Zytokine durch Immunzellen (Holtmann und Neurath 2004). TNF- $\alpha$ trägt so maßgeblich zur Unterhaltung chronisch-entzündlicher Erkrankungen wie des Morbus Crohn sowie zur Entstehung konsekutiver kolorektaler Karzinome bei. Dabei zeigte sich, dass im Wesentlichen durch Immunzellen, und nicht durch das Darmepithel gebildeter TNF- $\alpha$ die Tumorentstehung vorantreibt (Popivanova et al. 2008). In späteren Phasen des Tumorwachstums steigert TNF- $\alpha$ die Expression von Adhäsionsmolekülen auf Endothelzellen und damit die Invasion von Tumorzellen im Rahmen der Metastasierung (Balkwill und Mantovani 2001).

IL-1 $\beta$ verfügt über antiapoptotische und zellaktivierende Eigenschaften via Bindung an den Interleukin 1-Rezeptor Typ 1 (ILR-1). Wie TNF-a bewirkt es über Induktion des NF-KB-Pathway eine Entzündungsreaktion, unter anderem im Rahmen chronisch entzündlicher Darmerkrankungen (Andus et al. 1997). Auch ist es an der späteren Metastasierung eines Tumors beteiligt, indem es die Invasivität von Tumorzellen steigert (Voronov et al. 2003).

Über Aktivierung des NF-KB-Pathway bewirken sowohl TNF- $\alpha$ als auch IL-1 $\beta$ zudem die vermehrte Transkription von sowohl TNF- $\alpha$ und IL-1 $\beta$ selbst, aber auch von VEGF und EGFR (Abb. 1). Darüber bewirken sie sowohl in der Entzündungsphase als auch in fortgeschrittenen Stadien der Tumorentstehung gesteigerte Zellproliferation und Angiogenese. 


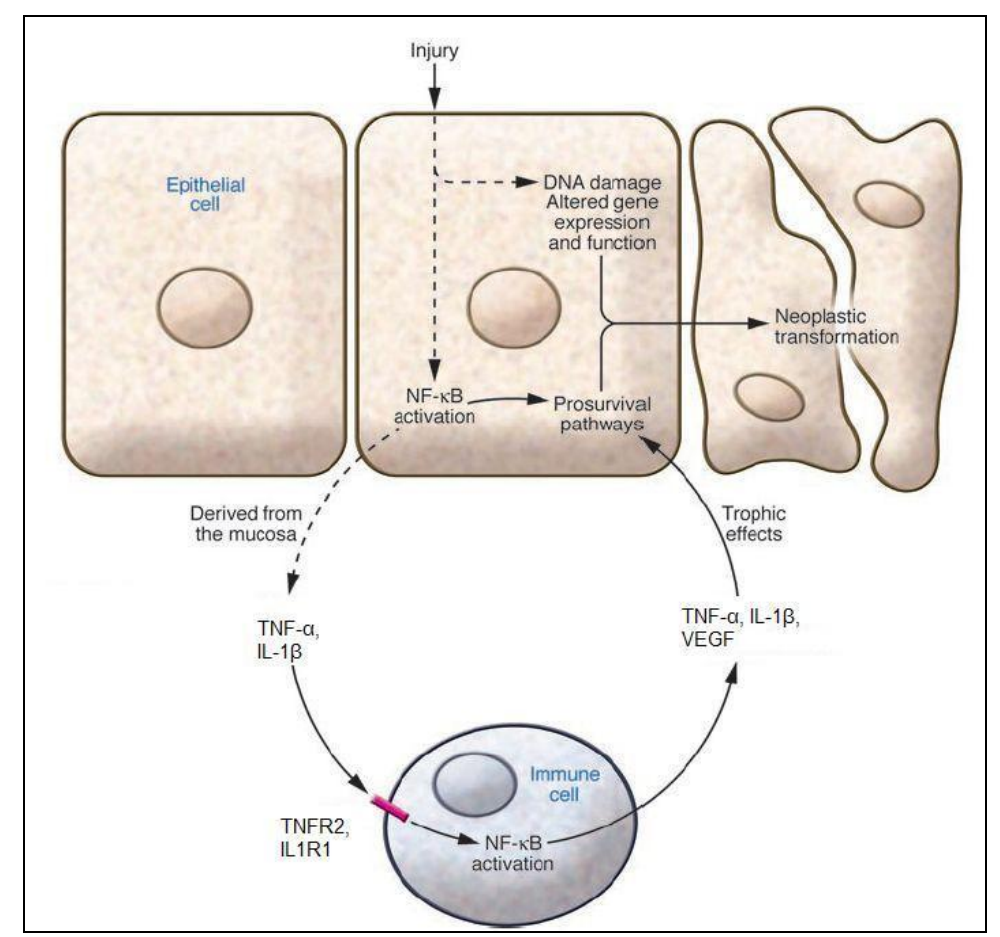

Abb. 1: Karzinogene Wirkung von TNF- $\alpha$ via NF-KB, nach: Burstein E, Fearon ER (2008): Colitis and cancer: a tale of inflammatory cells and their cytokines. $J$ Clin Invest 118(2), 465

$I F N-\gamma$

IFN-y wird vor allem von aktivierten T-Helferzellen und Natural Killer (NK)-Zellen produziert. Es hat eine immunsuppressive Wirkung, indem es die Reifung dendritischer Zellen induziert und dadurch die Präsentation von Tumorantigenen sowie eine adäquate Immunantwort erleichtert. Zudem hemmt es die Angiogenese (Yao et al. 1999). Gleichzeitig ist es ein proinflammatorischer Mediator, indem es nach Kontakt mit antigenpräsentierenden Zellen die Freisetzung von IL-1 $\beta$ und TNF$\alpha$ aus Makrophagen triggert. In Tiermodellen zu chronisch entzündlichen Darmerkrankungen war die IFN- $\gamma$-Expression im erkrankten Gewebe erhöht (Bosani et al. 2009). In einigen Fällen wurde eine gesteigerte Expression von IFN- $\gamma$ auch in kolorektalen Karzinomen beobachtet (Numata 1992, Csiszár et al. 2004). 


\section{2) Wachstumsfaktoren}

\subsection{1) Epidermaler Wachstumsfaktor (EGF) und sein Rezeptor (EGFR)}

EGF wird ubiquitär gebildet, vor allem aber in Speicheldrüsen und in den BrunnerDrüsen des Duodenums. Er ist ein potentes Mitogen, das Zellproliferation im Gastrointestinaltrakt bewirkt (Bosani et al. 2009) und dadurch beispielsweise die Abheilung gastrointestinaler Ulzera fördert. Auch maligne Neopolasien können EGF exprimieren, seine Wirkung auf das Tumorwachstum ist jedoch nicht vollständig geklärt. Es gibt Hinweise darauf, dass von Makrophagen gebildetes EGF maßgeblich an der Metastasierung maligner Neoplasien beteiligt ist, indem es Tumorzellen zur Migration und Gefäßinvasion anregt (Wyckoff et al. 2004).

Das Vorkommen des EGF-Rezeptors (EGFR, synonym ErbB1 oder HER-1) ist für nahezu alle ausdifferenzierten Gewebe mit Ausnahme von hämatopoetischen Zellen physiologisch (Fickova 2002). EGFR gehört mit ErbB2/HER-2, ErbB3/HER-3 und ErbB4/HER-4 zu einer Gruppe von Tyrosinkinase-Rezeptoren. Diese bestehen aus einer extrazellulären Bindungsdomäne, einem transmembranären Anteil und einer intrazellulären Tyrosinkinase-Domäne (Mendelsohn und Baselga 2000). Rezeptoraktivierung erfolgt durch Ligandenbindung und anschließende Rezeptor-dimerisierung, wobei entweder zwei gleichartige oder zwei verschiedene Erb-Monomere sich zu Homo- bzw. Heterodimeren verbinden. Darauf folgen die Phosphorylierung der intrazellulär gelegenen Tyrosinreste und die weitere Signalvermittlung vor allem über den RAS-RAF-MAPK-Pathway (Abb. 2). Liganden an EGFR sind die Wachstumsfaktoren EGF und transforming growth factor-beta (TGF- $\beta$ ), heparinbindendes EGF (HB-EGF), Amphiregulin, Betacellulin sowie Epiregulin (Yarden und Sliwkoski 2001). 


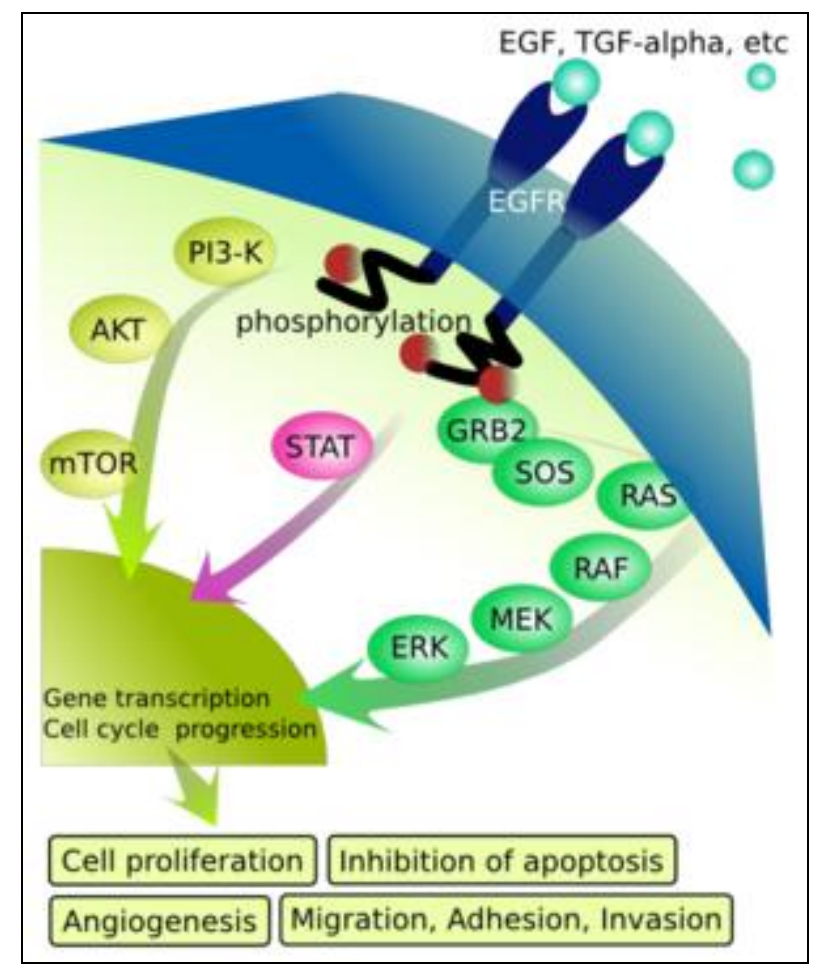

Abb. 2: Effekte der EGFR-Aktivierung,

http://en.wikibooks.org/wiki/Structural_Biochemistry/Cell_Signaling_Pathways/ Epidermal_Growth_Factor_Signaling, Aufrufdatum 30.11.2013

Seine Wirkung auf Zellproliferation, Differenzierung und Überleben von Zellen entfaltet EGFR vor allem während der Organogenese und - im erwachsenen Individuum - im Rahmen der Wundheilung. Überexpression von EGFR hat eine fördernde Wirkung auf das Wachstum von Tumoren: kolorektale Karzinome überexprimieren EGFR mit einer Häufigkeit von $72-80 \%$ und der Nachweis einer hohen Expressionsrate ist mit verstärkter Metastasierung und verminderter Lebenserwartung verbunden (Van Cutsem et al. 2004).

\subsection{2) Der vaskuläre endotheliale Wachstumsfaktor (VEGF) und seine Rezeptoren (VEGFR)}

Unterschieden werden VEGF-A, VEGF-B, VEGF-C und VEGF-D. Besonderes Augenmerk soll hier auf VEGF-A fallen. 
Es wird davon ausgegangen, dass prinzipiell alle Gewebe in der Lage sind, VEGF-A zu produzieren (Jelkmann 2001). Er wirkt vor allem auf Endothelzellen und vermittelt hier Zellüberleben, Proliferation, Migration und Steigerung der Gefäßpermeabilität. Damit ist VEGF der wichtigste Mediator der Angiogenese. Er bewirkt die prä- und postnatale Entwicklung der Blutgefäße und damit des Skelettsystems. Im Erwachsenen Inividuum kommt VEGF-A unter physiologischen Bedingungen vor allem im Rahmen der ovariellen Angiogenese und des weiblichen Zyklus zum Tragen. Pathologische Zustände erhöhter VEGF-Expression sind Entzündungen und Tumoren. Hypoxie sowie die Entzündungsmediatoren TNF- $\alpha$, IL-1 $\beta$ und EGF triggern die dafür notwendige Steigerung der VEGF-Expression via Hypoxie-induzierten Faktor (HIF)-1a beziehungsweise NF-KB. VEGF bewirkt damit maßgeblich den angiogenic switch, die Ausbildung eines tumoreigenen Gefäßbetts. Über einsprossende Blutgefäße wird das Tumorgewebe ernährt, gleichzeitig begünstigen sie die Verschleppung von Tumorzellen und damit die Metastasierung.

Neben der angiogenetischen spielt VEGF-A auch eine immunologische Rolle. Es wirkt chemotaktisch auf Monozyten und begünstigt durch seine Wirkung auf das Gefäßendothel das Einwandern von Immunzellen in Entzündungsgebiete. Zudem bewirkt es die Induktion der Zytokinbildung in Immunzellen. Dementsprechend ist seine Expression in einer Reihe chronisch entzündlicher Erkrankungen erhöht, darunter die Rheumatoide Arthritis (Lee und Weinblatt 2001) und die chronisch entzündlichen Darmerkrankungen (Griga et al. 1992).

Eine Überexpression von VEGF in Tumorzellen konnte mittlerweile für verschiedene maligne Erkrankungen nachgewiesen werden, darunter auch kolorektale Karzinome. Das Ausmaß der Expression gilt als negativer Prognoseparameter bezüglich Migration, Invasion und Gesamtüberleben (Cao et al. 2009). Auch für Immunzellen sowohl im peripheren Blut als auch im Stroma von Tumoren wurde eine gesteigerte VEGF-Expression beobachtet.

Von den übrigen Mitgliedern der VEGF-Familie sollen hier noch der placenta growth factor, kurz PIGF, und VEGF-B erwähnt werden, die beide an VEGFR-1 (s. u.) binden. PIGF wird vor allem in Plazenta, Herz und Lunge exprimiert. Es potenziert einerseits die Wirkung von VEGF-A an VEGFR-2, andererseits vermittelt es an 
VEGFR-1 eigenständig antiapoptotische Signale von vor allem wachsenden Endothelzellen und von Tumorzellen (Park et al. 1994, Fischer et al. 2007). Auf tumorassoziierte Makrophagen wirkt es ebenfalls antiapoptotisch (Adini et al. 2002), zudem induziert es in Monozyten die Bildung der Zytokine TNF- $\alpha$ und IL-1 $\beta$ (Selvaraj et al. 2003). Die Rolle von VEGF-B ist noch nicht ganz geklärt, er wird aber vor allem in quergestreifter Muskulatur, dem Myokard und braunem Fettgewebe exprimiert und ist wahrscheinlich an der Angiogenese in Geweben mit hohem Energiebedarf beteiligt (Olofsson et al. 1996). Auch verschiedene Tumorentitäten exprimieren VEGF-B (Salven et al. 1998). Eine hohe Expression des VEGF-B in kolorektalen Karzinomen korrelierte dabei mit dem Auftreten von lymphogenen Metastasen (Kawakami et al. 2003).

Für die Mitglieder der VEGF-Familie existieren drei verschiedene TyrosinkinaseRezeptoren, namentlich VEGFR-1/FIt-1, VEGFR-2/FIk-1 und VEGFR-3/Flt-4. Auch diese Rezeptoren sind Tyrosinkinasen, und Ligandenbindung führt zur Dimerisierung einzelner Rezeptormoleküle und konsekutiver intrazellulärer Signalvermittlung.

VEGFR-1 ist der Rezeptor für die oben genannten Liganden VEGF-A und -B sowie für PIGF. Eine lösliche Form des VEGFR-1, s(oluble) VEGFR-1, dient möglicherweise als Negativregulator der angiogenetischen VEGF-Wirkung, indem es VEGFMoleküle abfängt, ohne ein Signal zu vermitteln. Es gibt Hinweise, dass die Bestimmung des Serumspiegels dieser löslichen Rezeptorform Aussagen zur entzündlichen Aktivität chronisch entzündlicher Erkrankungen und zur Progression von Tumorerkrankungen zulässt (Robak et al. 2003, Bando et al. 2005). Die zellgebundene Form des Rezeptors hat nur schwache Kinaseaktivität. Auf Endothelzellen exprimiert, dient sie während der Embryonalentwicklung vermutlich als Bindungsstelle für exzessiv freigesetztes VEGF und damit ebenfalls als Inhibitor der VEGF-Wirkung (Ferrara et al. 2003). Im erwachsenen Individuum vermittelt VEGFR-1 auf Endothelien erst unter pathologischen Umständen - das heißt im Rahmen von Entzündungen und/oder Tumorwachstum - die Angiogenese.

Auf Monozyten exprimiertes VEGFR-1 vermittelt die bereits erwähnte Chemotaxis von VEGF-A, PIGF und VEGF-B auf diesen Zelltyp (Abb. 3). Im Mausmodell zeigten sich zudem Hinweise auf eine über VEGFR-1 auf Makrophagen vermittelte Zunahme 
der Lymphangiogenese (Murakami et al. 2008). In Kolonkarzinomzellen bewirkte VEGFR-1-Aktivierung in vitro eine Zunahme von Migration und Invasion (Fan et al. 2005). Weitere Studien zeigten, dass VEGFR-1 hier die - für die Metastasierung von Tumorzellen notwendige - epithelial-mesenchymale Transformation bewirkt (Bates et al. 2003). Am Ort der Metastasierung bilden VEGFR-1-tragende Vorläuferzellen aus dem Knochenmark die sogenannte prämetastatische Nische, in der sich disseminierte Tumorzellen ansiedeln können (Kaplan et al. 2005).

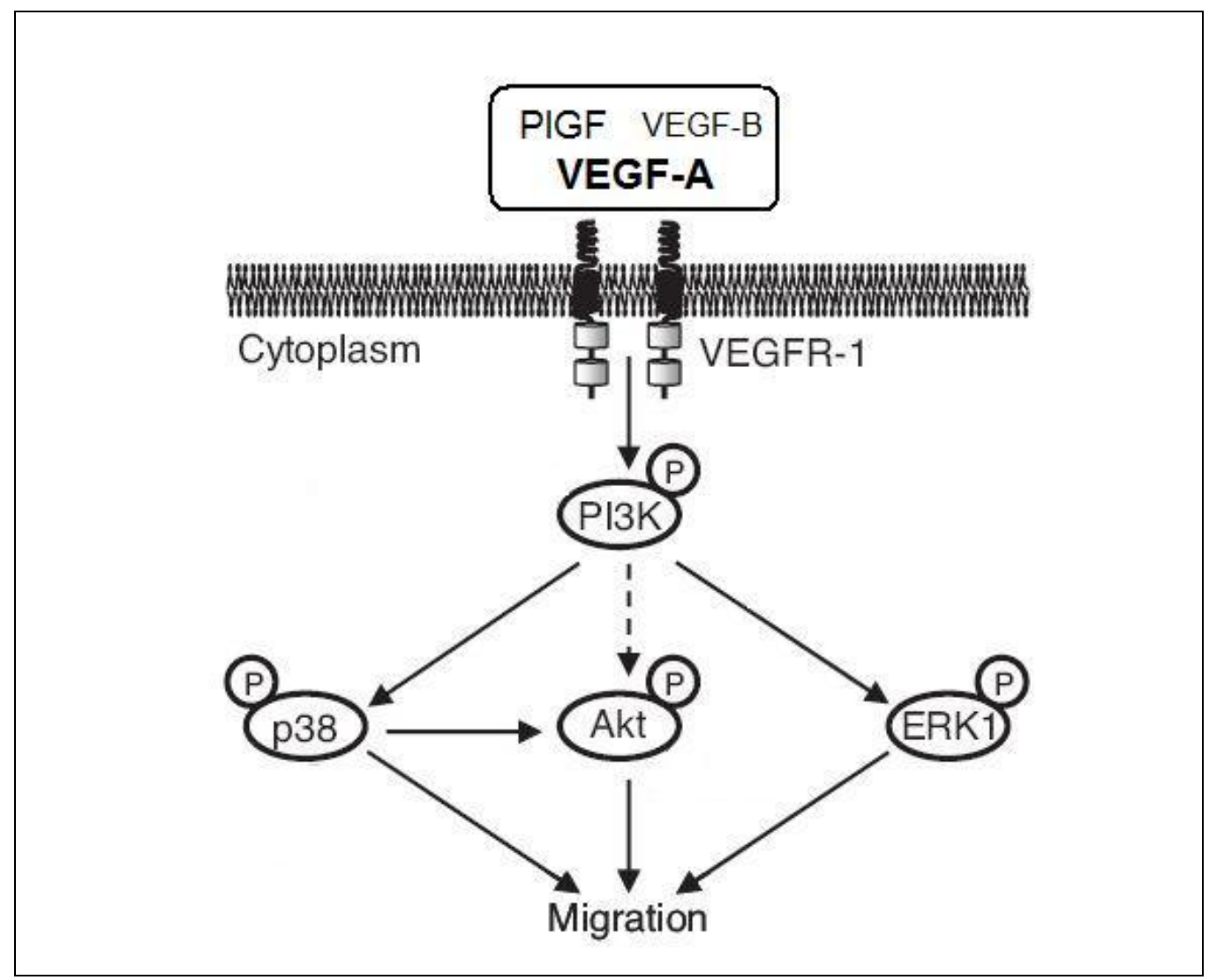

Abb. 3: VEGFR-1-Aktivierung auf Monozyten, aus: Tchaikovski V, Fellbrich G, Waltenberger $J$ (2008): The molecular basis of VEGFR-1 signal transduction pathways in primary human monocytes. Arterioscler Thromb Vasc Biol 28(2), 327

Die intrazelluläre Signalvermittlung des VEGFR-1 geschieht über die MAP-Kinase, die Phosphoinositid-3-Kinase (PI3K), Akt und ERK1/2 (Tchaikovski et al. 2008). 
Die Liganden am VEGF-Rezeptor-2 sind VEGF-A sowie VEGF-C und -D. VEGFR-2 vermittelt physiologische und Tumorangiogenese. An VEGFR-3 binden die Liganden VEGF-C und -D (Matsumoto und Mugishima 2006). Seine Aktivierung bewirkt Lymphangiogenese und begünstigt dadurch in Tumoren die lymphogene Metastasierung (Alitalo und Carmeliet 2002). VEGFR-2 ist von den drei Rezeptoren sicher derjenige mit der größten Wirkungsbreite. Da jedoch vor allem VEGFR-1 auf Immunzellen, genauer auf Monozyten, exprimiert wird, sollen die anderen beiden Rezeptorformen hier nicht weiter behandelt werden.

\section{3) Monoklonale Antikörper in der Therapie des kolorektalen Karzinoms}

Aufgrund ihrer tumorigenen Eigenschaften bewirken Wachstumsfaktoren Tumorprogression, zudem können sie eine Resistenz von Tumoren gegen Chemotherapeutika beziehungsweise Radiotherapie bewirken. Ihre Neutralisierung bildet deshalb einen Angriffspunkt für die zielgerichtete Tumortherapie.

\subsection{1) EGFR-Blockade}

Mittlerweile existieren verschiedene Wege der EGFR-Blockade (Abb. 4). Ein Weg ist der Einsatz von sogenannten TKIs, ATP-kompetitiven Inhibitoren der Tyrosinkinase des EGF-Rezeptors. Beispiele solcher Wirkstoffe sind Erlotinib und Gefitinib, die in der Therapie des nichtkleinzelligen Bronchialkarzinoms bzw. des metastasierten Pankreaskarzinoms Anwendung finden. TKls bergen jedoch zwei Nachteile: sie können auch an andere Kinasen binden, und ihre Wirkung ist von der Konzentration der Zielkinase(n) anhängig (Cohen 2006). Die Blockade des EGFR mittels eines Antikörpers bietet dagegen eine höhere Spezifität und stellt insbesondere bei Rezeptorüberexpression einen günstigen Therapieansatz dar. In kolorektalen Karzinomen liegt dieser zumeist eine aktivierende Mutation im KRAS- oder BRAFOnkogen zugrunde, die zu einer kontinuierlichen endogenen Rezeptoraktivierung führt. Nachdem im Rahmen der BOND-Studie die Wirksamkeit von Cetuximab bei Patienten mit EGFR-positivem kolorektalen Karzinom nachgewiesen wurde, (Cunningham et al. 2004), ist seit Juli 2008 der anti-EGFR-Antikörper Cetuximab für die Therapie von EGFR-exprimierenden, metastasierten kolorektalen KRAS-WildtypKarzinomen zugelassen. 


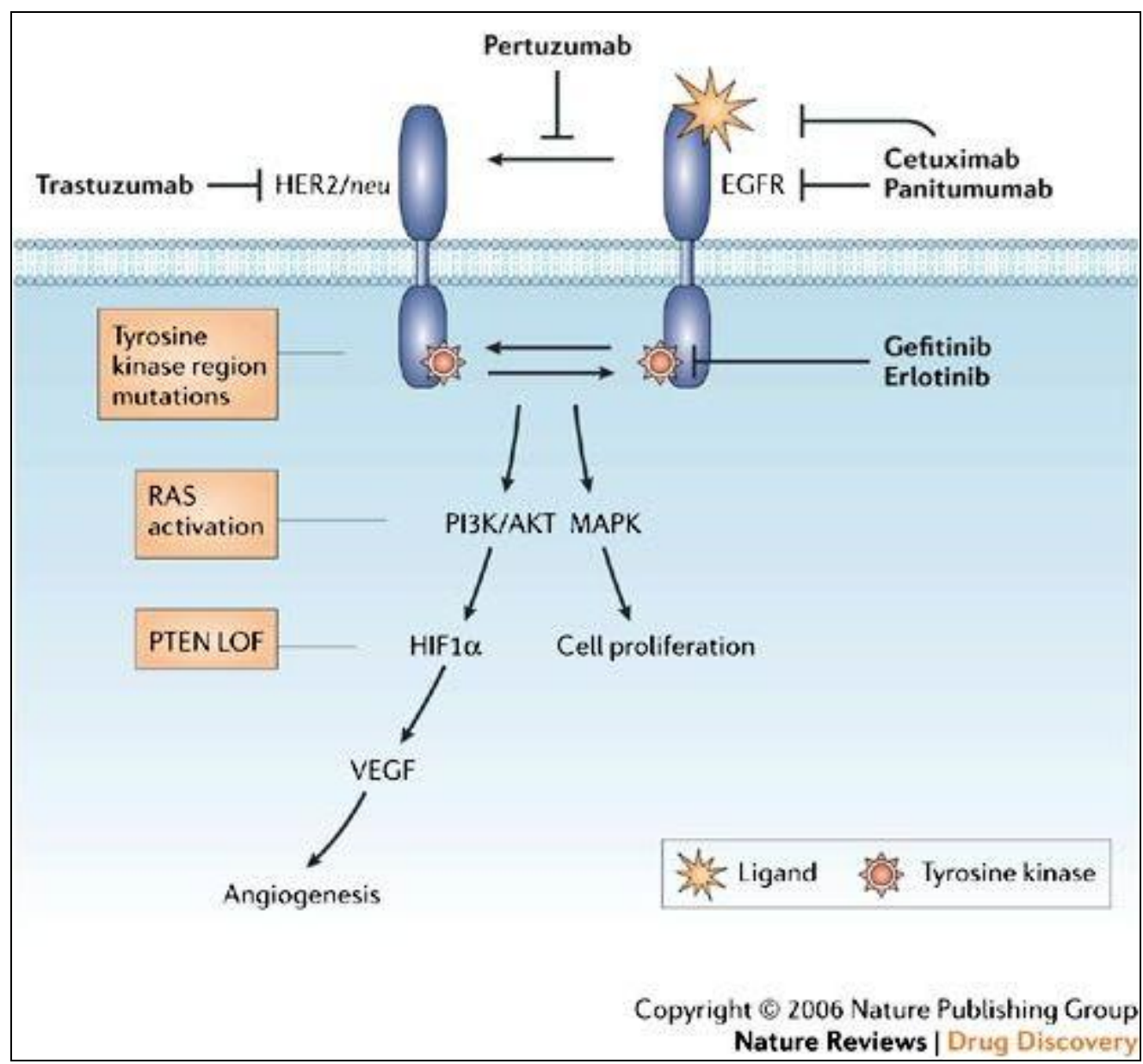

Abb. 4: EGFR-Blockade mittels Antikörpertherapie, nach: Krejsa C, Rogge M, Sadee W (2006): Protein therapeutics: new applications for pharmacogenetics. Nat Rev Drug Discov 5(6), 516

\subsection{2) VEGF-Blockade}

VEGF zirkuliert zu einem großen Teil frei im Blut und ist dadurch leicht zugänglich. In gesunden Erwachsenen werden physiologische Prozesse durch seine Blockade kaum gestört. Gleichzeitig ist die Hemmung der für das Tumorwachstum notwendigen Gefäßneubildung ein wirkungsvoller Weg, Tumorwachstum zu verhindern. VEGF bildet deshalb einen günstigen Angriffspunkt für die gezielte Therapie von Tumoren (Abb. 5). Die klinische Wirksamkeit der VEGF-Blockade wurde in der Studie von $\mathrm{H}$. Hurwitz an Patienten mit metastasiertem kolorektalen Karzinom nachgewiesen (Hurwitz et al. 2004). Dementsprechend wurde im Jahr 2005 der humanisierte anti-VEGF-Antikörper Bevacizumab als First-LineMedikament zur Behandlung metastasierter kolorektaler Karzinome zugelassen. 


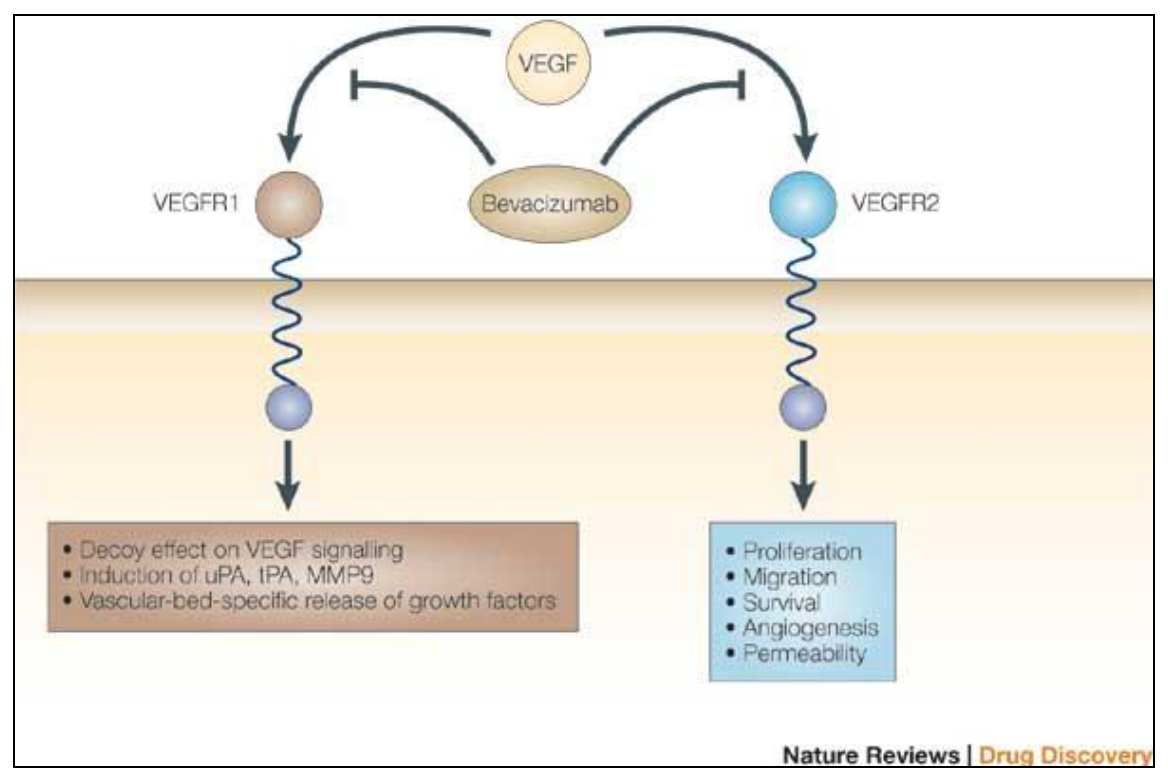

Abb. 5: Effekte von Bevacizumab, aus: Muhsin M, Graham J, Kirkpatrick P (2004): Bevacizumab. Nat Rev Drug Discov 3(12), 995

\section{4) Antikörpertherapie entzündlicher Erkrankungen: Infliximab}

Infliximab ist ein monoklonaler chimärer Antikörper gegen TNF- $\alpha$. Er neutralisiert lösliches TNF- $\alpha$ und verhindert so die durch TNF- $\alpha$ vermittelten entzündlichen Prozesse. Infliximab bindet außerdem die membrangebundene Form von TNF- $\alpha$ und entfaltet auf diesem Weg eine antikörpervermittelte Zytotoxizität. Therapeutischen Einsatz findet Infliximab unter anderem in der Rheumatoiden Arthritis. Es bewirkt hier eine Hemmung der Bildung von Zytokinen und Chemokinen, eine Reduktion der Angiogenese, Minderung der Infiltration entzündeter Gelenke durch Leukozyten und Hemmung von gewebszerstörenden Enzymen wie der Matrix-Metalloproteinasen. Die immunsuppressive Wirkung von Infliximab hat sich außerdem in der Therapie der chronisch-entzündlichen Darmerkrankungen (CED) bewährt (Hanauer et al. 2002, Rutgeerts et al. 2005). Im Zusammenhang mit malignen Neoplasien spielt Infliximab bisher therapeutisch zwar keine Rolle, mit Verweis auf die karzinogene Wirkung von TNF- $\alpha$ erscheint seine Blockade zur Kontrolle des Tumorwachstums jedoch sinnvoll. Verschiedene Studien ergaben eine niedrigere Rate an CED-assoziierten 
kolorektalen Karzinomen bei CED-Patienten, die eine antientzündliche Therapie mit Infliximab erhielten (Biancone et al. 2009).

\section{5) Ziel der Arbeit}

Unsere Abteilung arbeitet seit mehreren Jahren an der Erforschung der Zusammenhänge von Entzündung und Tumorwachstum. Moriconi et al. untersuchten die Expression der Zytokine IL-1 $\beta$, IFN- $\gamma$ und TNF- $\alpha$ in Monozyten des peripheren Blutes (PBMCs) nach Stimulation der Zellen mit Phytohämagglutinin, das heißt nach in-vitro-Simulation einer Entzündungssituation (Moriconi et al. 2007). Dabei zeigte sich eine Steigerung der Genexpression der durch Makrophagen gebildeten Zytokine IL-1 $\beta$ und TNF- $\alpha$ sowie des T-Zell-Zytokins IFN-y. Yeruva et al. konnten nachweisen, dass die Expression von CXCL10 (IP-10), einem Protein, das an der Rekrutierung von T-Zellen und Monozyten beteiligt ist, wiederum in verschiedenen Epithelzellinien des Kolons (CaCo2, DLD-1 und HT-29) durch diese Zytokine in unterschiedlichem Ausmaß induziert wird und dass dadurch die Entstehung und Unterhaltung einer Entzündungssituation begünstigt werden kann (Yeruva et al. 2008). Dabei zeigte sich ein eindeutiger Synergismus der Kombination von IFN-y mit jeweils IL-1 $\beta$ und TNF- $\alpha$. Die Autoren konnten mittels weiterer Experimente zeigen, dass dieser Synergismus auf Ebene des CXCL-10-Promotors zum Tragen kommt, welcher sowohl via TNF- $\alpha$ und IL-1 $\beta$ als auch über IFN-y aktiviert wird.

Cameron et al. untersuchten schließlich das Aufkommen der verschiedenen Subpopulationen von Immunzellen in c-kit-positiven gastrointestinalen Stromatumoren (GIST) sowie die Bildung verschiedener Zytokine durch diese Tumorentität (Cameron et al. 2008). Die Arbeitsgruppe stellte dabei fest, dass dendritische Zellen des Monozyten-Makrophagen-Systems die am stärksten vertretene Klasse von Immunzellen sind, CD3-positive T-Lymphozyten machten die größte Zahl an Lymphozyten in den untersuchten Tumoren aus. Die Expression der durch diese Zellpopulationen vorrangig gebildeten Zytokine - TNF- $\alpha$ und IL-1 $\beta$ bzw. IFN- $\gamma$ - war dabei jedoch relativ gering. Die Autoren kamen zu dem Schluss, dass dies auf ein hohes Aufkommen an unreifen dendritischen Zellen und damit auf eine fehlende Aktivierung von TLymphozyten zurückzuführen ist. Neben der Bildung von tumor survival factors ist demnach auch der Grad der Reifung sowie der Aktivierung der Immunzellen entscheidend für das Tumormikromilieu. 
Diese Arbeit dient der Fortsetzung der bisherigen Arbeit der Abteilung zum Thema Entzündung und Tumorentstehung, die in den letzten Jahren sowohl auf klinischer als auch auf experimenteller Ebene durchgeführt wurde, mit explorativem Ansatz.

VEGF und seine Rezeptoren sowie der EGF-Rezeptor und seine Liganden haben sich in der Vergangenheit als wichtige Mediatoren der Zell-Zell-Interaktion und damit als survival factors in diversen Tumoren erwiesen. Ihre Blockade bildet heute die Grundlage für die Therapie verschiedener Tumorerkrankungen. Gleichzeitig weiß man, dass Immunzellen durch Zytokinbildung das Tumorwachstum fördern können. Sie regen dadurch wiederum stromale Zellen, Tumor- und Endothelzellen zur Bildung von tumor survival factors an. Diese Arbeit soll das Wechselspiel zwischen Tumorund Immunzellen in malignen Neoplasien untersuchen. Zum einen soll untersucht werden, wie die Expression der tumor survival factors VEGF und EGF in Tumorzellen durch die lokale Entzündungssituation beeinflusst wird, zum anderen, wie sich die systemische Entzündungsreaktion auf die Expression dieser Faktoren in zirkulierenden Immunzellen auswirkt. Zusätzlich soll die Wirkung therapeutischer Maßnahmen wie der Einsatz spezifischer Antikörper auf die Bildung von EGF und VEGF untersucht werden. Dabei kommen in der Therapie von Tumoren und chronisch entzündlichen Krankheiten bereits etablierte Methoden zum Einsatz, wie die Blockade von VEGF und TNF-a mittels eines spezifischen Antikörpers. Aber auch bisher nicht oder nur spärlich untersuchte Herangehensweisen sollen erprobt werden. So ist die Blockade des EGF-Rezeptors in der Vergangenheit Objekt zahlreicher Studien gewesen, während in der Literatur kaum Angaben zur Rolle seines Liganden EGF und dessen Hemmung zu finden sind. Die Modulation der durch die tumorassoziierten Immunzellen verursachten Entzündungsreaktion bietet möglicherweise ebenfalls einen Ansatz zur therapeutischen Einflussnahme auf das Tumorwachstum. Analog zur Antikörpertherapie auf dem Gebiet der Tumorangiogenese wurde in dieser Arbeit deshalb die Wirkung von Infliximab auf die entzündlich aktivierten Zellen untersucht. Zur Untersuchung der Interaktion zwischen Tumorzellen und Immunzellen bedienten wir uns eines in-vitro-Modells in Anlehnung an die Methode von Moriconi et al. (Moriconi et al. 2007). Die Immunzellen werden durch die aus peripher venösem Blut dreier verschiedener gesunder männlicher Probanden isolierten Lymphozyten (PBMCs) repräsentiert (Abb. 6). Durch 
Stimulation mit Phytohämagglutinin (PHA) beziehungsweise Lipopolysaccharid (LPS) wurden die Zellen angeregt, um die durch den Tumor verursachte systemische Entzündungssituation zu simulieren. Dabei entsprechen die PBMCs am ehesten den aktivierten Immunzellen des Blutes in der Anfangsphase der Tumorentwicklung, die sich kurz vor dem Eintritt in das veränderte Gewebe befinden. Phytohämagglutinin (PHA) - ein pflanzliches Lectin - stimuliert insbesondere die T-Lymphozyten. Sie bilden in diesem Zustand - je nach Subtyp - unter anderem TNF- $\alpha$ und IFN- $\gamma$. Lipopolysaccharid (LPS) als Bestandteil der Wand gramnegativer Bakterien wirkt über den CD14-Rezeptor vor allem auf das Monozyten-Makrophagen-System und führt zur Ausschüttung von TNF- $\alpha$ und IL-1 $\beta$ durch diese Zellen.

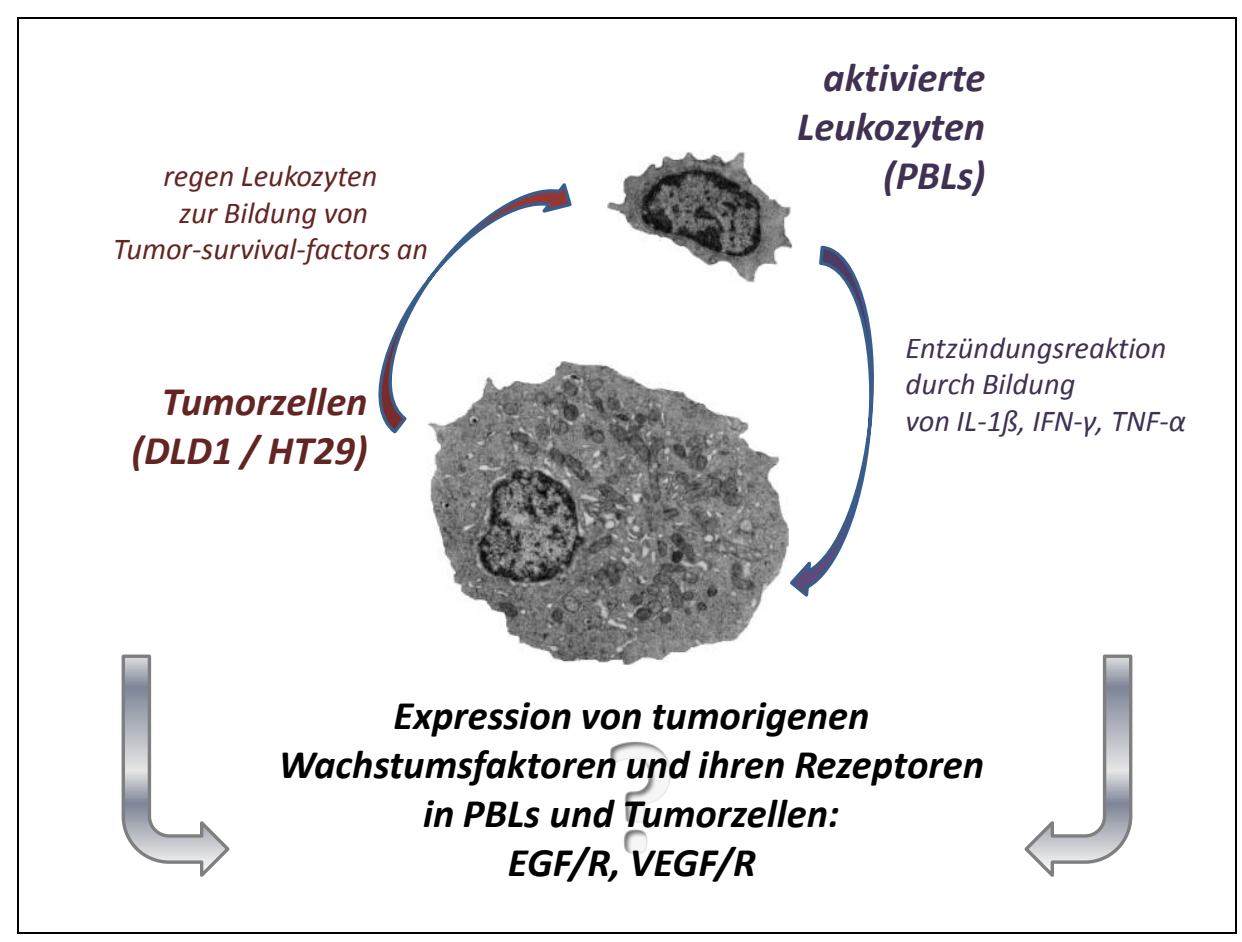

Abb. 6: Wechselwirkungen zwischen Tumor- und Immunzellen

Als Tumorzellen wählten wir die Kolonkarzinom-Zellinien DLD-1 und HT-29. Die in diesem Fall undifferenzierten HT-29-Zellen entsprechen dabei den in den Krypten gelegenen Enterozyten, die das Darmlumen noch nicht erreicht haben (Böcker et al. 2000). 
Da $30-60 \%$ aller kolorektalen Tumoren eine Mutation des KRAS- und 5-15\% eine Mutation des BRAF-Gens aufweisen, wurden KRAS-mutierte DLD-1-Zellen bzw. BRAF-mutierte HT-29-Zellen verwendet. Die Zelllinien wurden einerseits mit IL-1 $\beta$ und TNF- $\alpha$ als monozytäre Zytokine, andererseits mit IFN- $\gamma$ als T-LymphozytenZytokin behandelt. Anschließend wurde die Bildung der Wachstumsfaktoren EGF und VEGF beziehungsweise ihrer Rezeptoren sowohl in den Tumorzellen als auch in den PBMCs mittels Messung der mRNA des zugehörigen Gens ermittelt. 


\section{2) Material und Methoden}

\section{1) Material}

\subsection{1) Laborgeräte}

ABI Prism 7000 Real-Time PCR-Cycler (Applied Biosystems, Carlsbad, US)

GeneQuant RNA/DNA-Messgerät (Pharmacia, Freiburg, Deutschland)

Heraeus Laminair® (Heraeus Instruments GmbH, Hanau, Deutschland)

Heraeus Thermostat (Heraeus Instruments $\mathrm{GmbH}$, Hanau, Deutschland)

Labor-Mikroskop Axiovert 25 Zeiss (Zeiss, Oberkochen, Deutschland)

Omnigene Temperature Cycling System (Hybaid Limited, Tedington, Middlesex, UK)

Zentrifuge Eppendorf 5415D (Eppendorf-Netheler-Hinz GmbH, Hamburg, Deutschland)

Zentrifuge Hettich Rotixa/K (Hettich Zentrifugen, Tuttlingen, Deutschland)

Zentrifuge Sigma 3K30 (Sigma-Aldrich Chemie GmbH, Deisenhofen, Deuschland)

Zentrifuge Sigma 5415D (Sigma-Aldrich Chemie GmbH, Deisenhofen, Deutschland)

\subsection{2) Zubehör}

6-Well-Platten (Nunc, Roskilde, Dänemark)

24-Well-Platten (Corning Incorporated, Corning, US)

96-Well-Platten (Nunc, Roskilde, Dänemark)

Eppendorf-Gefäße (Eppendorf-Netheler-Hinz GmbH, Hamburg, Deutschland)

Falcon-Röhrchen (Becton Dickinson and Company, Franklin Lakes, US) 
Leucosep-Röhrchen (Becton Dickinson and Company, Franklin Lakes, US)

Neubauer-Zählkammer (Brand GmbH \& Co KG, Wertheim, Deutschland)

Pipetus Akku (Hirschmann Laborgeräte, Eberstadt, Deutschland)

Pipettenspitzen für Pipetus Akku $5 \mathrm{ml} / 10 \mathrm{ml}$ (Greiner Bio-One, Frickenhausen, Deutschland)

S-Monovette (Sarstedt, Nümbrecht, Deutschland)

\subsection{3) Zellen}

Monozyten aus peripherem Blut (PBMCs): aus peripher-venösem Blut dreier verschiedener gesunder, erwachsener, männlicher Probanden (s. Material und Methoden, Teil „PBMC-Isolation“ 2.2.1).

HT-29 und DLD-1: jeweils aus humanem Adenokarzinom des Kolons (Deutsche Sammlung von Mikroorganismen und Zellkulturen $\mathrm{GmbH}$, Braunschweig, Deutschland)

\subsection{4) Chemikalien}

2-Mercaptoethanol (Merck, Darmstadt, Deutschland)

Ampuwa (Fresenius Kabi, Bad-Homburg, Deutschland)

Anti-human EGF-Antikörper (R\&D Systems, Wiesbaden, Deutschland)

Anti-human VEGF-Antikörper (R\&D Systems, Wiesbaden, Deutschland)

Fötales Kälberserum (GIBCO BRL, Grand Island, US)

Ficoll (Amersham Biosciences, Uppsala, Schweden)

Interferon $\mathrm{y}$, human (Roche Molecular Biochemicals, Mannheim, Deutschland)

Interleukin-1 $\beta$, human (Roche Molecular Biochemicals, Mannheim, Deutschland ) 
Lipopolysaccharid LPS (E. coli, L6529, Sigma-Aldrich Chemie GmbH, Deisenhofen, Deutschland)

Medium RPMI 1640 (PAA Laboratories GmbH, Pasching, Österreich)

Moloney Maus-Leukämie-Virus reverse Transkriptase (Invitrogen, Carlsbad, US)

Natriumpyruvat (GIBCO BRL, Grand Island, US)

Nicht-essentielle Aminosäuren (Bio Whittaker, Verviers, Belgien)

Penicillin/Streptomycin (GIBCO BRL, Grand Island, US)

Phosphatgepufferte Kochsalzlösung PBS (Biochrom AG, Berlin, Deutschland)

Phytohämagglutinin PHA (Boehringer Mannheim Biochemica, Deutschland)

Primer für cDNA-Synthese/p(dT)15 (Roche Molecular Biochemicals, Mannheim, Deutschland)

Remicade® (Infliximab Centocor B. V., Leiden, Niederlande)

SybrGreen (Invitrogen, Carlsbad, US)

Tumor-Nekrose-Faktor alpha, human (Roche Molecular Biochemicals, Mannheim, Deutschland)

Medium für Zellkulturen:

RPMI-Medium (s. o.)

10\% fötales Kälberserum

$1 \%$ Penicillin/Streptomycin

$1 \%$ Glutamin

$1 \%$ Pyruvat 


\subsection{5) Kits}

RNeasy Mini Kit (QIAGEN GmbH, Hilden, Deutschland)

\subsection{6) Primer-Sequenzen Real-Time-PCR}

$\beta$-Aktin, human (Invitrogen, Karlsruhe, Deutschland)

Forward 5'-ATG ACT TCC AAG CTG GCC G-3‘

Reverse 5'-GCT GCA GAA ATC AGG AAG GC-3'

EGF, human (MWG Biotech, Ebersberg, Deutschland)

Forward 5'-TGA CTC TGA ATG TCC CCT GTC -3‘

Reverse 5'-CAG TTC CCA CCA CTT CAG GT -3“

EGFR, human (Invitrogen, Karlsruhe, Deutschland)

Forward 5‘- CTC CGG TCA GAA AAC CAA AA -3‘

Reverse 5'- TTC TCC ACA AAC TCC CTT GG -3‘

VEGF, human (Invitrogen, Karlsruhe, Deutschland)

Forward 5‘- CCC ACT GAG GAG TCC AAC AT -3`

Reverse 5'- TTT CTT GCG CTT TCG TTT TT -3‘

VEGFR-1, human (Invitrogen, Karlsruhe, Deutschland)

Forward 5"- AAT CAT TCC GAA GCA AGG TG -3“

Reverse 5'- TTT CTT CCC ACA GTC CCA AC -3“ 


\section{2) Methoden}

\subsection{1) PBMC-Isolation}

Für die PBMC-Experimente wurden von drei verschiedenen gesunden männlichen Probanden 100-150 ml peripher-venösen Blutes in EDTA-beschichteten S-Monovetten entnommen. PBMCs wurden mittels der Ficoll-Methode (entsprechend Herstellerprotokoll: Amersham Biosciences, Uppsala, Schweden) isoliert. Die Methode basiert auf der unterschiedlichen Migration verschiedener Zelltypen durch die Trennlösung auf Basis von synthetischen Saccharose-Polymeren während der Zentrifugation. Es entstehen mehrere Schichten, die die verschiedenen Zelltypen enthalten. Dabei enthält der Bodensatz durch Ficoll aggregierte Erythrozyten, Granulozyten und Thrombozyten. Lymphozyten und Monozyten sammeln sich an der Grenze zwischen Plasma und Ficoll und werden abpipettiert. Anschließend werden sie wiederholt mit PBS gewaschen.

Die einzelnen Schritte der PBMC-Isolation:

Entnahme von peripher-venösem Blut eines gesunden, erwachsenen männlichen Probanden in EDTA-beschichteten Monovetten

Sammeln des Blutes in einem Falcon-Röhrchen

Füllen eines Leucosep-Röhrchens mit $15 \mathrm{ml}$ Ficoll und anschließendes Zentrifugieren für 30 Sekunden bei 2300 rpm bei Zimmertemperatur

Vorsichtiges Pipettieren des Blutes in das Leucosep-Röhrchen, welches anschließend für 20 Minuten bei 2300 rpm und Zimmertemperatur zentrifugiert wird; die Bremse der Zentrifuge ist dabei auszuschalten

Überführen des Lymphozytenrings sowie des restlichen Plasmas in ein neues Falcon-Röhrchen und Auffüllen des Röhrchens mit $40 \mathrm{ml}$ PBS, anschließend Zentrifugieren für 10 Minuten bei $1200 \mathrm{rpm}$ und $4^{\circ} \mathrm{C}$

Verwerfen des Überstands und Aufschütteln der Zellen, Auffüllen mit $40 \mathrm{ml}$ PBS und erneute Zentrifugation für 10 Minuten bei $1200 \mathrm{rpm}$ und $4^{\circ} \mathrm{C}$. Dreimaliges Wiederholen dieses Schrittes 
Aufschütteln der Zellen, abhängig von der Größe des Zellpellets, Zugabe von bis zu 20 ml PBMC-Medium (s. o.)

Mischen von $50 \mu \mathrm{l}$ der Zellsuspension mit $50 \mu \mathrm{l}$ Trypanblau in einem Eppendorfgefäß, Zählen der Zellen mittels Neubauer-Zählkammer

\subsection{2) Stimulation und Inkubation der Zellen und Zellernte}

PBMCs wurden in 24-Well-Platten zu jeweils ca. $2,5 \times 10^{6}$ Zellen in $1 \mathrm{ml}$ Medium pro Well in Kultur genommen. Anschließend wurden die Zellen wie folgt inkubiert:

Versuchsdesign a), Inkubation der Zellen pro Well mit:

1) Kontrolle (ohne Zusatz von Stimulatien)

2) $\mathrm{PHA} 5 \mu \mathrm{g} / \mathrm{ml}$

3) PHA $5 \mu \mathrm{g} / \mathrm{ml}+$ anti-EGF-Antikörper $3 \mu \mathrm{g} / \mathrm{ml}$

4) $\mathrm{PHA} 5 \mu \mathrm{g} / \mathrm{ml}+$ anti-VEGF-Antikörper $3 \mu \mathrm{g} / \mathrm{ml}$

5) $\mathrm{LPS} 1 \mu \mathrm{g} / \mathrm{ml}$

6) LPS $1 \mu \mathrm{g} / \mathrm{ml}$ + anti-EGF-Antikörper $3 \mu \mathrm{g} / \mathrm{ml}$

7) $\mathrm{LPS} 1 \mu \mathrm{g} / \mathrm{ml}+$ anti-VEGF-Antikörper $3 \mu \mathrm{g} / \mathrm{ml}$

Versuchsdesign b), Inkubation der Zellen pro Well mit:

1) Kontrolle (ohne Zusatz von Stimulantien)

2) $\mathrm{PHA} 5 \mu \mathrm{g} / \mathrm{ml}$

3) LPS $1 \mu \mathrm{g} / \mathrm{ml}$

4) $T N F-\alpha 10 \mathrm{ng} / \mathrm{ml}$

5) Infliximab $1000 \mu \mathrm{g} / \mathrm{ml}$

6) PHA $5 \mu \mathrm{g} / \mathrm{ml}+$ Infliximab $1 \mathrm{mg} / \mathrm{ml}$

7) LPS $1 \mu \mathrm{g} / \mathrm{ml}+$ Infliximab $1 \mathrm{mg} / \mathrm{ml}$

8) TNF- $\alpha 10 \mathrm{ng} / \mathrm{ml}+$ Infliximab $1 \mathrm{mg} / \mathrm{ml}$

Um eine ausreichend hohe Zellzahl für die einzelnen Versuche zu gewährleisten, wurden die Experimente für die beiden Versuchsdesigns getrennt durchgeführt. Die Zellernte erfolgte jeweils zu Beginn des Experiments („Kontrolle 0 Stunden“, unstimuliert) und nach jeweils $1,4,8$ und 20 Stunden Inkubation bei $37^{\circ} \mathrm{C}$ und $5 \%$ 
$\mathrm{CO}_{2}$. Um im Well verbliebene Zellen in Suspension zu erfassen, wurde das zum Erntezeitpunkt geleerte Well mit $1 \mathrm{ml}$ PBS gewaschen und anschließend weiter bei $37^{\circ} \mathrm{C}$ inkubiert. Die zuvor abgenommene Zellsuspension wurde in ein Eppendorfgefäß überführt und für zehn Minuten bei $1200 \mathrm{rpm}$ und $4^{\circ} \mathrm{C}$ zentrifugiert. Der Überstand wurde abgenommen und bei $-80^{\circ} \mathrm{C}$ konserviert. Die abzentrifugierten Zellen wurden aufgeschüttelt und anschließend das PBS aus dem Inkubator zugegeben. Das jeweilige Well auf der Kulturplatte wurde diesmal mit $600 \mu \mathrm{l}$ mercaptoethanolhaltigem RLT-Puffer (10 $\mu \mathrm{l}$ Mercaptoethanol/ 1ml RLT-Puffer) gewaschen, um auch der Kulturplatte adhärente Zellen zu erfassen, und wiederum bei $37^{\circ} \mathrm{C}$ weiter inkubiert. Das PBS-Zellgemisch wurde für 10 Minuten bei $1200 \mathrm{rpm}$ und $4^{\circ} \mathrm{C}$ zentrifugiert, der Überstand verworfen und die Zellen erneut aufgeschüttelt. Zuletzt wurden die $600 \mu \mathrm{l}$ mercaptoethanolhaltigen RLT-Puffers aus der Kulturplatte zugegeben, um die Zellen zu lysieren. Zellen und Mercaptoethanol-Pufferlösung wurden mittels Vortex gut vermischt und das Lysat anschließen bei $-80^{\circ} \mathrm{C}$ eingefroren.

Auch die HT-29- und DLD-1-Zell-Experimente erfolgten jeweils in dreifacher Ausführung. Die Zellen wurden in RPMI-Medium gezüchtet, welches $10 \%$ FCS, 1 \% Natriumpyruvat sowie jeweils $100 \mathrm{U} / \mathrm{ml}$ Penicillin und Streptomycin enthielt. Die Stimulation beider Zelllinien erfolgte in 6 -Well-Platten bei einer Zelldichte von $5 \times 10^{5}$ Zellen pro Well in $2 \mathrm{ml}$ Medium, bis sie eine Konfluenz von 70-80\% erreichten (nach ca. 24 h). Anschließend wurden die Zellen mit IL-1ß, TNF- $\alpha$ und IFN- $\gamma$ wie folgt behandelt:

1) Kontrolle (ohne Zusatz von Stimulantien)

2) $\mathrm{IL}-1 \beta 1 \mathrm{ng} / \mathrm{ml}$

3) $\mathrm{TNF}-\alpha 50 \mathrm{ng} / \mathrm{ml}$

4) IFN-ץ $50 \mathrm{ng} / \mathrm{ml}$

5) $T N F-\alpha 50 \mathrm{ng} / \mathrm{ml}+\mathrm{IL}-1 \beta 0,5 \mathrm{ng} / \mathrm{ml}$

6) $\mathrm{IFN}-\gamma 50 \mathrm{ng} / \mathrm{ml}+\mathrm{IL}-1 \beta 0,5 \mathrm{ng} / \mathrm{ml}$

7) $\mathrm{TNF}-\alpha 50 \mathrm{ng} / \mathrm{ml}+\mathrm{IFN}-\gamma 50 \mathrm{ng} / \mathrm{ml}$

Nach der Ernte wurden die Zellen mit 3 ml PBS gewaschen und anschließend in 350 $\mu l$ hochgradig denaturierendem guanidiniumisothiocyanathaltigen Puffer (RLT-Puffer) 
lysiert. RNasen wurden zuvor inaktiviert, indem $\beta$-Mercaptoethanol dem Puffer hinzugefügt wurde (10 $\mu / 1 / \mathrm{ml}$ RLT-Puffer).

\subsection{3) RNA-Isolation}

Die RNA-Isolation erfolgte mittels RNeasy Mini Kit (QIAGEN GmbH, Hilden, Deutschland) entsprechend Herstellerprotokoll. Die so isolierte RNA wurde bei $-80^{\circ} \mathrm{C}$ gelagert.

\subsection{4) RNA-Messung}

Die Messung der isolierten RNA erfolgte mittels Photospektrometrie im GeneQuant RNA/DNA-Messgerät (Pharmacia, Freiburg, Deutschland), indem die Absorption bei 260 und bei $280 \mathrm{~nm}$ gemessen wurde. Dabei entspricht eine Einheit Absorption einer Menge von $40 \mu \mathrm{g}$ RNA pro $\mathrm{ml}$.

\subsection{5) Reverse Transkription (RT) und Polymerasekettenreaktion (PCR)}

$1 \mu \mathrm{g}$ isolierter RNA wurde eingesetzt, um mittels RT-PCR innerhalb einer Stunde bei $37^{\circ} \mathrm{C}$ die entsprechende komplementäre DNA (cDNA) in einem Volumen von $40 \mu \mathrm{l}$ zu erhalten. Der Reaktionsansatz enthielt $400 \mathrm{U}$ M-MLV reverse Transkriptase, 50 $\mathrm{mM}$ Tris $\mathrm{HCl} \mathrm{pH}$ 8,3, $75 \mathrm{mM} \mathrm{KCl}, 3 \mathrm{mM} \mathrm{MgCl}, 10 \mathrm{mM}$ DTT, $10 \mu \mathrm{g} / \mathrm{ml}$ (dT)15-Primer und $10 \mathrm{mM}$ dNTP-Mix.

Für die Real-Time PCR wurden $24 \mu \mathrm{l}$ PCR-Mix per Well angesetzt, bestehend aus jeweils $13 \mu \mathrm{l}$ SYBR Green, $8 \mu \mathrm{l}$ Ampuwa, sowie jeweils $1,5 \mu \mathrm{l}(0,3 \mu \mathrm{mol} / \mathrm{l})$ genspezifischer sense- und antisense-Primer. Dazu wurde je $1 \mu \mathrm{l}$ der DNA-Lösung gegeben. Zur Durchführung der Real-Time-PCR wurde der ABI Prism 7000 RealTime PCR-Cycler (Applied Biosystems, Carlsbad, US) verwendet. Es wurde ein Amplifikations-Protokoll in zwei Schritten gewählt, welches aus einer initialen Denaturierung für 10 Minuten bei $95^{\circ} \mathrm{C}$ und anschließend 45 Zyklen zu jeweils 15 Sekunden Denaturierung bei $95^{\circ} \mathrm{C}$ und 30 Sekunden Anlagerung/Verlängerung bei $60^{\circ} \mathrm{C}$ bestand. Zuletzt folgte ein Dissoziationsprotokoll, um die Spezifität der Amplifikationsprodukte zu prüfen. Die relative Expression der untersuchten Gene 
wurde dann mittels Cycle-Threshold (CT) -Methode errechnet. Die Expression der untersuchten Gene wurde auf die Expression des Housekeeping-Gens $\beta$-Aktin bezogen.

\subsection{6) Statistik}

Zur statistischen Auswertung wurde die GraphPad Prism Software Version 4 verwendet (San Diego, US). Auswertung des Expressionsunterschieds zwischen Probe und Kontrolle erfolgte mittels $t-T e s t$. Das Signifikanzniveau liegt bei $p<0,05$. 


\section{3) Ergebnisse}

3.1) Regulation der Expression der Wachstumsfaktoren und ihres Rezeptors in PBMCs

Untersucht wurde die Expression von EGF und VEGF sowie der Rezeptoren EGFR und VEGFR-1 in PBMCs ohne Stimulation (Kontrolle) und nach Inkubation gemäß der folgenden Versuchsdesings: a) für unstimulierte Kontrolle und Inkubation mit PHA oder LPS mit und ohne anti-VEGF-Antikörper, b) für unstimulierte Kontrolle und Inkubation mit PHA, LPS, TNF- $\alpha$ oder Infliximab einzeln bzw. PHA, LPS und TNF- $\alpha$ jeweils in Kombination mit Infliximab. Zur Normalisierung wurden die per Real-TimePCR gemessenen CT-Werte für das untersuchte Gen auf die Expression des Housekeeping-Gens $\beta$-Aktin bezogen. Die Grafiken geben die Vervielfachung der Genexpression wieder, bezogen auf die Expression ohne vorangegangene Stimulation (Kontrolle) zum Zeitpunkt Oh. Die jeweils statistisch signifikanten Veränderungen der Genexpression werden der Übersichtlichkeit halber in Tabellenform angegeben.

\subsection{1) Regulation der EGF- und EGFR-mRNA-Expression in PBMCs}

EGF wurde in PBMCs auf niedrigem Niveau exprimiert. Inkubation mit PHA, LPS oder TNF- $\alpha$ ergab dabei keine eindeutige Expressionsänderung gegenüber der unstimulierten Kontrolle, ebenso Zugabe von anti-EGF- bzw. anti-VEGF-Antikörper oder Infliximab (ohne Abbildung). EGFR-mRNA- konnte in PBMCs nicht nachgewiesen werden. Auf die Darstellung der Expression der jeweiligen Gene nach Inkubation mit EGF-Antikörper wird deshalb in der Folge verzichtet. 


\subsection{2) Regulation der VEGF mRNA-Expression in PBMCs}

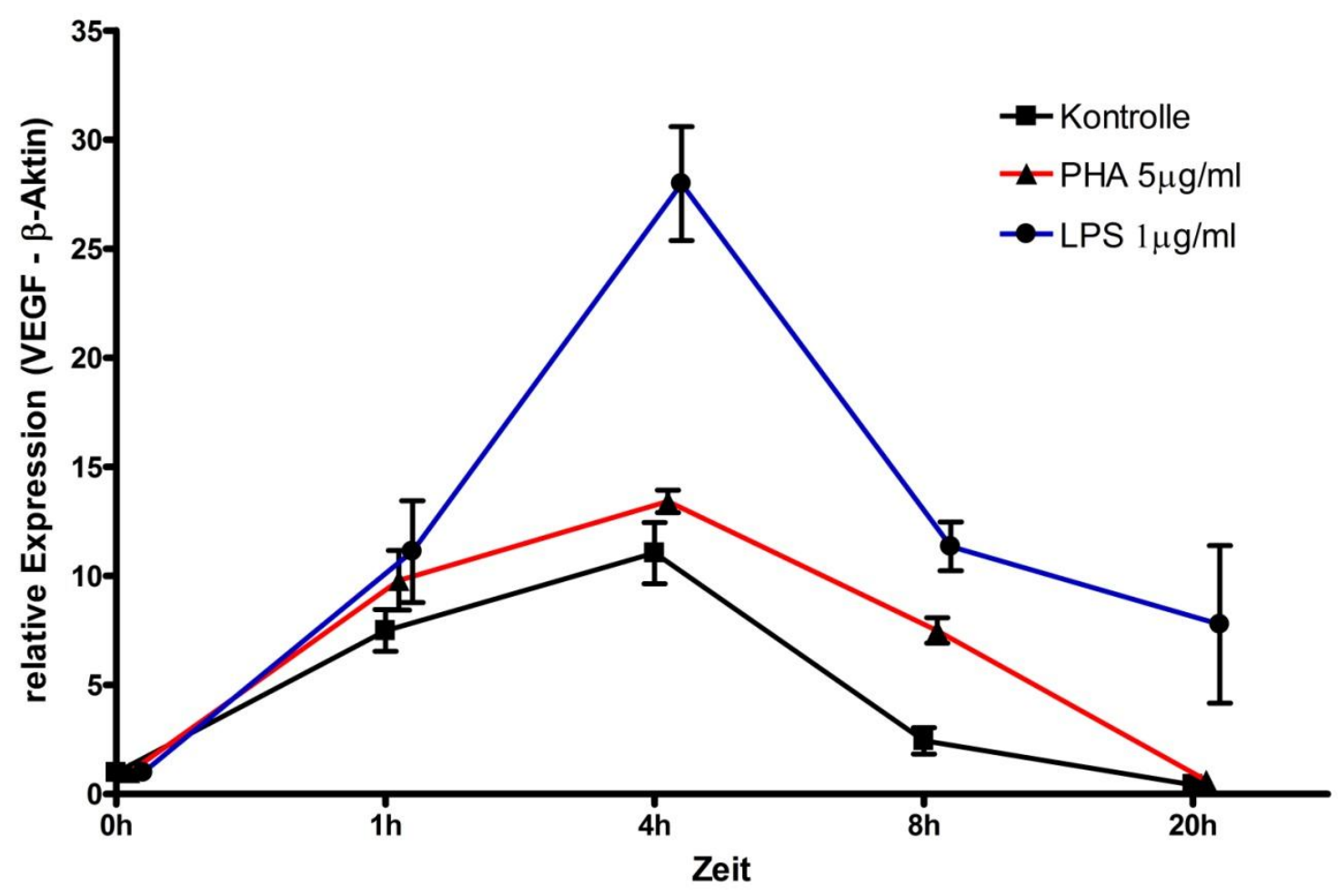

Abb. 7: Expression von VEGF in PBMCs (Versuchsdesign a)

Tab. 2: Signifikant veränderte Expression $(p \leq 0,05)$ von VEGF in PBMCs (Versuchsdesign a)

\begin{tabular}{|l|l|}
\hline PHA $₫$ vs. Kontrolle $\rightarrow-$ & $8 \mathrm{~h}$ \\
\hline LPS $\rightarrow$ vs. Kontrolle $\bullet-$ & $4 \mathrm{~h} ; 8 \mathrm{~h}$ \\
\hline
\end{tabular}

PBMCs exprimieren VEGF. Inkubation der Zellen mit LPS führte zum Zeitpunkt $4 \mathrm{~h}$ zu einer deutlichen Steigerung der VEGF-Expression. Inkubation mit PHA hatte keinen eindeutigen Effekt. 


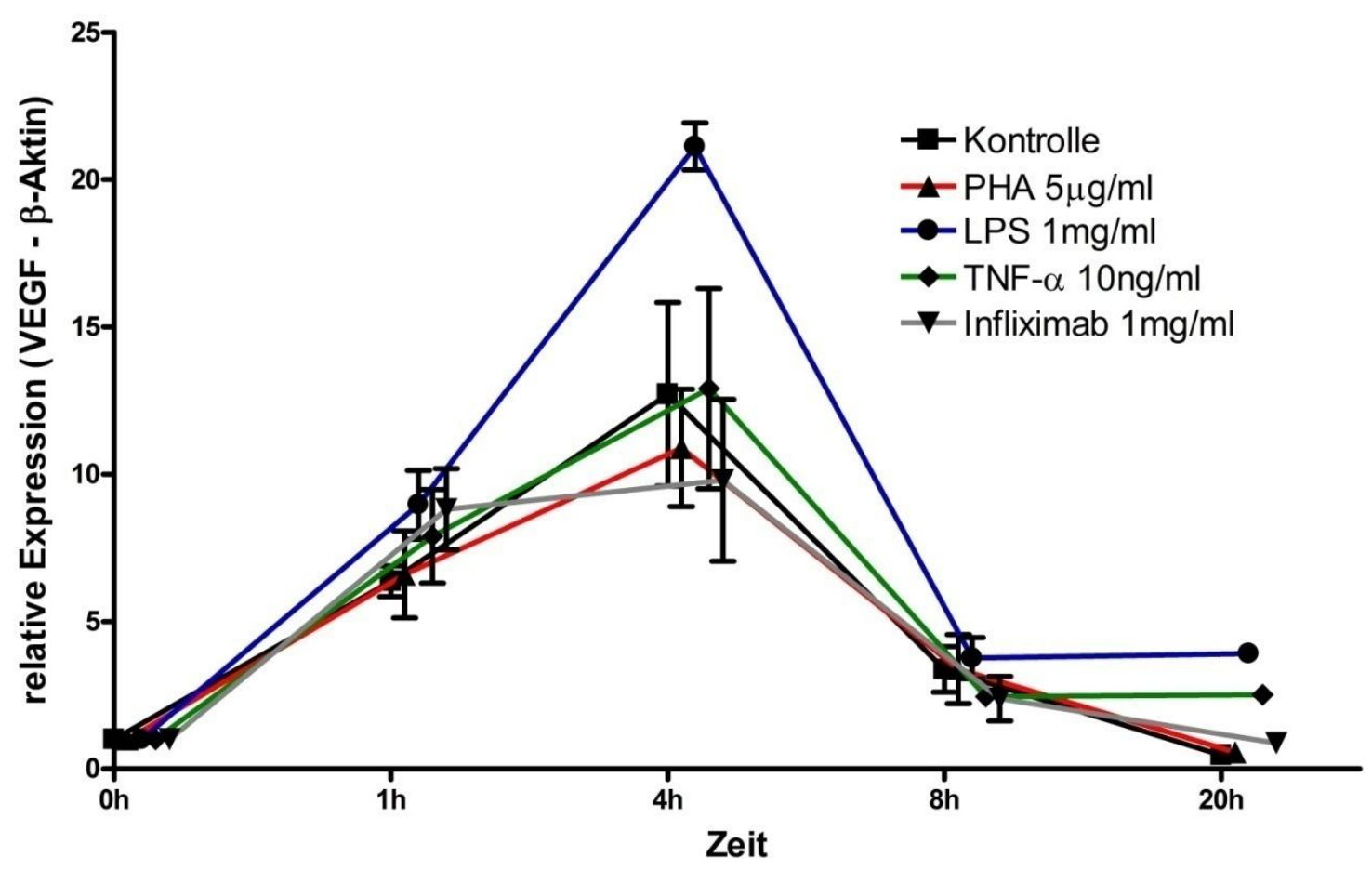

Abb. 8: Expression von VEGF in PBMCs (Versuchsdesign b)

Tab. 3: Signifikant veränderte Expression $(p \leq 0,05)$ von VEGF in PBMCs (Versuchsdesign b)

\begin{tabular}{|l|l|}
\hline PHA $₫$ vs. Kontrolle -- & - \\
\hline LPS $\rightarrow$ vs. Kontrolle $\bullet-$ & $20 \mathrm{~h}$ \\
\hline TNF $-\alpha-$ vs. Kontrolle -- & $20 \mathrm{~h}$ \\
\hline Infliximab $\bullet-$ vs. Kontrolle - & - \\
\hline
\end{tabular}

PBMCs exprimieren VEGF. Inkubation der Zellen mit LPS führte zum Zeitpunkt $4 \mathrm{~h}$ zu einer deutlichen Steigerung der VEGF-Expression. Inkubation mit PHA oder TNF- $\alpha$ hatte keinen eindeutigen Effekt. Unter Inkubation mit Infliximab fiel die Genexpression zum Zeitpunkt 4h geringfügig ab. 


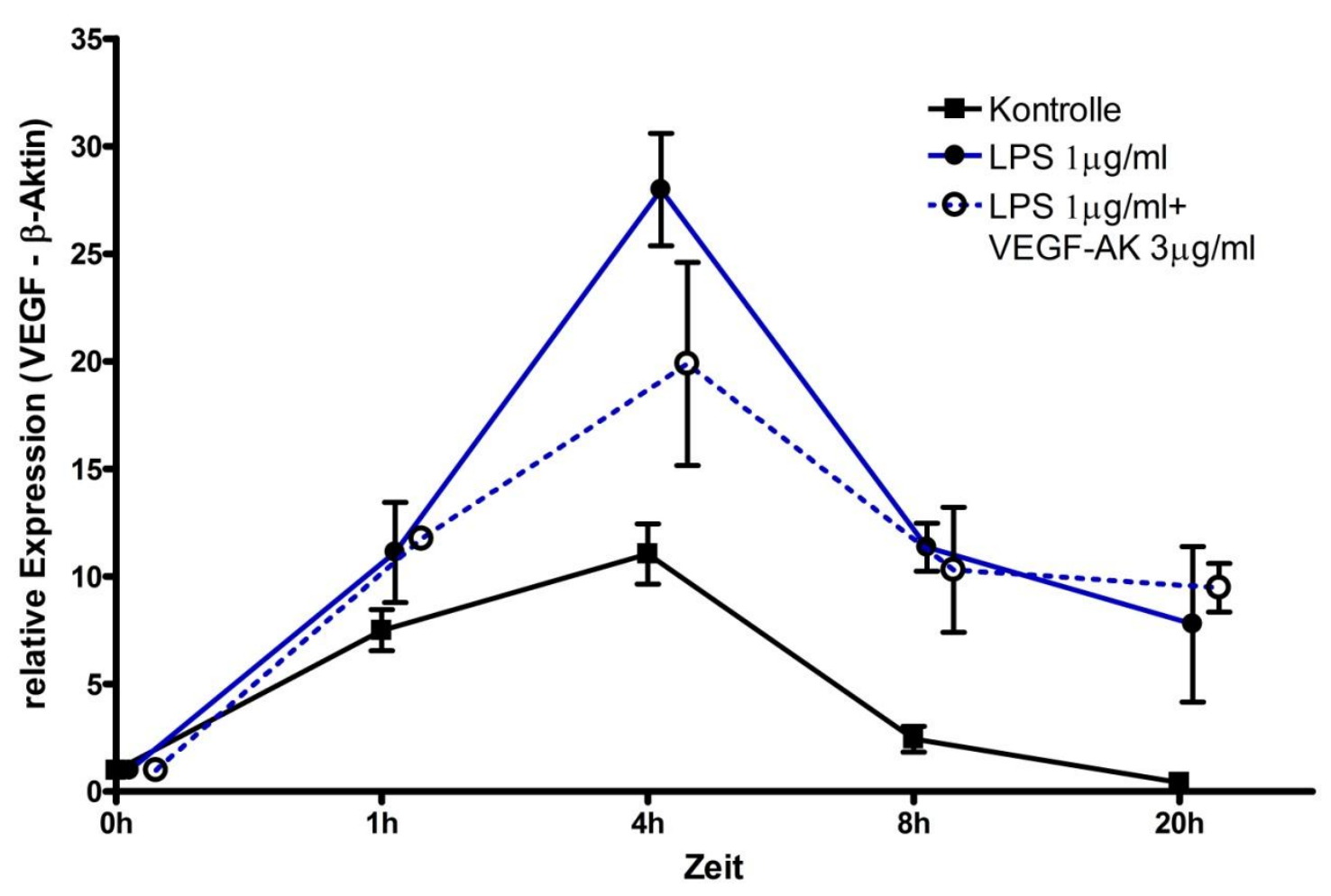

Abb. 9: Expression von VEGF in PBMCs (Versuchsdesign a)

Tab. 4: Signifikant veränderte Expression $(p \leq 0,05)$ von VEGF in PBMCs (Versuchsdesign a)

\begin{tabular}{|l|l|}
\hline LPS $\rightarrow-$ vs. Kontrolle $\rightarrow-$ & $4 \mathrm{~h} ; 8 \mathrm{~h}$ \\
\hline LPS+VEGF-AK· $\cdot \mathbf{v} \cdot$ vs. Kontrolle $-\mathbf{-}$ & $1 \mathrm{~h} ; 8 \mathrm{~h} ; 20 \mathrm{~h}$ \\
\hline LPS+VEGF-AK $\cdot \mathbf{0} \cdot$ vs. LPS $\rightarrow-$ & - \\
\hline
\end{tabular}

Inkubation der Zellen mit dem VEGF-Antikörper zusätzlich zu LPS führte zu einer geringfügig, nicht signifikant niedrigeren Expression von VEGF in PBMCs als Inkubation mit LPS allein. 


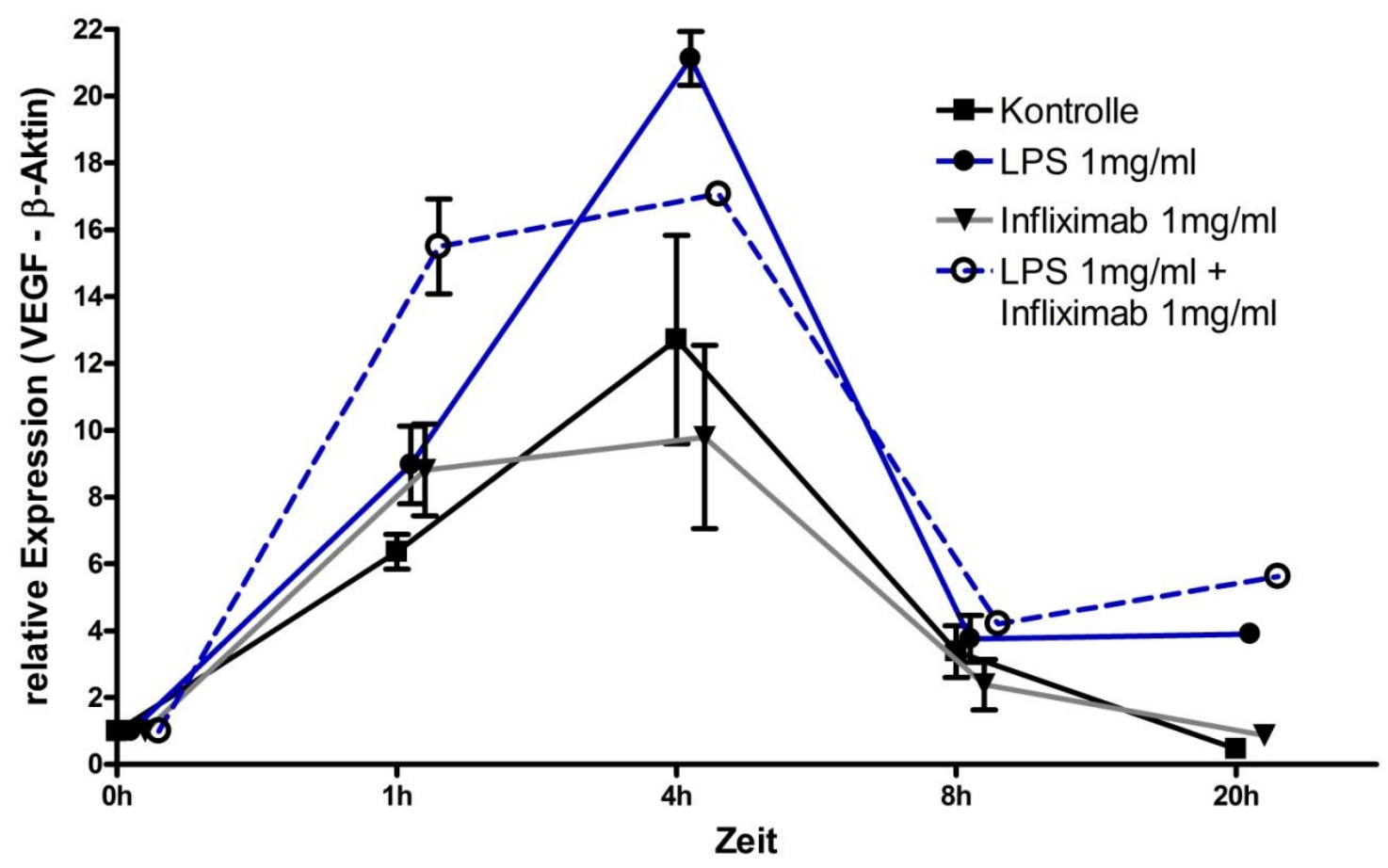

Abb. 10: Expression von VEGF in PBMCs (Versuchsdesign b)

Tab. 5: Signifikant veränderte Expression $(p \leq 0,05)$ von VEGF in PBMCs (Versuchsdesign b)

\begin{tabular}{|c|c|}
\hline LPS $\rightarrow-$ vs. Kontrolle $\rightarrow-$ & $20 \mathrm{~h}$ \\
\hline Infliximab - vs. Kontrolle $\rightarrow-$ & \\
\hline LPS+Infliximab-o-vs. Kontrolle $\rightarrow-$ & $1 \mathrm{~h} ; 4 \mathrm{~h} ; 20 \mathrm{~h}$ \\
\hline LPS+Infliximab-o・vs. LPS $\rightarrow-$ & $1 \mathrm{~h} ; 4 \mathrm{~h} ; 20 \mathrm{~h}$ \\
\hline LPS +Infliximab-0 $\cdot$ vs. Infliximab- $₹$ & $1 \mathrm{~h} ; 20 \mathrm{~h}$ \\
\hline
\end{tabular}

Inkubation der Zellen mit Infliximab zusätzlich zu LPS bewirkte eine geringgradige Hemmung der LPS-induzierten Expressionszunahme zum Zeitpunkt 4h. 


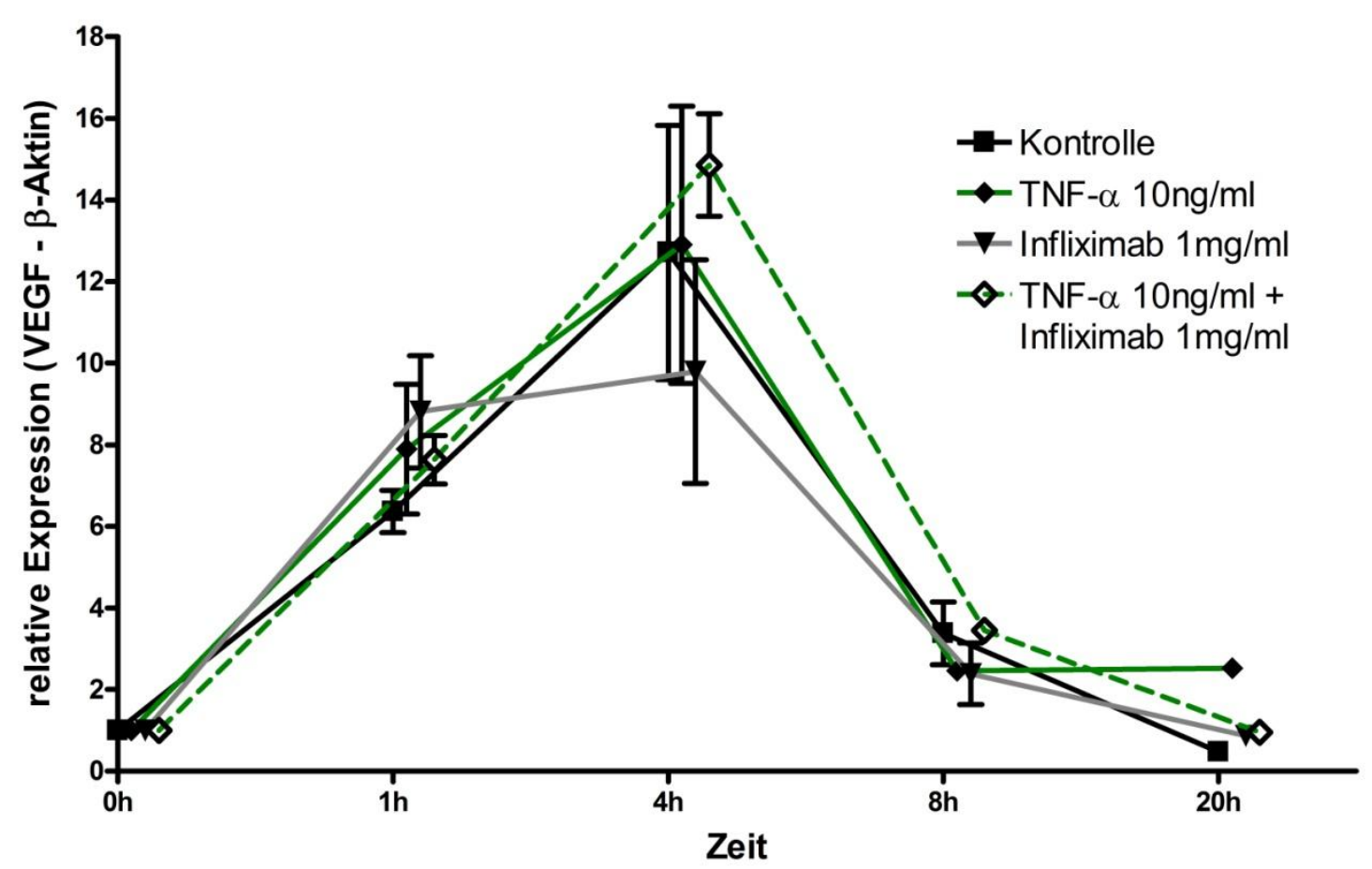

Abb. 11: Expression von VEGF in PBMCs (Versuchsdesign b)

Tab. 6: Signifikant veränderte Expression von $(p \leq 0,05)$ VEGF in PBMCs (Versuchsdesign b)

\begin{tabular}{|c|c|}
\hline TNF- $\alpha \rightarrow$ vs. Kon & $20 \mathrm{~h}$ \\
\hline Infliximab $\nabla$ vs. $r$ & \\
\hline TNF- $\alpha+\operatorname{lnfliximab}-\alpha$ vs. Kontrolle $\rightarrow-$ & $20 \mathrm{~h}$ \\
\hline TNF- $\alpha+\operatorname{lnfliximab} \diamond$ vs. TNF- $\alpha \rightarrow-$ & $8 \mathrm{~h} ; 20 \mathrm{~h}$ \\
\hline TNF- $\alpha+$ +Infliximab $\diamond$ vs. Infliximab $\nleftarrow$ & \\
\hline
\end{tabular}

Inkubation der Zellen mit TNF- $\alpha$ hatte keinen Effekt auf die VEGF-Expression, Infliximab bewirkte eine geringgradige Hemmung. 


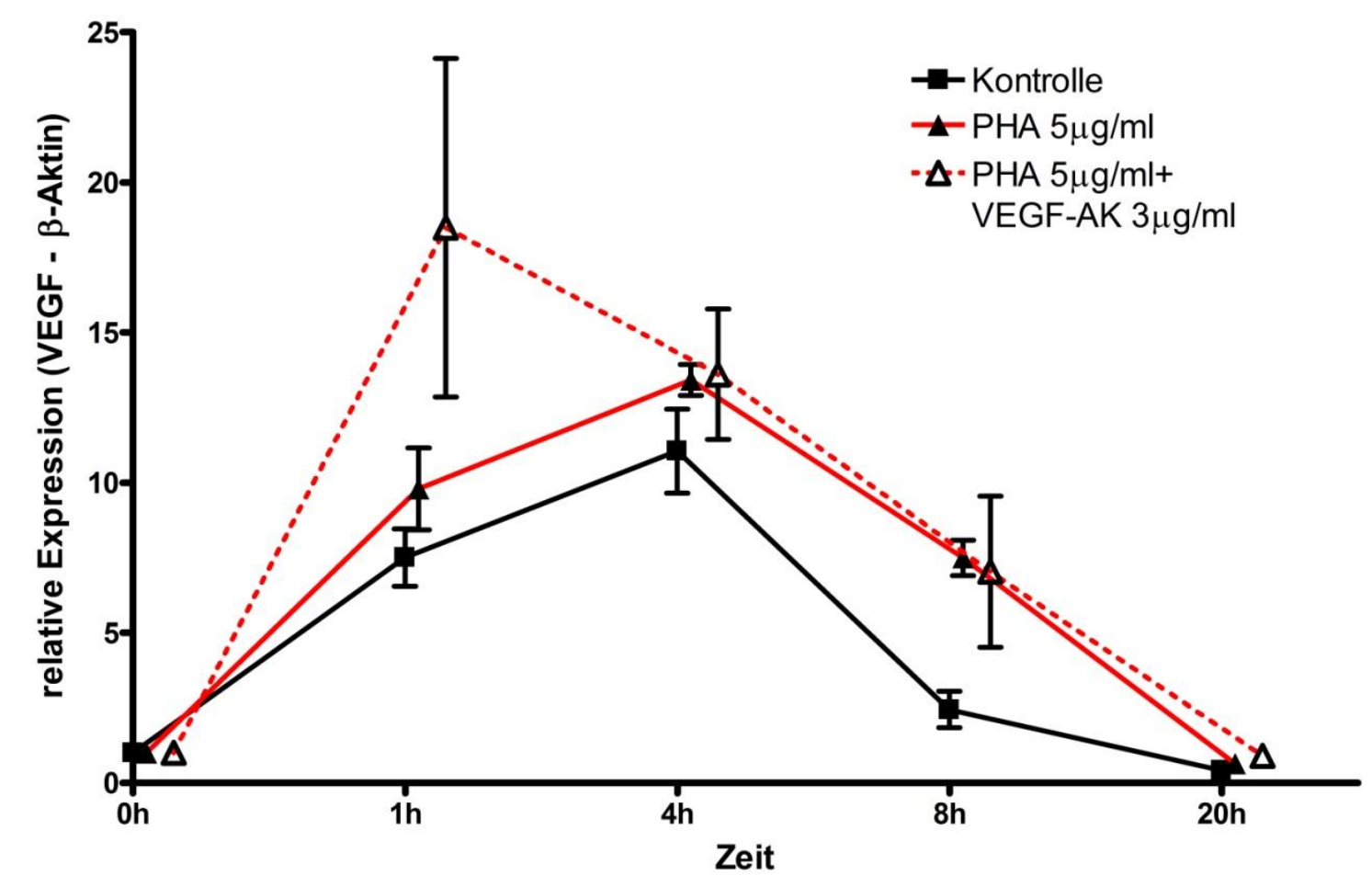

Abb. 12: Expression von VEGF in PBMCs (Versuchsdesign a)

Tab. 7: Signifikant veränderte Expression $(p \leq 0,05)$ von VEGF in PBMCs (Versuchsdesign a)

\begin{tabular}{|c|c|}
\hline $\mathrm{PHA} \approx$ vs. $\mathrm{Ko} \rightleftharpoons$ & $8 \mathrm{~h}$ \\
\hline $\mathrm{PHA}+\mathrm{VEGF}-\mathrm{AK}^{*} \Delta$ vs. Kontrolle - & \\
\hline $\mathrm{PHA}+$ VEGF-AK ${ }^{\star} \Delta$ vs. $\mathrm{PHA} \star$ & \\
\hline
\end{tabular}

Inkubation der Zellen mit dem VEGF-Antikörper zusätzlich zu PHA hatte keinen eindeutigen Effekt auf die Expression von VEGF in PBMCs. 


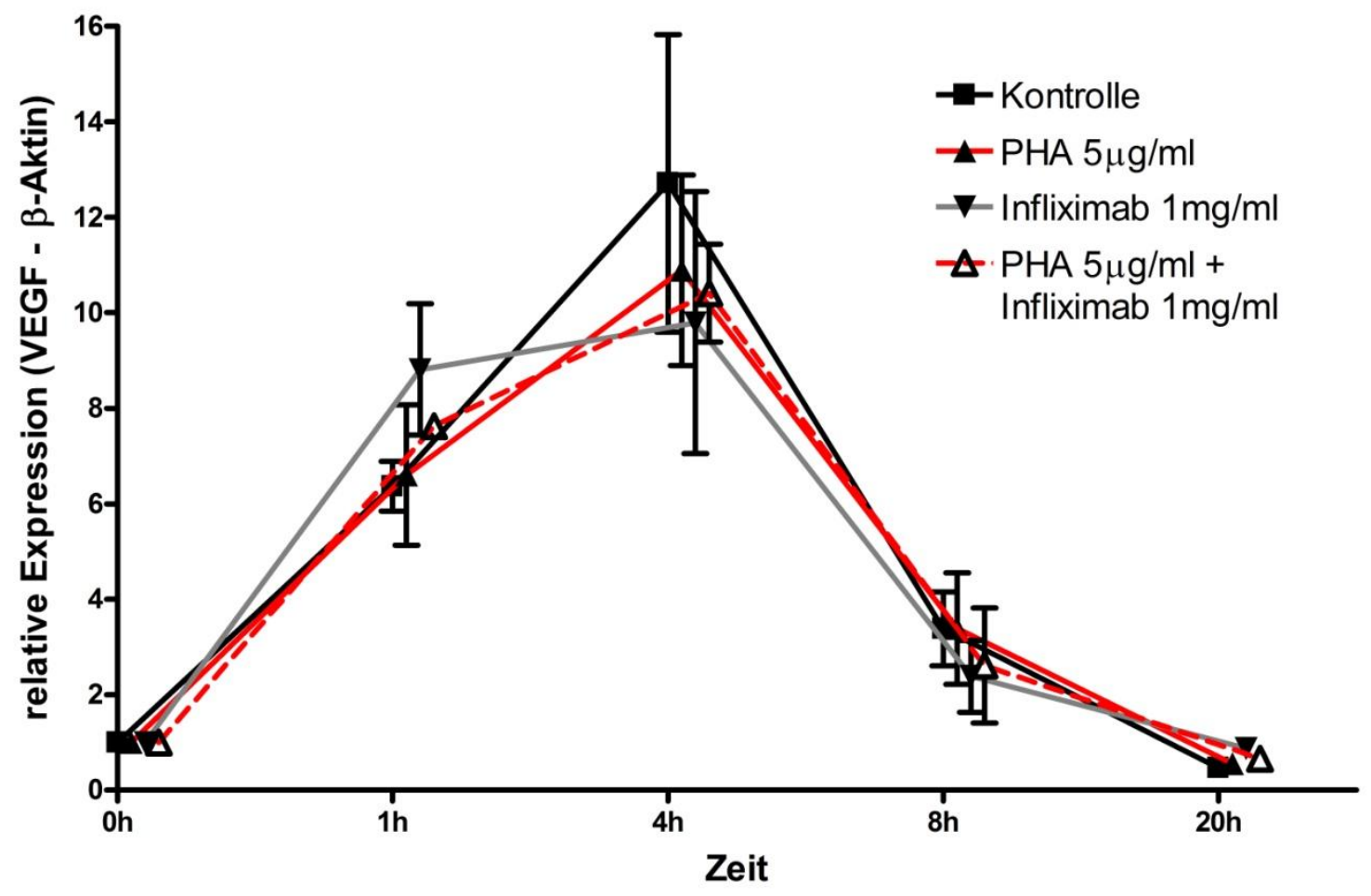

Abb. 13: Expression von VEGF in PBMCs (Versuchsdesign b)

Tab. 8: Signifikant veränderte Expression $(p \leq 0,05)$ von VEGF in PBMCs (Versuchsdesign b)

\begin{tabular}{|c|}
\hline $\mathrm{PHA}$ — vs. Kontrolle $\rightarrow$ \\
\hline Infliximab $\rightarrow$ vs. Kontrolle $\rightarrow-$ \\
\hline $\mathrm{PHA}+\operatorname{Infliximab} \Delta^{\Delta}$ vs. Kontrolle $\bullet$ \\
\hline $\mathrm{PHA}+\operatorname{Infliximab} \triangle{ }^{-}$vs. $\mathrm{PHA} \_$ \\
\hline $\mathrm{PHA}+\operatorname{Infliximab}{ }^{-\Delta}$ vs. Infliximab $\boldsymbol{\nabla}$ \\
\hline
\end{tabular}

Inkubation mit Infliximab zusätzlich zu PHA ergab keine eindeutige Veränderung der VEGF-Expression gegenüber der Inkubation mit PHA allein. 


\subsection{3) Regulation der VEGFR-1 mRNA-Expression in PBMCs}

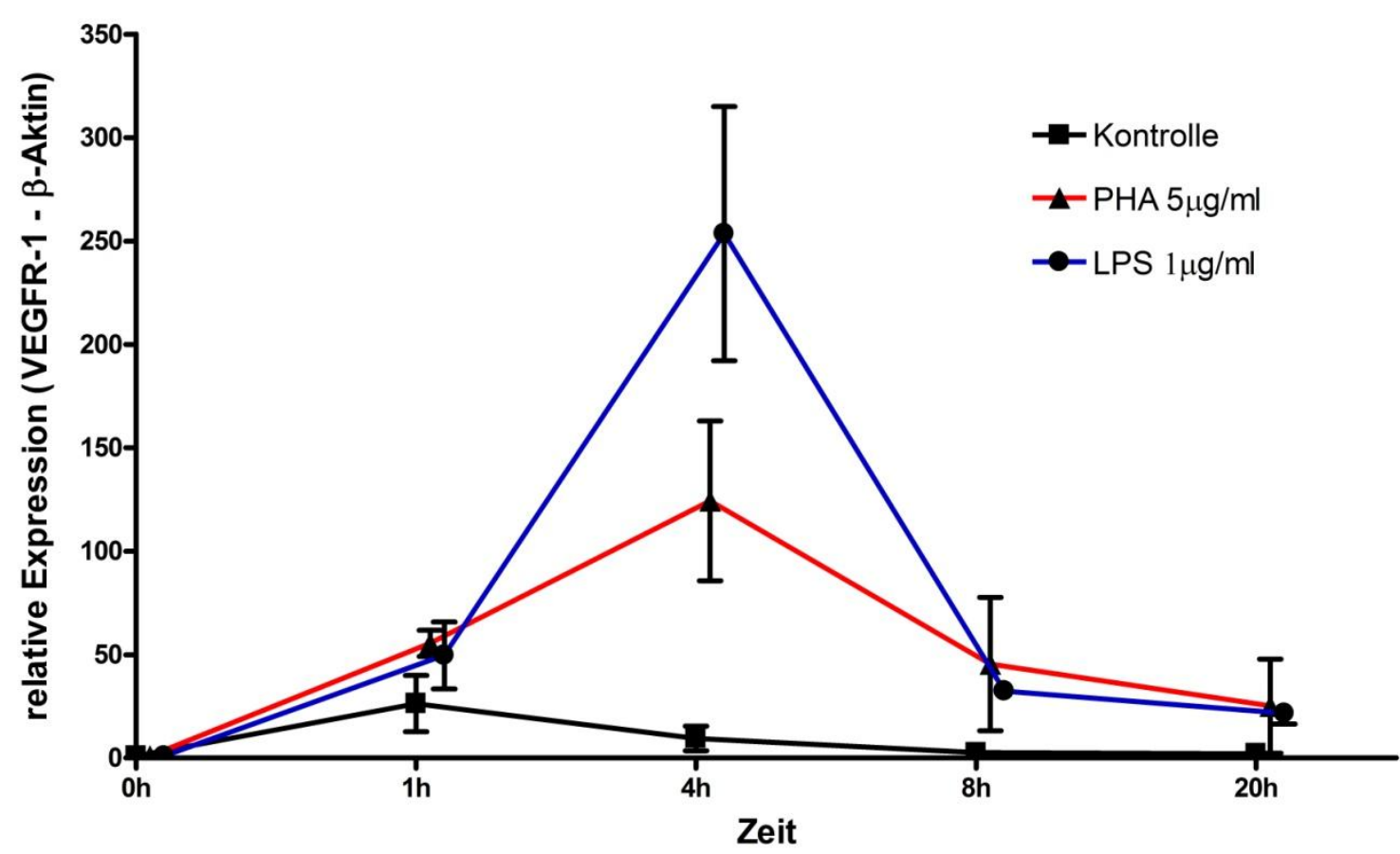

Abb. 14: Expression von VEGFR-1 in PBMCs (Versuchsdesign a)

Tab. 9: Signifikant veränderte Expression $(p \leq 0,05)$ von VEGFR-1 in PBMCs (Versuchsdesign a)

\begin{tabular}{|l|l|}
\hline $\mathrm{PHA} \star$ ¿v. Ko $\rightarrow-$ & 1h; 4h \\
\hline LPS $\bullet$ vs. Kontrolle $\rightarrow-$ & $4 \mathrm{~h} ; 8 \mathrm{~h} ; 20 \mathrm{~h}$ \\
\hline
\end{tabular}

Inkubation mit LPS bewirkte einen deutlichen Anstieg der VEGFR-1-Expression. In geringerem Ausmaß führte auch Inkubation mit PHA zu einem Expressionsanstieg. 


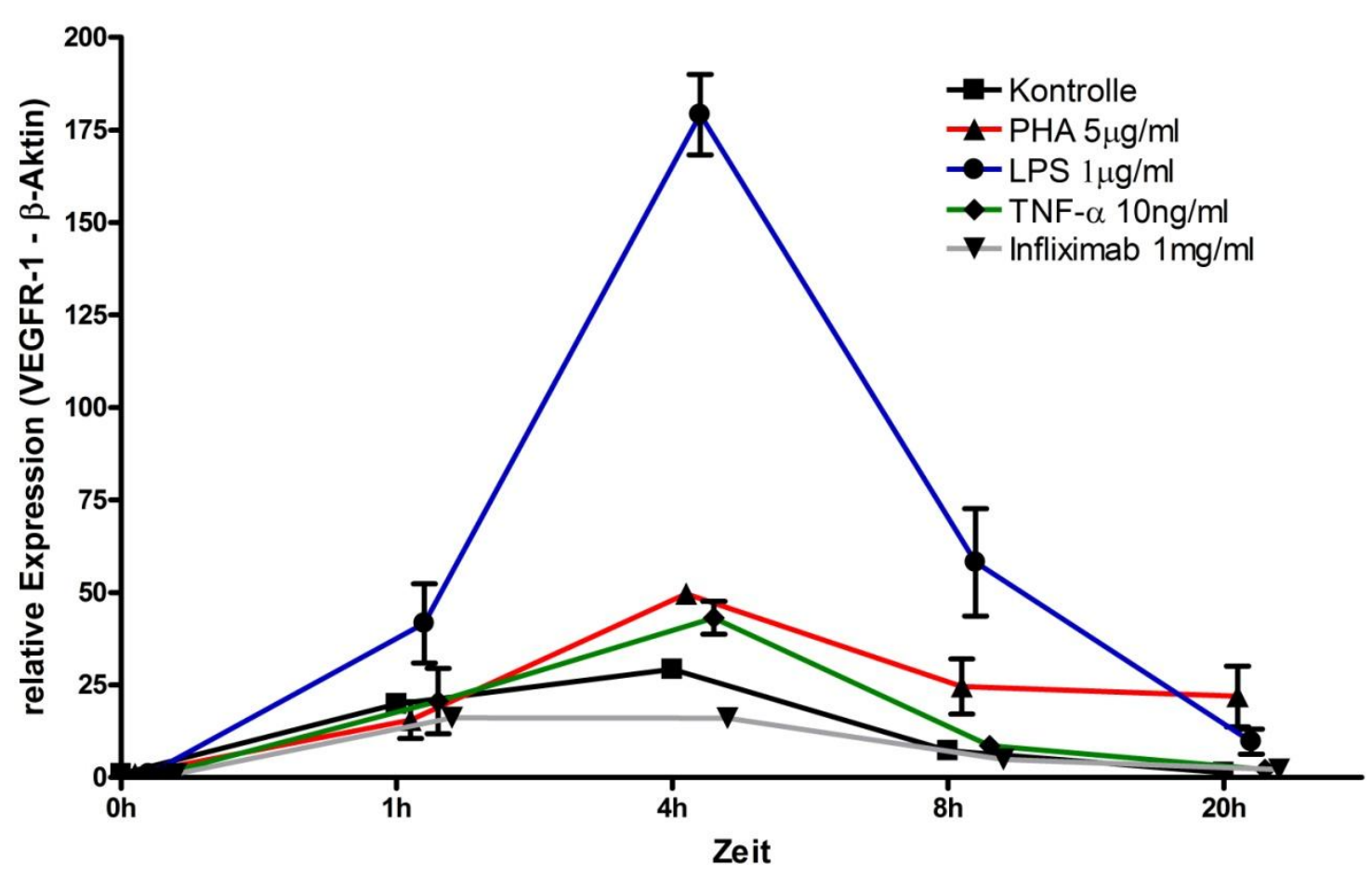

Abb. 15: Expression von VEGFR-1 in PBMCs (Versuchsdesign b)

Tab. 10: Signifikant veränderte Expression $(p \leq 0,05)$ von VEGFR-1 in PBMCs (Versuchsdesign b)

\begin{tabular}{|l|l|}
\hline $\mathrm{PHA} \star$-vs. Kontrolle $\bullet-$ & $4 \mathrm{~h} ; 8 \mathrm{~h}$ \\
\hline $\mathrm{LPS} \rightarrow$ - vs. Kontrolle $\rightarrow-$ & $4 \mathrm{~h} ; 8 \mathrm{~h}$ \\
\hline $\mathrm{TNF} \bullet$ vs. Kontrolle $\bullet-$ & - \\
\hline Infliximab $\bullet$ vs. Kontrolle $\rightarrow-$ & $4 \mathrm{~h}$ \\
\hline
\end{tabular}

Inkubation mit LPS bewirkte einen deutlichen Anstieg der VEGFR-1-Expression. In geringerem Ausmaß führte auch Inkubation mit PHA oder TNF- $\alpha$ zu einem Expressionsanstieg, Behandlung der Zellen mit Infliximab allein führte zu einer geringgradigen Abnahme der Genexpression. 


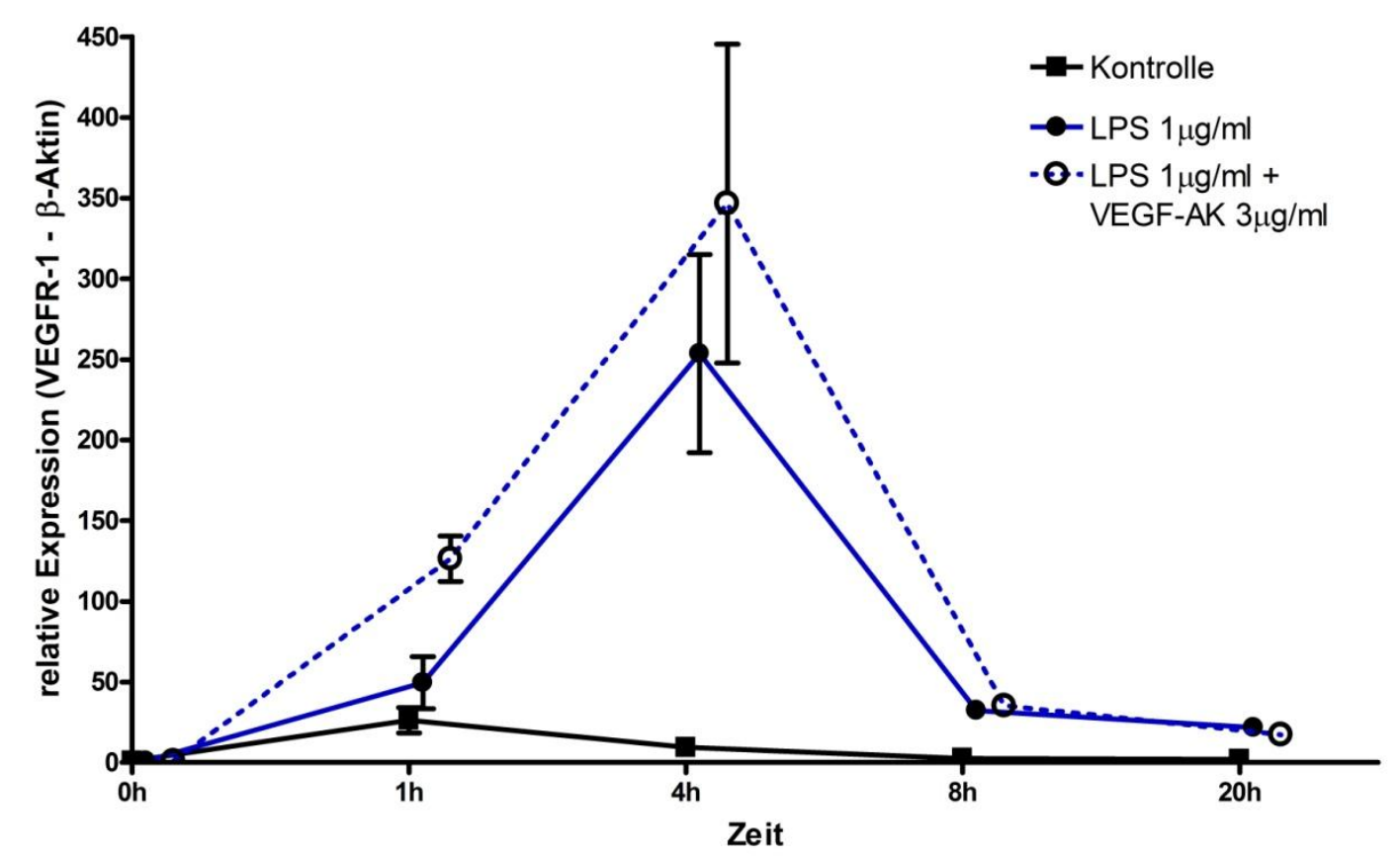

Abb. 16: Expression von VEGFR-1 in PBMCs (Versuchsdesign a)

Tab. 11: Signifikant veränderte Expression $(p \leq 0,05)$ von VEGFR-1 in PBMCs (Versuchsdesign a)

\begin{tabular}{|l|l|}
\hline LPS $\rightarrow-$ vs. Kontrolle $\rightarrow-$ & $4 \mathrm{~h} ; 8 \mathrm{~h} ; 20 \mathrm{~h}$ \\
\hline LPS+VEGF-AK $\cdot \boldsymbol{0} \cdot$ vs. Kontrolle $\rightarrow-$ & $1 \mathrm{~h} ; 4 \mathrm{~h} ; 8 \mathrm{~h} ; 20 \mathrm{~h}$ \\
\hline LPS+VEGF-AK $\cdot \boldsymbol{0} \cdot$ vs. LPS $\rightarrow-$ & $1 \mathrm{~h}$ \\
\hline
\end{tabular}

Unter Behandlung der PBMCs mit VEGF-AK zusätzlich zu LPS zeigte sich eine geringgradige Expressionszunahme von VEGFR-1. 


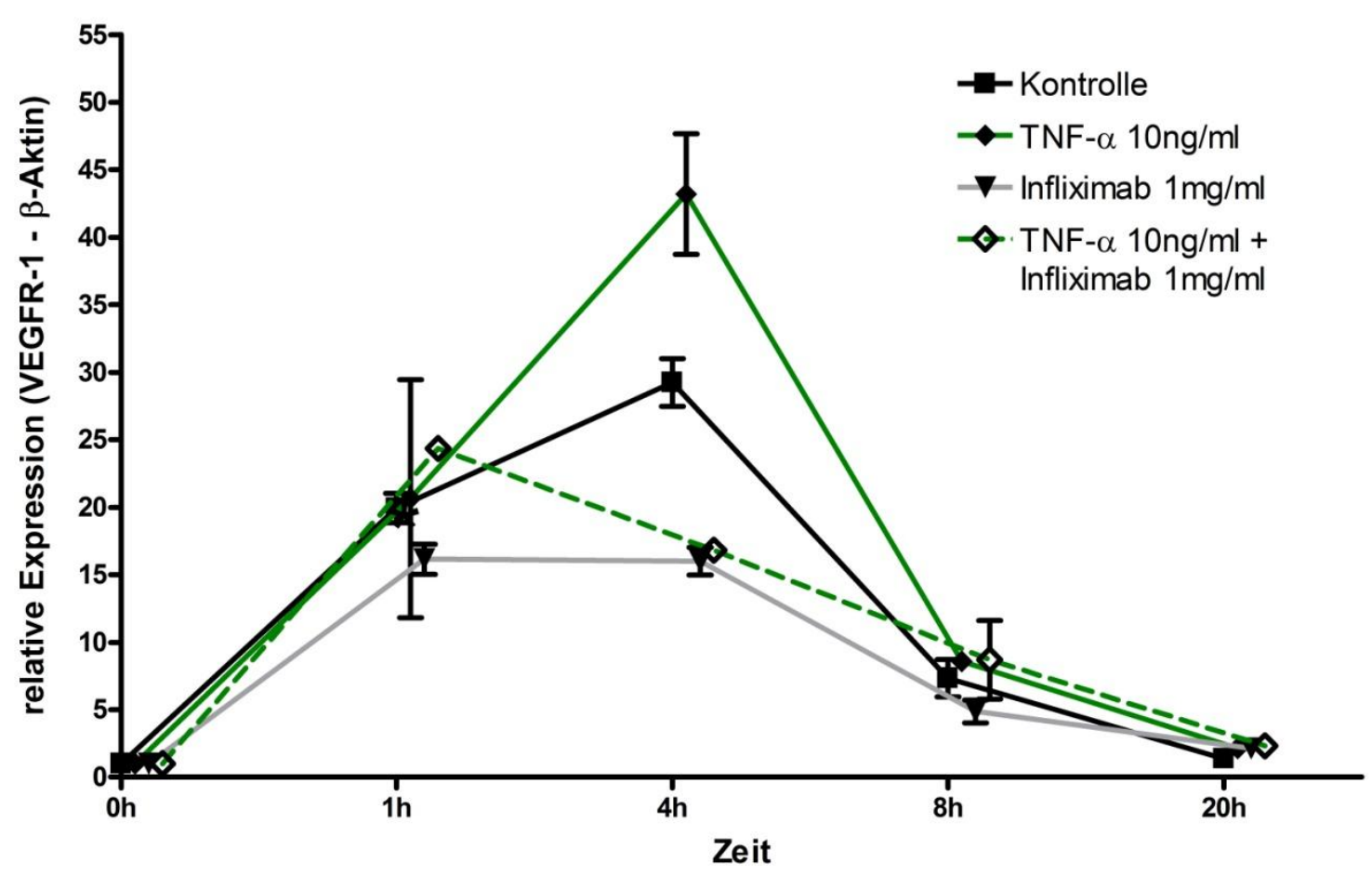

Abb. 17: Expression von VEGFR-1 in PBMCs (Versuchsdesign b)

Tab. 12: Signifikant veränderte Expression $(p \leq 0,05)$ von VEGFR-1 in PBMCs (Versuchsdesign b)

\begin{tabular}{|c|c|}
\hline TNF- $\alpha \rightarrow-$ vs. Kontrolle $\rightarrow-$ & \\
\hline Infliximab $\rightarrow$ vs. Kontrolle $\rightarrow-$ & $4 \mathrm{~h}$ \\
\hline TNF $-\alpha+\operatorname{Infliximab} \diamond$ vs. Kontrolle $\rightarrow-$ & $1 \mathrm{~h} ; 4 \mathrm{~h}$ \\
\hline TNF- $\alpha+$ Infliximab $\diamond$ vs. TNF- $\alpha \rightarrow-$ & $4 \mathrm{~h}$ \\
\hline 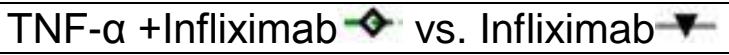 & $1 \mathrm{~h}$ \\
\hline
\end{tabular}

Inkubation der Zellen mir TNF- $\alpha$ bewirkte eine geringgradige Steigerung der VEGFR1-Expression, Inkubation der PBMCs mit Infliximab zusätzlich zu TNF-a neutralisierte den expressionssteigernden Effekt. 


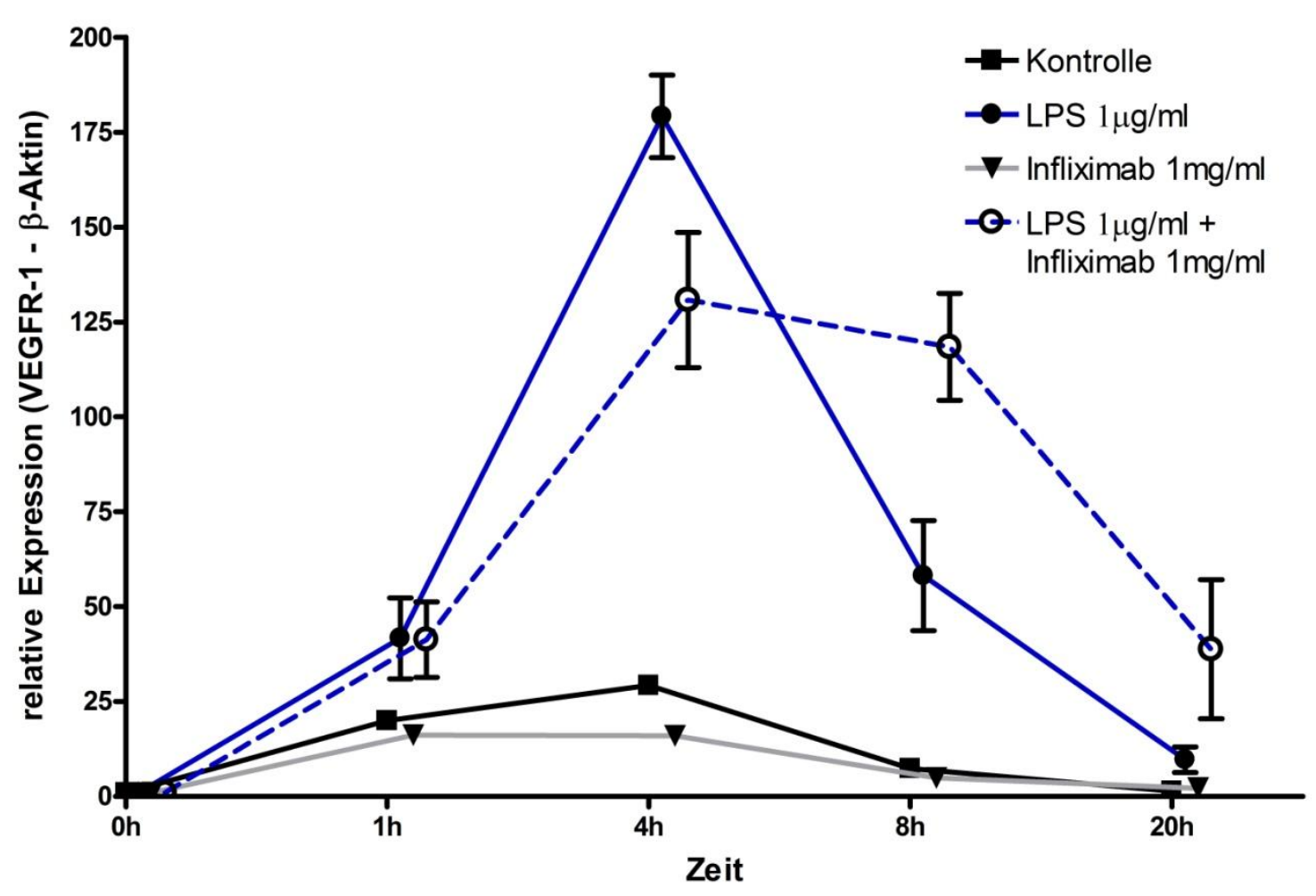

Abb. 18: Expression von VEGFR-1 in PBMCs (Versuchsdesign b)

Tab. 13: Signifikant veränderte Expression $(p \leq 0,05)$ von VEGFR-1 in PBMCs (Versuchsdesign b)

\begin{tabular}{|c|c|}
\hline LPS $\rightarrow-$ vs. Kontrolle $\rightarrow-$ & $4 h ; 8 h$ \\
\hline Infliximab- $\nabla$ vs. Kontrolle - \pm & $4 \mathrm{~h}$ \\
\hline LPS+Infliximab-o. vs. Kontrolle - - & $4 \mathrm{~h} ; 8 \mathrm{~h}$ \\
\hline LPS+Infliximab-o·vs. LPS - - & $8 \mathrm{~h}$ \\
\hline LPS+Infliximab-o* vs. Infliximab- & 4h; 8h \\
\hline
\end{tabular}

Inkubation der Zellen mir Infliximab zusätzlich zu LPS wirkte geringgradig hemmend auf die LPS-induzierte VEGFR-1-Expression. 


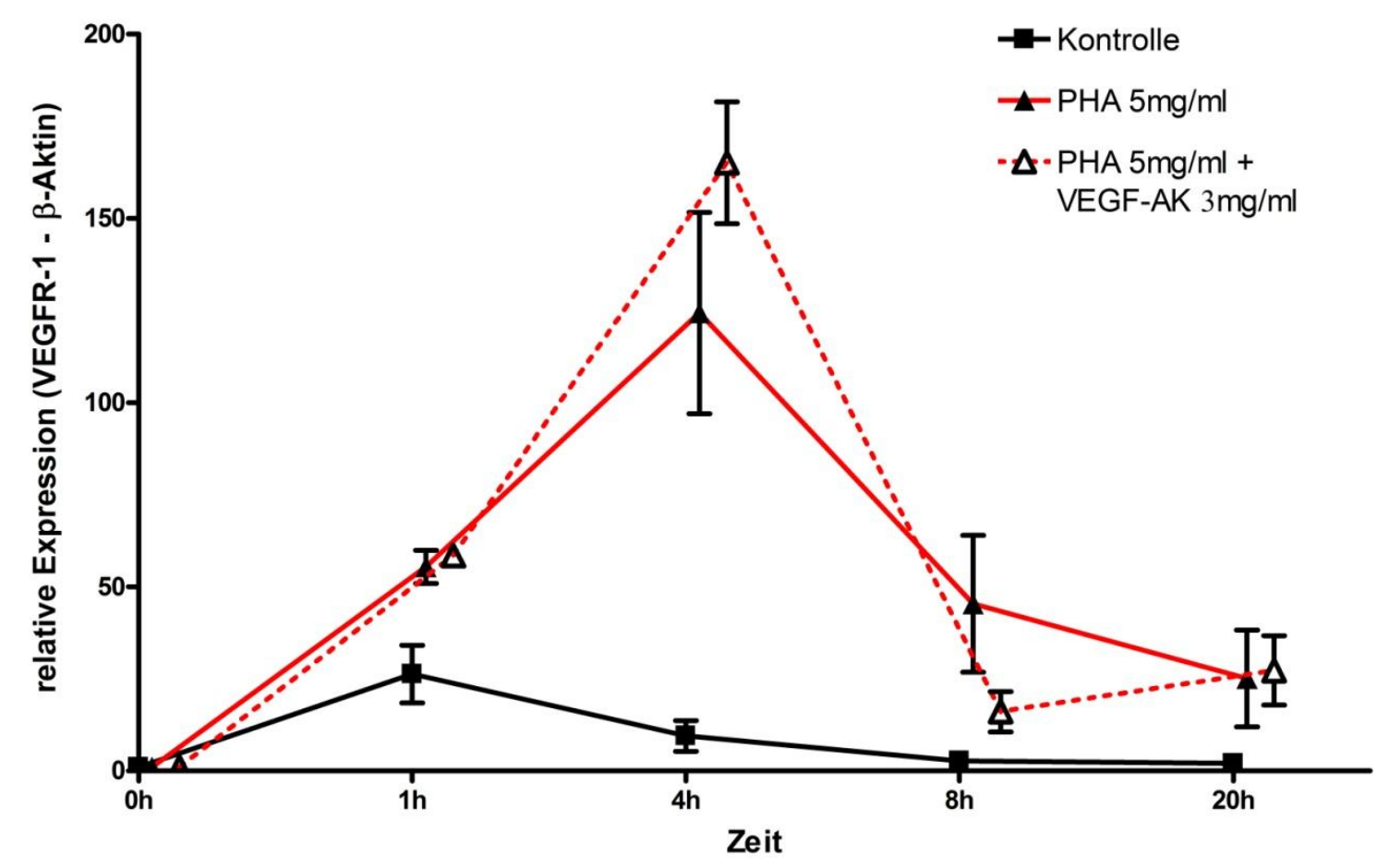

Abb. 19: Expression von VEGFR-1 in PBMCs (Versuchsdesign a)

Tab. 14: Signifikant veränderte Expression $(p \leq 0,05)$ von VEGFR-1 in PBMCs \begin{tabular}{|l|l|}
\hline $\mathrm{PHA} \star$ - vs. Kontrolle $\rightarrow-$ & $1 \mathrm{~h} ; 4 \mathrm{~h}$ \\
\hline
\end{tabular} PHA+VEGF-AK $\Delta^{*}$ vs. Kontrolle $\rightarrow-1 \mathrm{~h} ; 4 \mathrm{~h}$

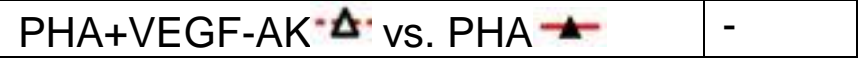

Inkubation der PBMCs mit PHA bewirkte eine Expressionssteigerung von VEGFR-1, zusätzliche Inkubation mit anti-VEGF-AK ergab keine relevante Veränderung. 


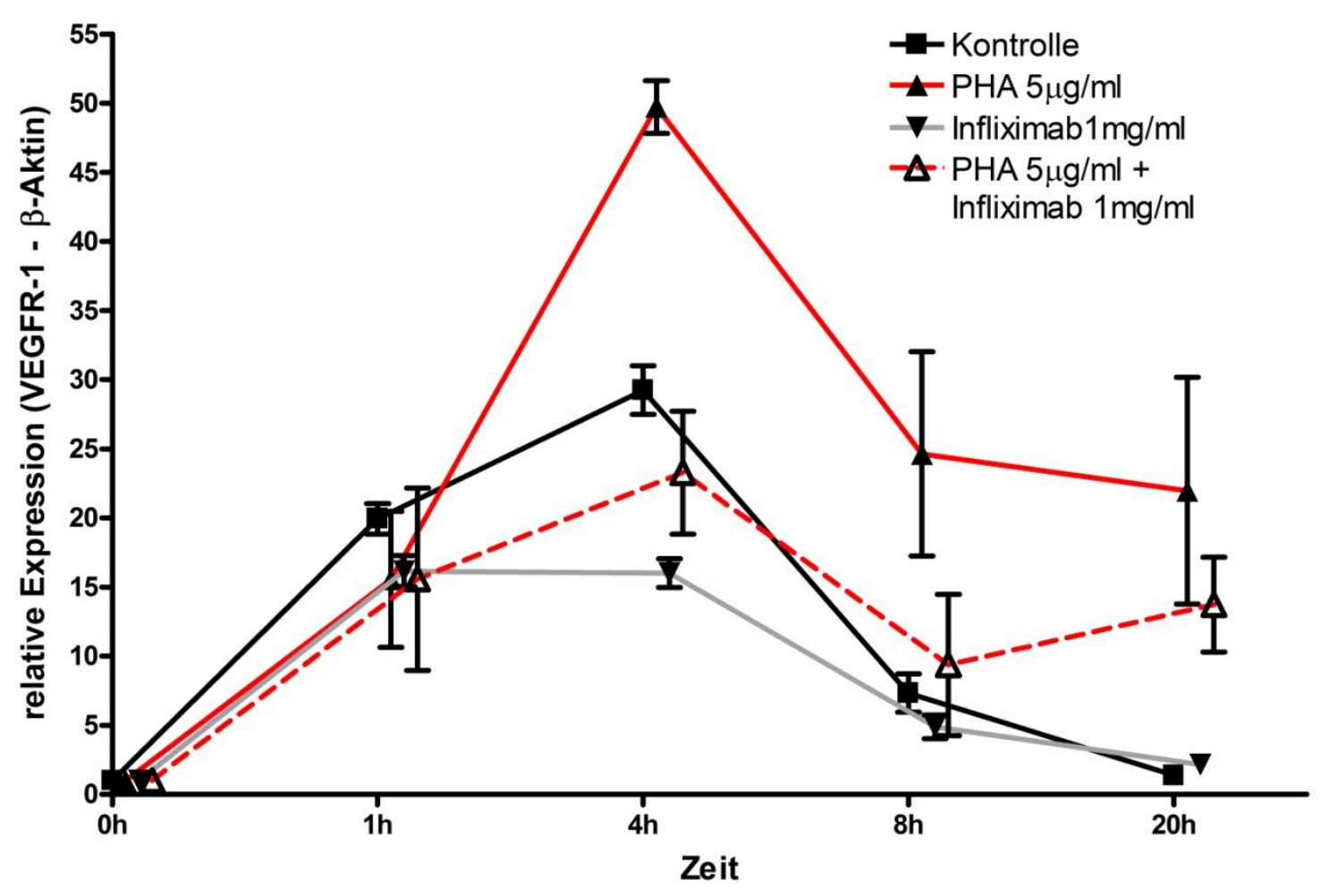

Abb. 20: Expression von VEGFR-1 in PBMCs (Versuchsdesign b)

Tab. 15: Signifikant veränderte Expression $(p \leq 0,05)$ von VEGFR-1 in PBMCs (Versuchsdesign b)

\begin{tabular}{|c|c|}
\hline $\mathrm{PHA} \approx$ vs. Kontrolle $\rightarrow-$ & $4 \mathrm{~h} ; 8 \mathrm{~h}$ \\
\hline Infliximab $¥$ vs. Kontrolle $\rightarrow-$ & $4 \mathrm{~h}$ \\
\hline $\mathrm{PHA}+\operatorname{Infliximab}{ }^{\Delta}{ }^{*}$ vs. Kontrolle $=$ & $20 \mathrm{~h}$ \\
\hline $\mathrm{PHA}+\operatorname{Infliximab} \Delta$ vs. $\mathrm{PHA} \star$ & $4 \mathrm{~h}$ \\
\hline $\mathrm{PHA}+\operatorname{Infliximab} \Delta^{\Delta}$ vs. Infliximab $\nabla$ & $20 \mathrm{~h}$ \\
\hline
\end{tabular}

Inkubation der PBMCs mit PHA bewirkte eine Expressionssteigerung von VEGFR-1, zusätzliche Inkubation mit Infliximab zusätzlich zu PHA neutralisierte den stimulierenden PHA-Effekt. 
3.2) Regulation der Expression der Wachstumsfaktoren EGF und VEGF und ihrer Rezeptoren in Kolonkarzinomzellen

Untersucht wurde die Expression von EGF und VEGF sowie die der Rezeptoren EGFR und VEGFR-1 in DLD-1- und HT-29-Kolonkarzinomzellen ohne Stimulation (Kontrolle) und nach Inkubation mit IL-1 $\beta$, TNF- $\alpha$ und IFN- $\gamma$ einzeln bzw. in den Kombinationen IL-1 $\beta+$ IFN- $\gamma$, TNF- $\alpha+$ IFN- $\gamma$ und IL-1 $\beta+$ TNF- $\alpha$. Zur Normalisierung wurden die per Real-Time-PCR gemessenen CT-Werte für das untersuchte Gen auf die Expression des Housekeeping-Gens $\beta$-Aktin bezogen. Die Grafiken geben die Vervielfachung der Genexpression wieder, bezogen auf die Expression ohne vorangegangene Stimulation (Kontrolle) zum Zeitpunkt Oh. Die jeweils statistisch signifikanten Veränderungen der Genexpression werden der Übersichtlichkeit halber in Tabellenform angegeben. 


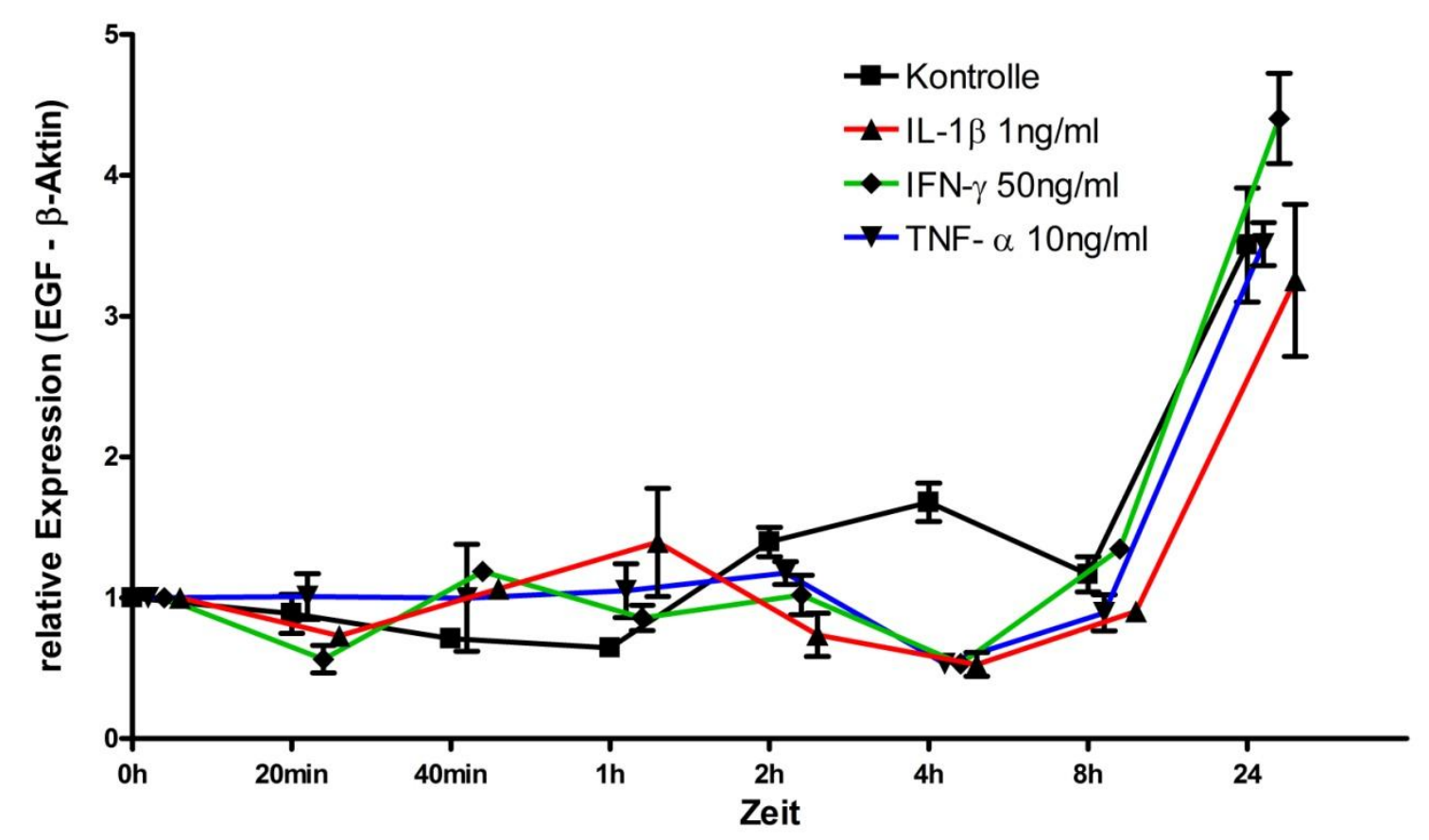

Abb. 21: Expression von EGF in DLD-1-Zellen

Tab. 16: Signifikant veränderte Expression $(p \leq 0,05)$ von EGF in DLD-1-Zellen \begin{tabular}{|l|l|}
\hline $\mathrm{IL}-1 \beta \star$ vs. Kontrolle $\rightarrow-$ & $40 \mathrm{~min} ; 2 \mathrm{~h} ; 4 \mathrm{~h}$ \\
\hline $\mathrm{IFN}-\mathrm{\gamma} \bullet$ vs. Kontrolle $\rightarrow-$ & $40 \mathrm{~min} ; 4 \mathrm{~h}$ \\
\hline TNF- $\alpha \multimap$ vs. Kontrolle $\rightarrow-$ & $4 \mathrm{~h}$
\end{tabular}

DLD-1-Zellen exprimieren den EGF. Dabei zeigte sich nach acht Sunden eine Zunahme der Genexpression auch in der Kontrolle. Einzelinkubation der DLD-1 Zellen mit IL-1 $\beta$, IFN- $\gamma$ oder TNF- $\alpha$ hatte keinen nennenswerten Effekt auf die Expression von EGF. 


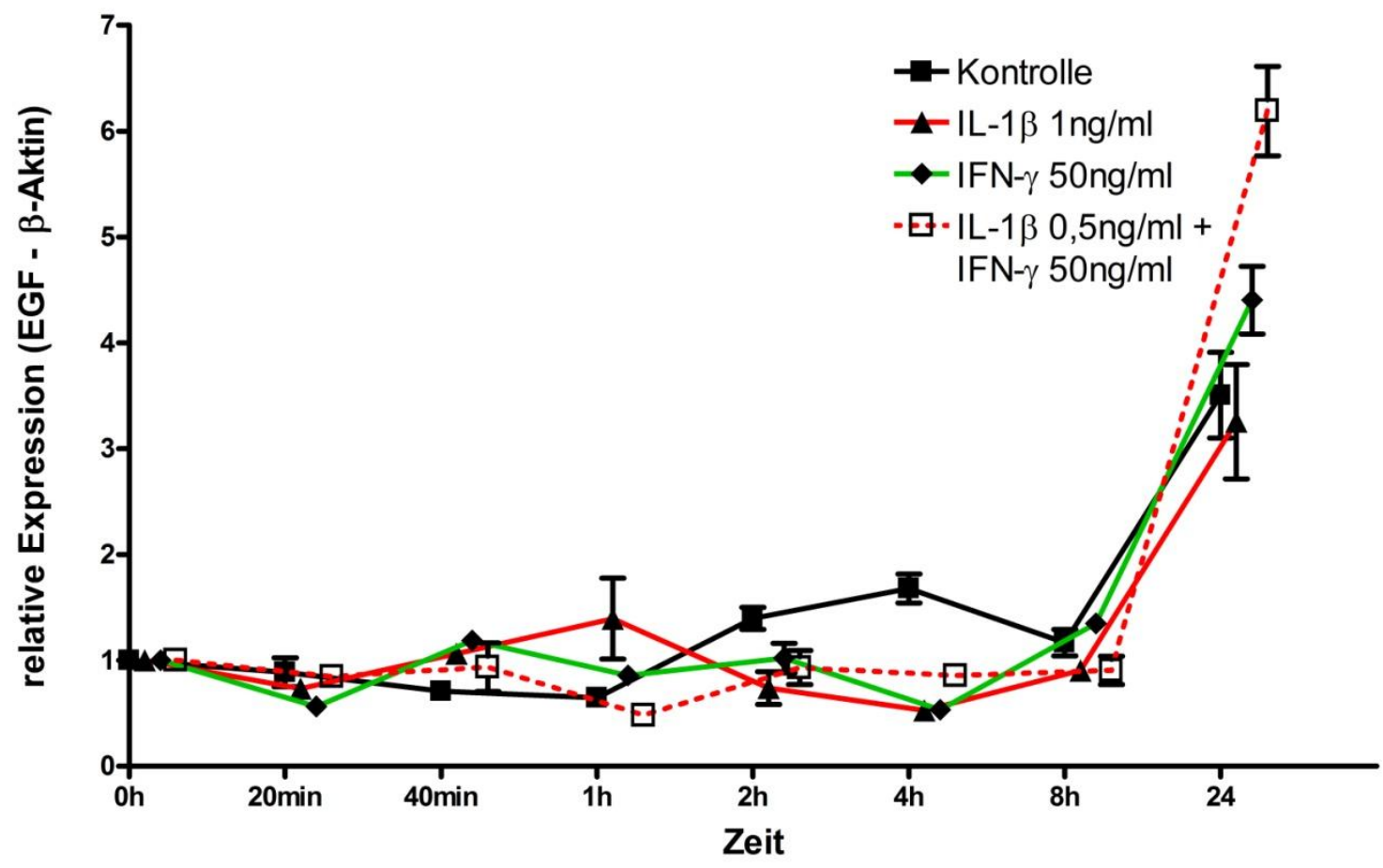

Abb. 22: Expression von EGF in DLD-1-Zellen

Tab. 17: Signifikant veränderte Expression $(p \leq 0,05)$ von EGF in DLD-1-Zellen

\begin{tabular}{|c|c|}
\hline $\mathrm{IL}-1 \beta \star$ vs. Kontrolle $\rightarrow-$ & $40 \mathrm{~min} ; 2 \mathrm{~h} ; 4 \mathrm{~h}$ \\
\hline IFN-y־- vs. Kontrolle $\rightarrow-$ & $40 \mathrm{~min} ; 4 \mathrm{~h}$ \\
\hline $\mathrm{IL}-1 \beta+\mathrm{IFN}-\mathrm{\gamma}-\mathrm{-}$ vs. Kontrolle - & $1 \mathrm{~h} ; 4 \mathrm{~h} ; 24 \mathrm{~h}$ \\
\hline 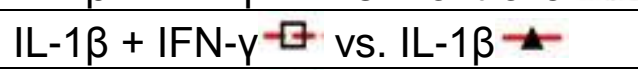 & $20 \mathrm{~min} ; 4 \mathrm{~h} ; 24 \mathrm{~h}$ \\
\hline 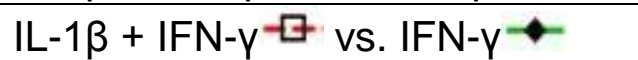 & $4 \mathrm{~h} ; 24 \mathrm{~h}$ \\
\hline
\end{tabular}

Kombinierte Inkubation der DLD-1-Zellen mit IL-1 $\beta$ und IFN- $\gamma$ ergab eine geringgradige Steigerung der EGF-Genexpression zum Zeitpunkt 24h. 


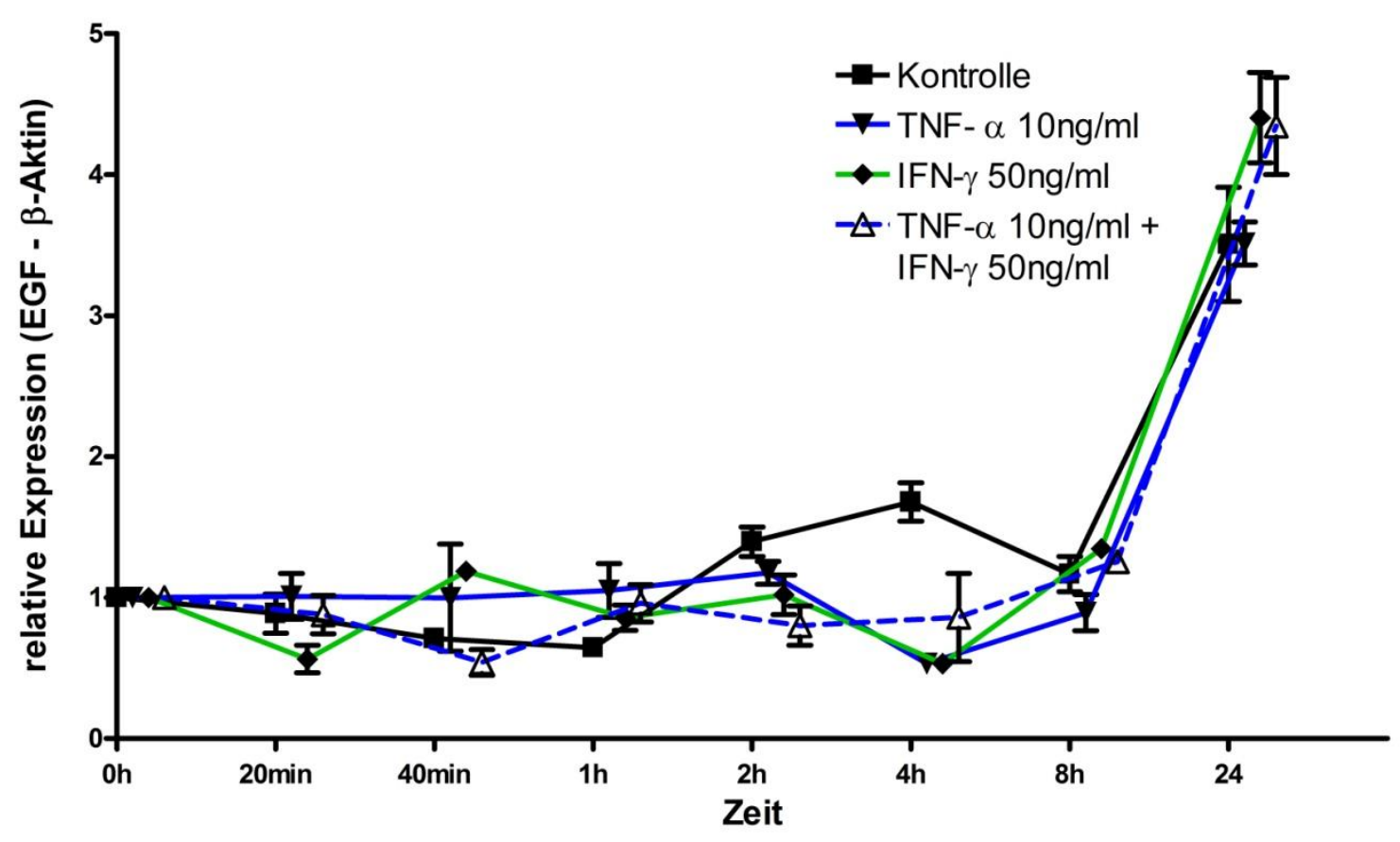

Abb. 23: Expression von EGF in DLD-1-Zellen

Tab. 18: Signifikant veränderte Expression $(p \leq 0,05)$ von EGF in DLD-1-Zellen

\begin{tabular}{|c|c|}
\hline TNF- $\alpha \rightarrow$ vs. Kontrolle $\rightarrow-$ & $4 \mathrm{~h}$ \\
\hline IFN- $\gamma^{-} \leftarrow$ vs. Kontrolle $\rightarrow-$ & $40 \mathrm{~min} ; 4 \mathrm{~h}$ \\
\hline TNF- $\alpha+$ IFN- $\gamma^{-\Delta} \cdot$ vs. Kontrolle - & $2 \mathrm{~h}$ \\
\hline TNF- $\alpha+$ IFN- $\gamma^{-\Delta \cdot}$ vs. TNF- $\alpha \rightarrow$ & $2 \mathrm{~h}$ \\
\hline TNF- $\alpha+$ IFN- $\gamma^{-\Delta \cdot}$ vs. IFN- $\gamma^{\bullet} \bullet-$ & $40 \mathrm{~min}$ \\
\hline
\end{tabular}

Kombinierte Inkubation mit TNF- $\alpha$ und IFN-y hatte keinen zusätzlichen Effekt auf die Genexpression von EGF. 


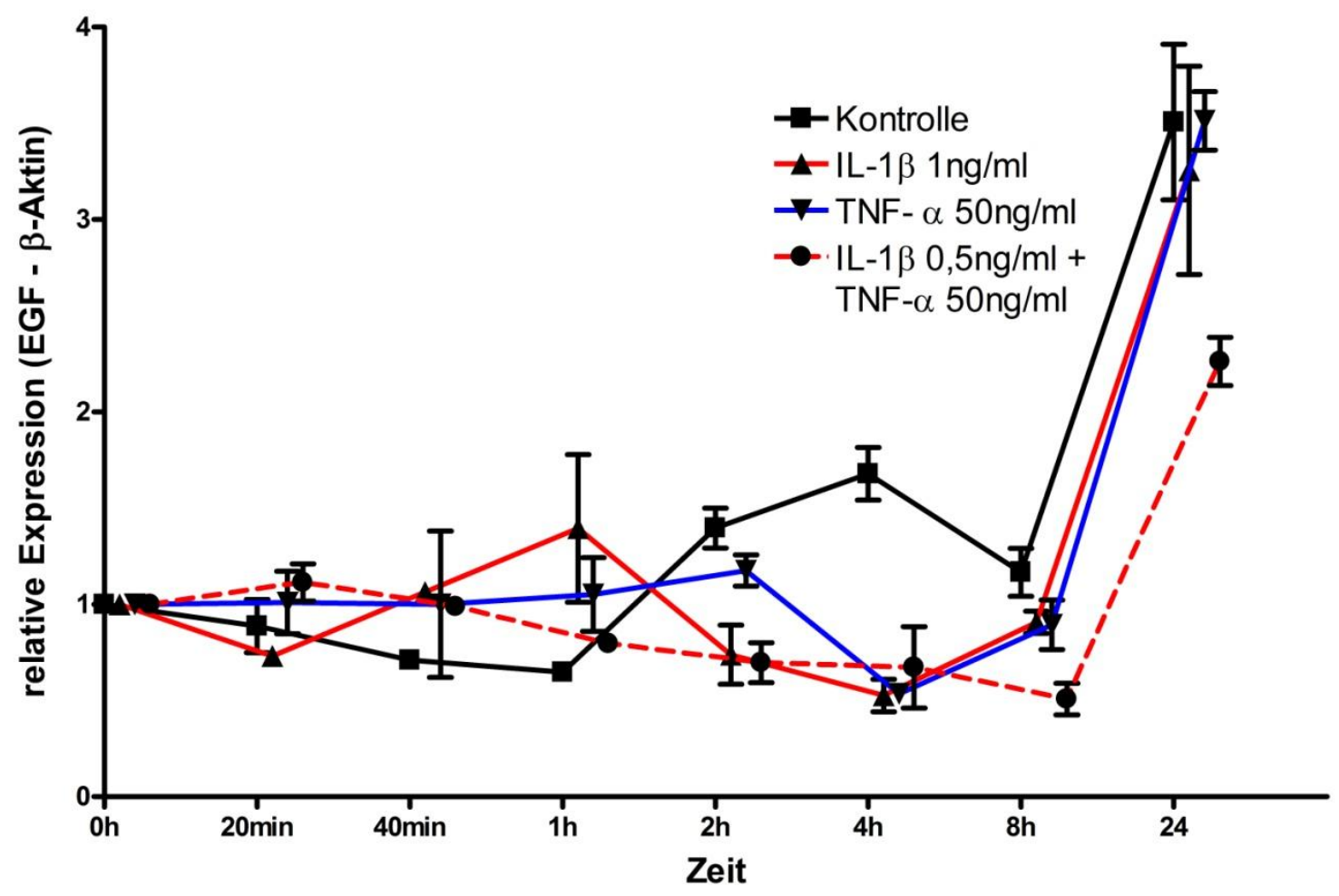

Abb. 24: Expression von EGF in DLD-1-Zellen

Tab. 19: Signifikant veränderte Expression $(p \leq 0,05)$ von EGF in DLD-1-Zellen

\begin{tabular}{|c|c|}
\hline vs. Kontrolle $\rightarrow$ & $40 \mathrm{~min} ; 2 \mathrm{~h} ; 4 \mathrm{~h}$ \\
\hline TNF- $\alpha \rightarrow$ vs. Kontrolle $\rightarrow-$ & $4 \mathrm{~h}$ \\
\hline $\mathrm{IL}-1 \beta+\mathrm{TNF}-\alpha \rightarrow$ vs. Kontrolle $\rightarrow-$ & 40min; 1h;2h;4h;8h \\
\hline 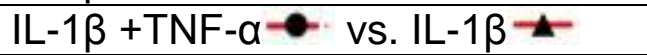 & $20 \mathrm{~min} ; 40 \mathrm{~min} ; 8 \mathrm{~h}$ \\
\hline $\mathrm{IL}-1 \beta+$ TNF- $\alpha \rightarrow$ vs. TNF- $\alpha \rightarrow$ & $2 \mathrm{~h} ; 24 \mathrm{~h}$ \\
\hline
\end{tabular}

Kombinierte Inkubation mit IL-1 $\beta$ und TNF- $\alpha$ hatte keinen eindeutigen Effekt auf die EGF-Expression. 
3.2.2) Regulation der EGFR mRNA-Expression in DLD-1-Zellen

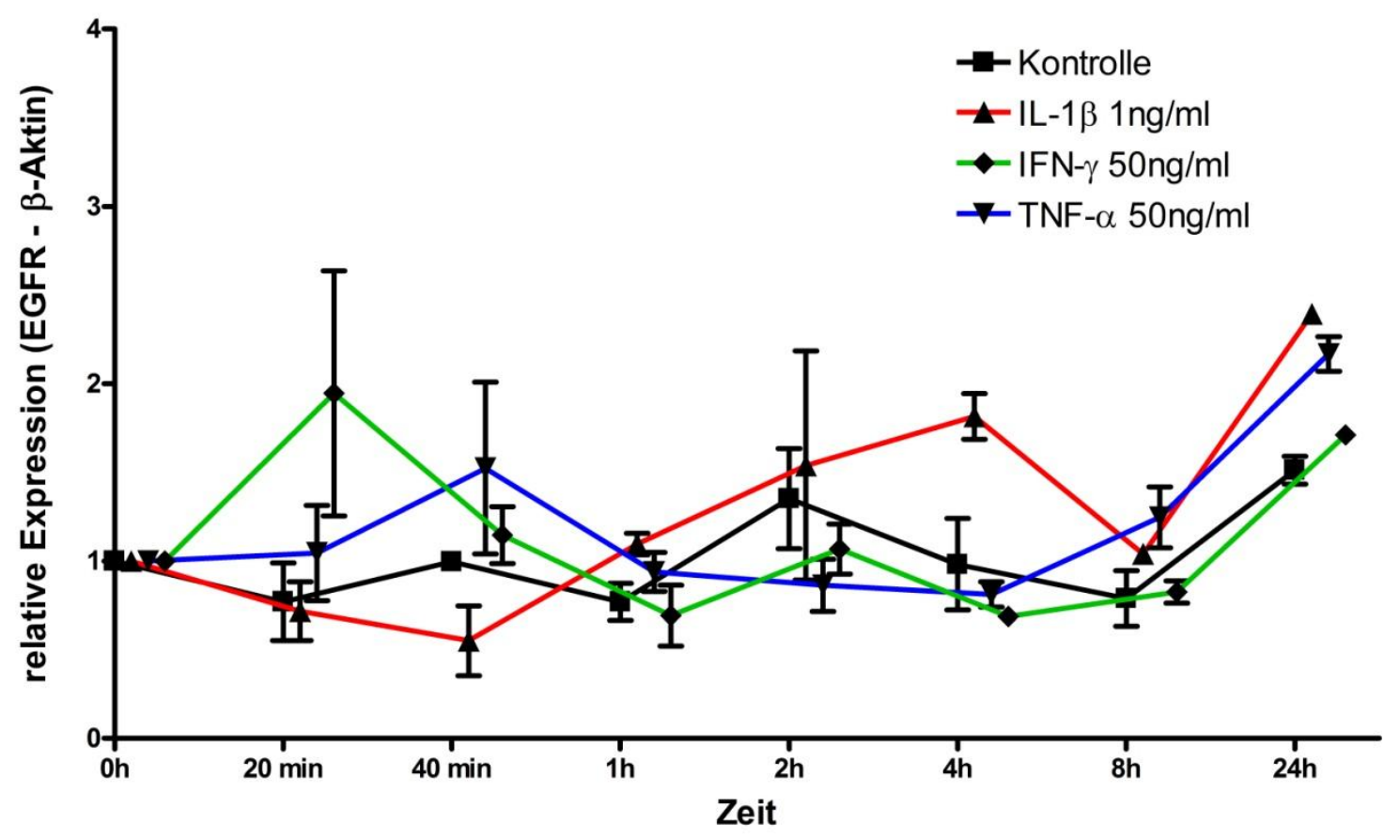

Abb. 25: Expression von EGFR in DLD-1-Zellen

Tab. 20: Signifikant veränderte Expression $(p \leq 0,05)$ von EGFR in DLD-1-Zellen \begin{tabular}{|l|l|}
\hline $\mathrm{IL}-1 \beta \star$ vs. Kontrolle $\rightarrow-$ & $4 \mathrm{~h} ; 24 \mathrm{~h}$ \\
\hline $\mathrm{IFN}-\mathrm{y}^{\bullet-}$ vs. Kontrolle $\rightarrow-$ & - \\
\hline TNF- $\alpha \multimap$ vs. Kontrolle $\rightarrow-$ & $24 \mathrm{~h}$ \\
\hline
\end{tabular}

DLD-1-Zellen exprimieren EGFR. Einzelinkubation der Zellen mit IL-1 $\beta$, IFN- $\gamma$ oder TNF- $\alpha$ hatte jeweils keinen nennenswerten Effekt auf die Genexpression. 


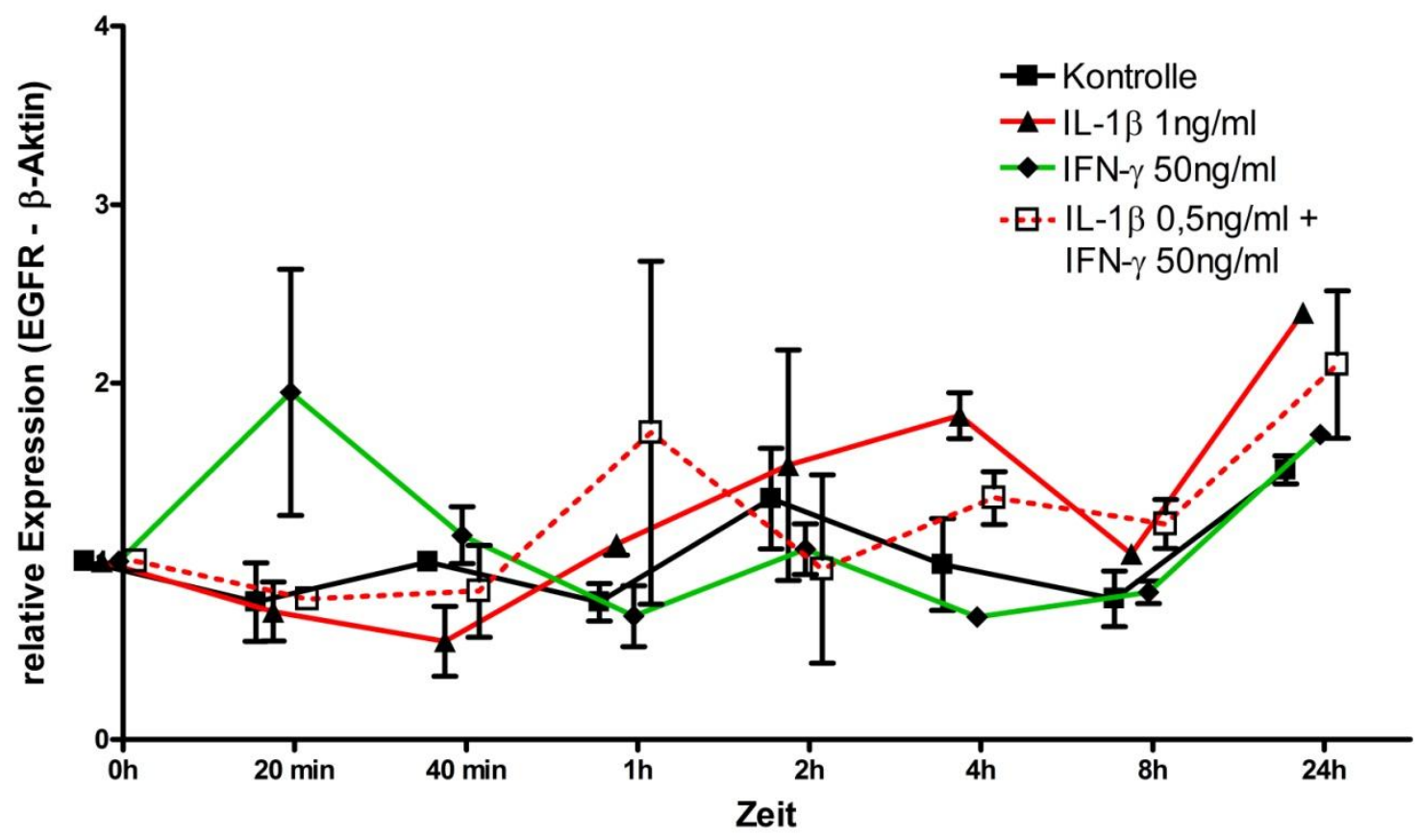

Abb. 26: Expression von EGFR in DLD-1-Zellen

Tab. 21: Signifikant veränderte Expression $(p \leq 0,05)$ von EGFR in DLD-1-Zellen

\begin{tabular}{|c|c|}
\hline $\mathrm{IL}-1 \beta \star$ vs. Kontrolle $\rightarrow-$ & $4 \mathrm{~h} ; 24 \mathrm{~h}$ \\
\hline IFN- $\gamma^{\bullet-}$ vs. Kontrolle $\rightarrow-$ & 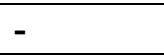 \\
\hline$I \mathrm{~L}-1 \beta+\mathrm{IFN}-\gamma^{-\square}$ vs. Kontrolle - & - \\
\hline 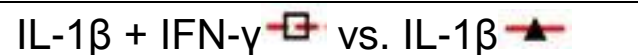 & \\
\hline 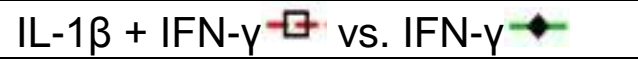 & - \\
\hline
\end{tabular}

Kombinierte Inkubation der DLD-1-Zellen mit IL-1 $\beta$ und IFN- $\gamma$ hatte keinen relevanten Effekt auf die Genexpression von EGFR. 


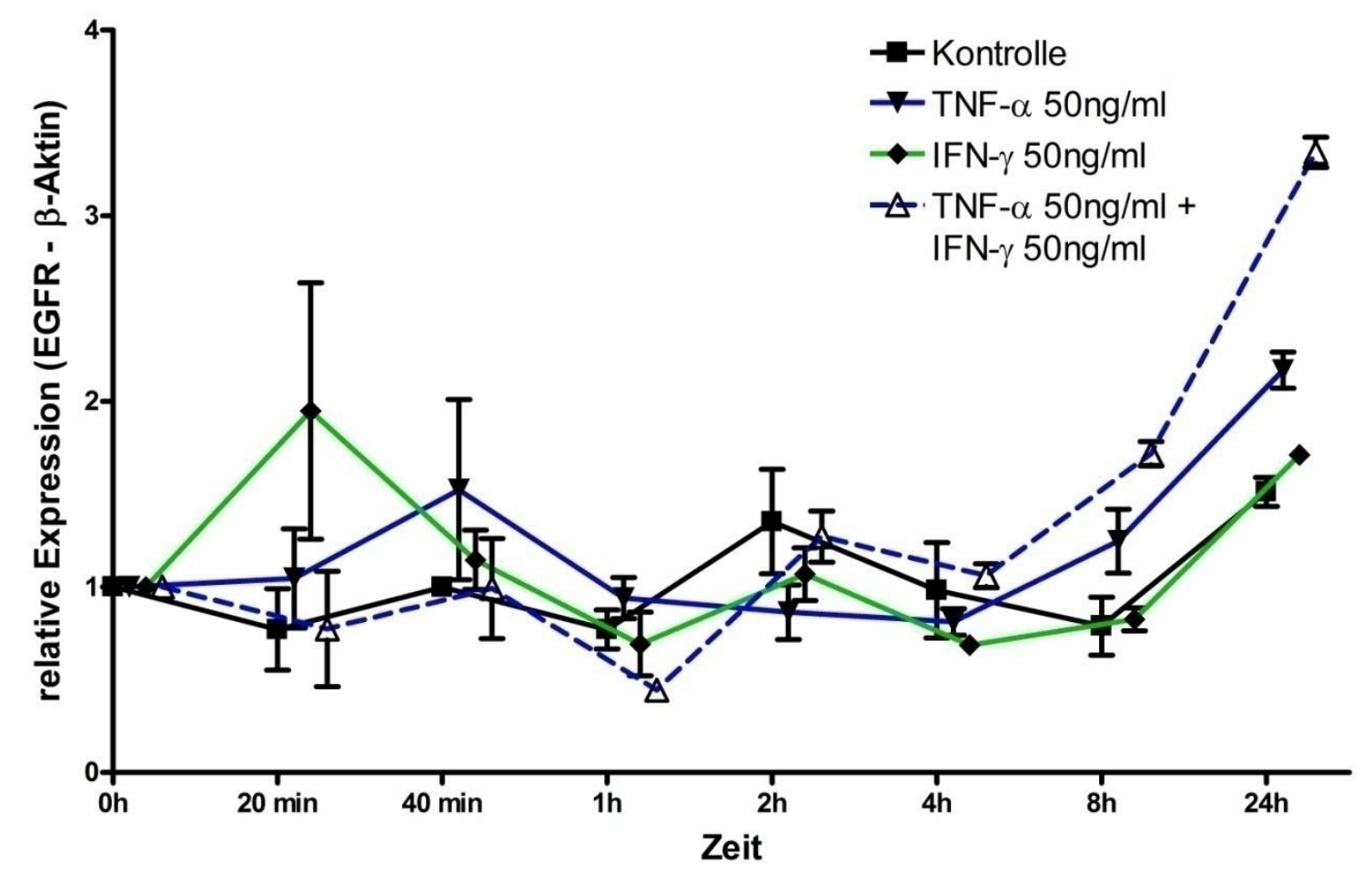

Abb. 27: Expression von EGFR in DLD-1-Zellen

Tab. 22: Signifikant veränderte Expression $(p \leq 0,05)$ von EGFR in DLD-1-Zellen

\begin{tabular}{|c|c|}
\hline TNF- $a \rightarrow$ vs. Kontrolle $\rightarrow-$ & $24 \mathrm{~h}$ \\
\hline IFN- $\gamma^{\bullet}-$ vs. Kontrolle $\bullet$ & \\
\hline TNF- $\alpha+$ IFN- $\gamma^{-\Delta \cdot}$ vs. Kontrolle $\rightarrow-$ & $1 \mathrm{~h} ; 8 \mathrm{~h} ; 24 \mathrm{~h}$ \\
\hline TNF- $\alpha+$ IFN- ${ }^{*} \Delta \cdot$ vs. TNF- $\alpha \rightarrow$ & $1 \mathrm{~h} ; 4 \mathrm{~h}$ \\
\hline TNF- $\alpha+$ IFN- ${ }^{-\Delta} \cdot$ vs. IFN- $y^{-\bullet}$ & $4 h ; 8 h ; 24 h$ \\
\hline
\end{tabular}

Inkubation der Zellen mit TNF- $\alpha$ führte tendenziell zu einem Anstieg der EGFRExpression zum Zeitpunkt 24h, Inkubation mit IFN-y allein hatte keinen Effekt. Kombination von TNF- $\alpha$ und IFN- $y$ führte zu einer Steigerung der Genexpression zum Zeitpunkt 24h gegenüber dem Kontrollwert. 


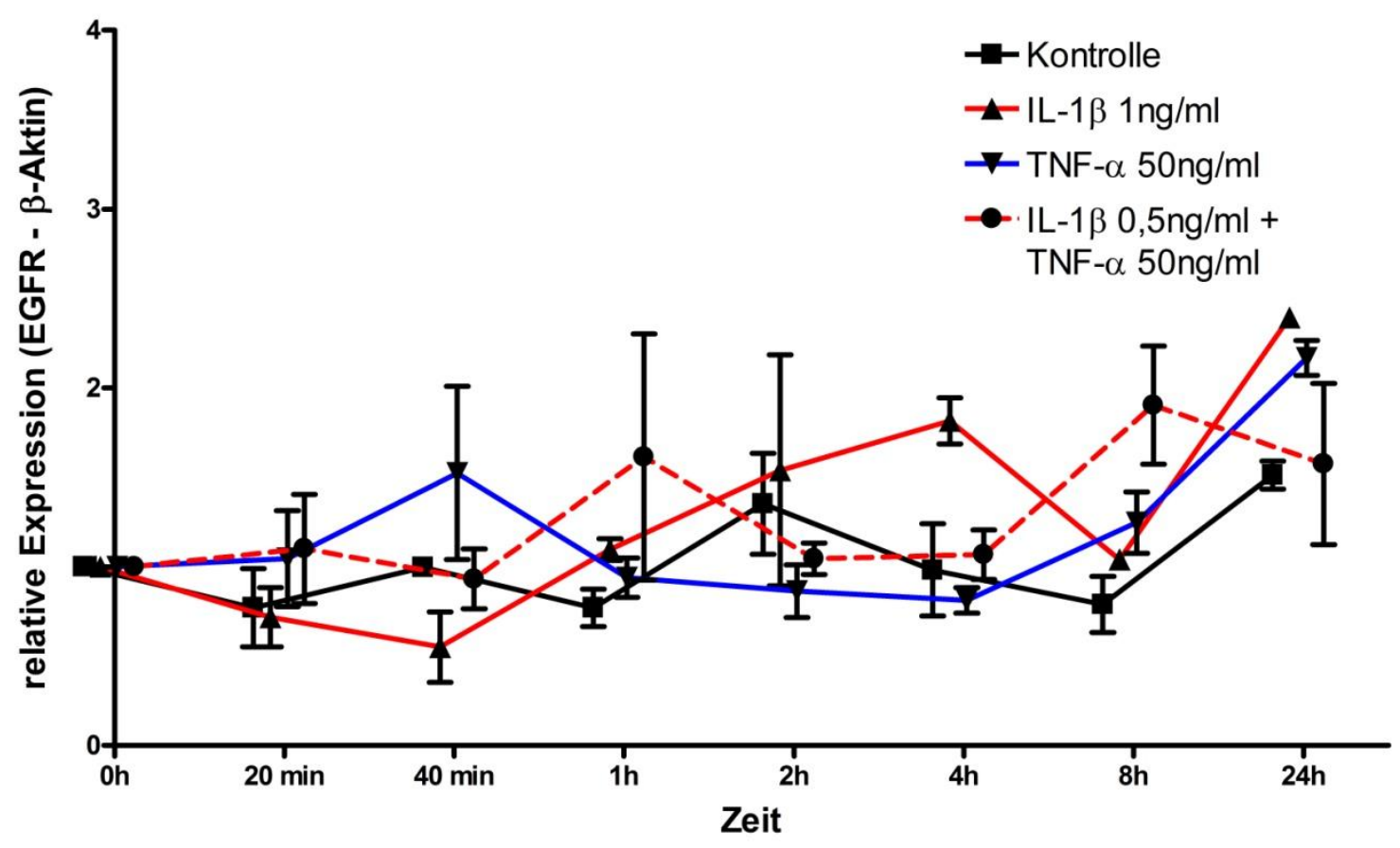

Abb. 28: Expression von EGFR in DLD-1-Zellen

Tab. 23: Signifikant veränderte Expression $(p \leq 0,05)$ von EGFR in DLD-1-Zellen

\begin{tabular}{|c|c|}
\hline IL-1 $\beta$ - vs. Kontrolle & $4 \mathrm{~h} ; 24 \mathrm{~h}$ \\
\hline TNF- $a \rightarrow-$ vs. Kontrolle $\rightarrow-$ & $24 \mathrm{~h}$ \\
\hline IL-1 $\beta+$ TNF- $\alpha \rightarrow$ vs. Kontrolle $\rightarrow$ & $8 \mathrm{~h}$ \\
\hline 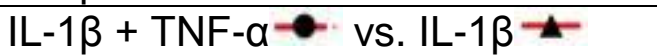 & $4 \mathrm{~h}$ \\
\hline$I L-1 \beta+$ TNF- $\alpha \rightarrow$ vs. TNF- $\alpha \rightarrow$ & \\
\hline
\end{tabular}

Inkubation der DLD-1-Zellen mit IL-1 $\beta$ und TNF- $\alpha$ führte zu keiner nennenswerten Änderung der EGFR-Expreeesion in DLD-1-Zellen. 


\subsection{3) Regulation der VEGF mRNA-Expression in DLD-1-Zellen}

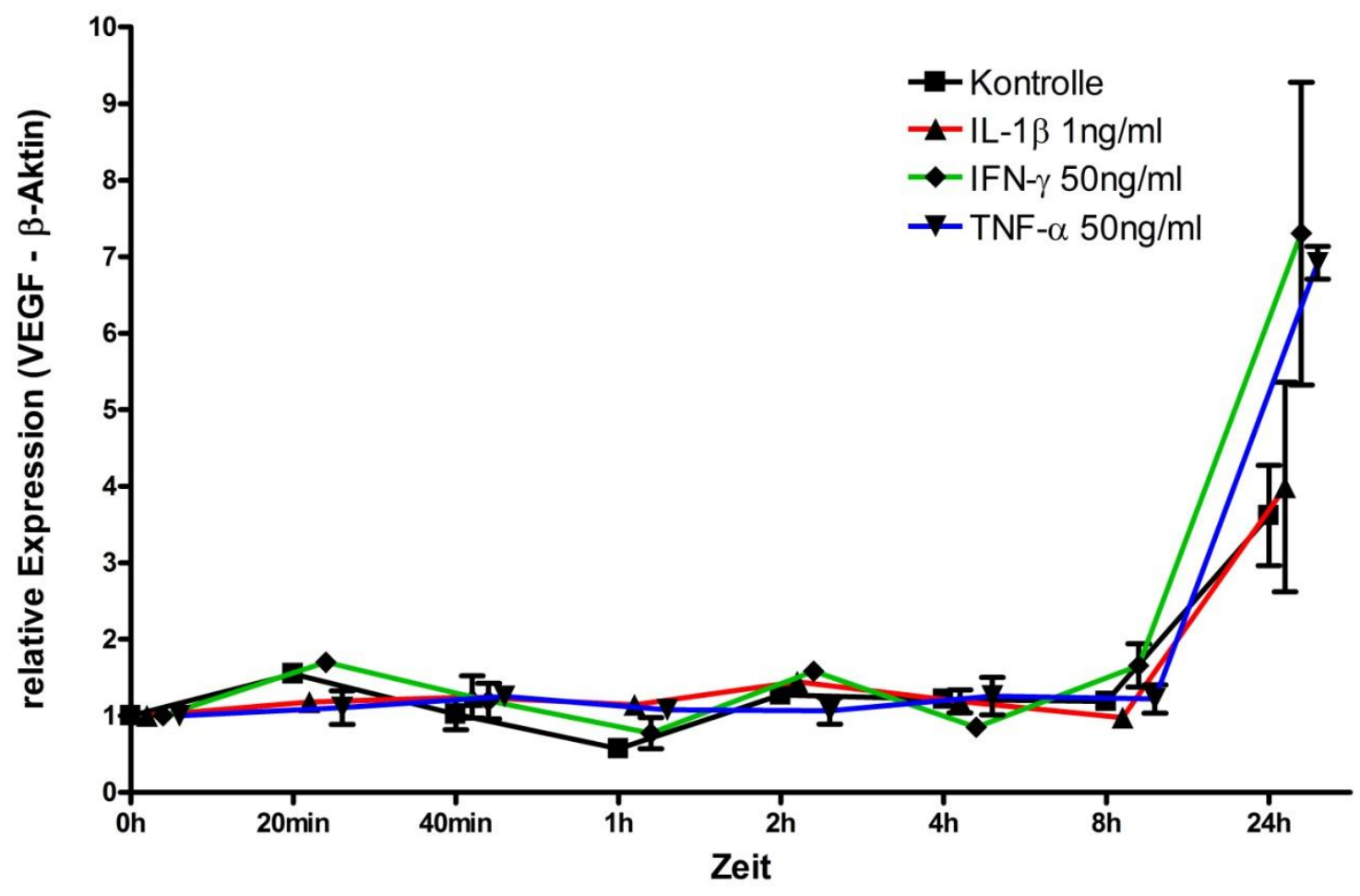

Abb. 29: Expression von VEGF in DLD-1-Zellen

Tab. 24: Signifikant veränderte Expression $(p \leq 0,05)$ von VEGF in DLD-1-Zellen

\begin{tabular}{|l|l|}
\hline $\mathrm{IL}-1 \beta \star$ vs. Kontrolle $\rightarrow-$ & $40 \mathrm{~min} ; 4 \mathrm{~h}$ \\
\hline $\mathrm{IFN}-\mathrm{\gamma} \bullet-$ vs. Kontrolle $\bullet$ & $1 \mathrm{~h}$ \\
\hline TNF- $\alpha \rightarrow$ vs. Kontrolle $\rightarrow-$ & $1 \mathrm{~h} ; 24 \mathrm{~h}$ \\
\hline
\end{tabular}

DLD-1-Zellen exprimieren VEGF, ab dem Zeitpunkt acht Stunden kam es zu einem Anstieg der Genexpression auch in der Kontrolle. Inkubation der Zellen mit TNF- $\alpha$ oder IFN-y führte zu einer Zunahme der VEGF-Expression, IL-1 $\beta$ hatte keinen nennenswerten Effekt. 


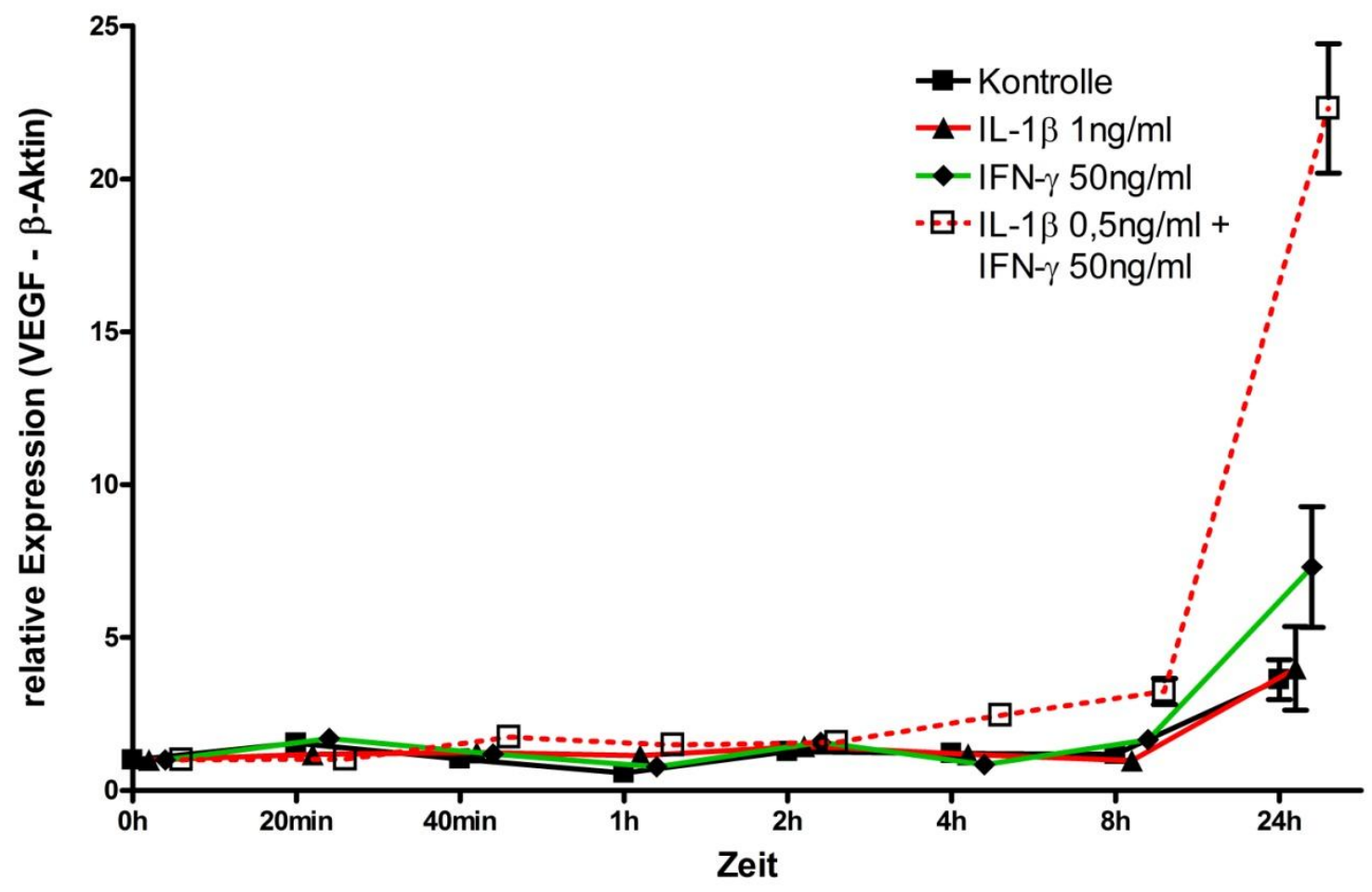

Abb. 30: Expression von VEGF in DLD-1-Zellen

Tab. 25: Signifikant veränderte Expression $(p \leq 0,05)$ von VEGF in DLD-1-Zellen

\begin{tabular}{|c|c|}
\hline IL-1 $\beta \approx$ vs. Kontrolle $\rightarrow-$ & 40min; 4h \\
\hline IFN- $\gamma^{\bullet-}$ vs. Kontrolle $\rightarrow-$ & $1 \mathrm{~h}$ \\
\hline IL-1 $\beta+$ IFN- $\gamma^{-\square}$ vs. Kontrolle $\rightarrow$ & 40min; 1h; 4h; 8h;24h \\
\hline 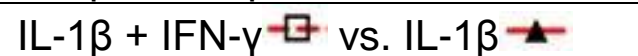 & $2 h ; 4 h ; 8 h ; 24 h$ \\
\hline 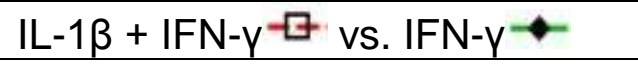 & $1 \mathrm{~h} ; 4 \mathrm{~h} ; 8 \mathrm{~h} ; 24 \mathrm{~h}$ \\
\hline
\end{tabular}

Kombinierte Inkubation der DLD-1-Zellen mit IL-1 $\beta$ und IFN-y führte zu einem deutlichen Anstieg der VEGF-Genexpression ab dem Zeitpunkt 8h. 


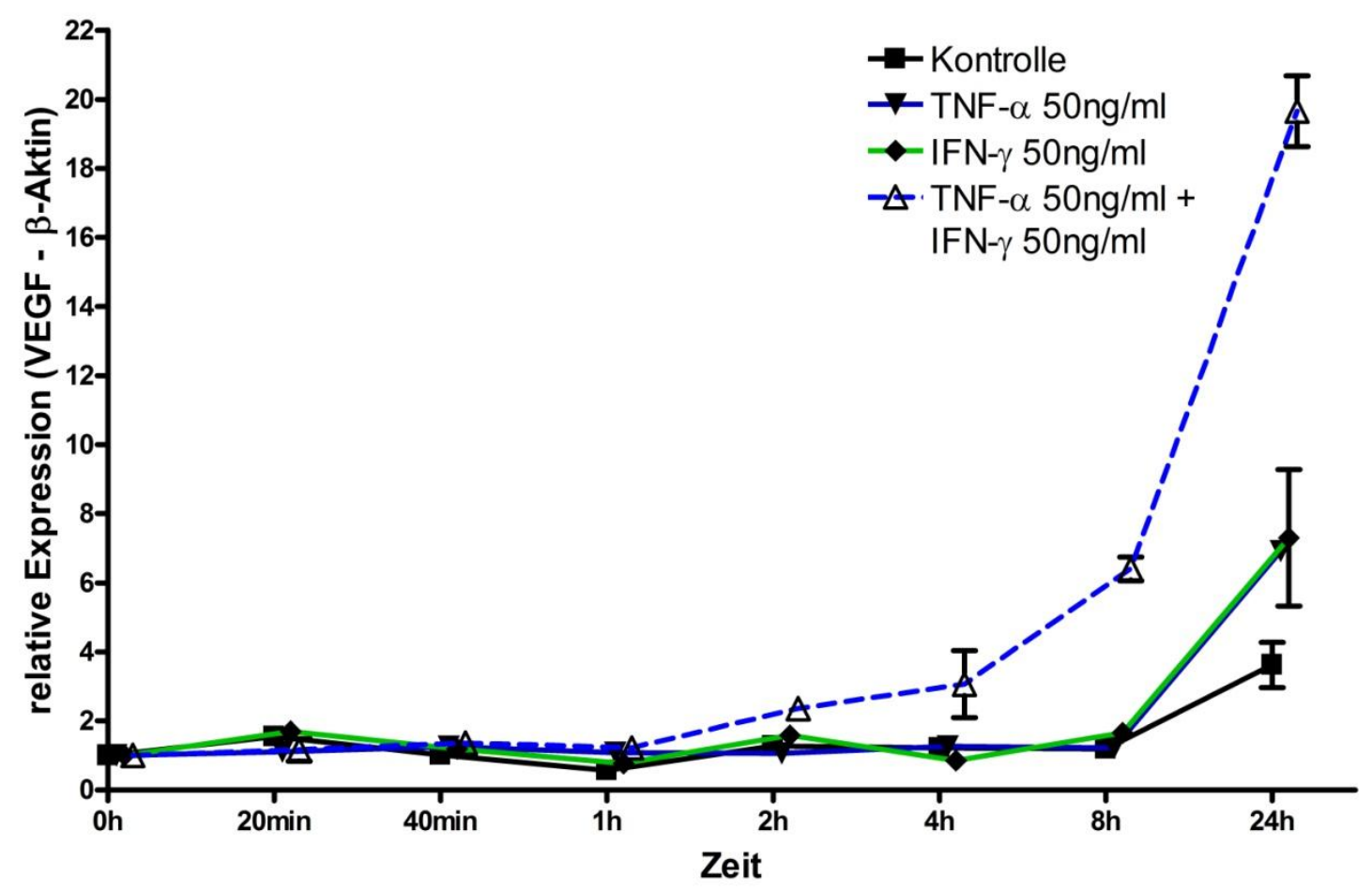

Abb. 31: Expression von VEGF in DLD-1-Zellen

Tab. 26: Signifikant veränderte Expression $(p \leq 0,05)$ von VEGF in DLD-1-Zellen

\begin{tabular}{|c|c|}
\hline TNF- $\alpha \rightarrow$ vs. Kontrolle $\rightarrow-$ & $1 \mathrm{~h} ; 24 \mathrm{~h}$ \\
\hline IFN- $\gamma^{\bullet}$ vs. Kontrolle $\bullet$ & 40min; $4 \mathrm{~h}$ \\
\hline TNF- $\alpha+$ IFN- $\gamma^{-\Delta \cdot}$ vs. Kontrolle $=$ & \\
\hline TNF- $\alpha+$ IFN- $\gamma^{-\Delta \cdot}$ vs. TNF- $\alpha \rightarrow$ & $2 h ; 8 h ; 24 h$ \\
\hline TNF- $\alpha+$ IFN- $\gamma^{-\Delta \cdot}$ vs. IFN- $\gamma^{\bullet-}$ & $2 h ; 8 h ; 24 h$ \\
\hline
\end{tabular}

Kombinierte Inkubation der DLD-1-Zellen mit TNF- $\alpha$ und IFN-y führte zu einem deutlichen Anstieg der VEGF-Genexpression ab dem Zeitpunkt $1 \mathrm{~h}$. 


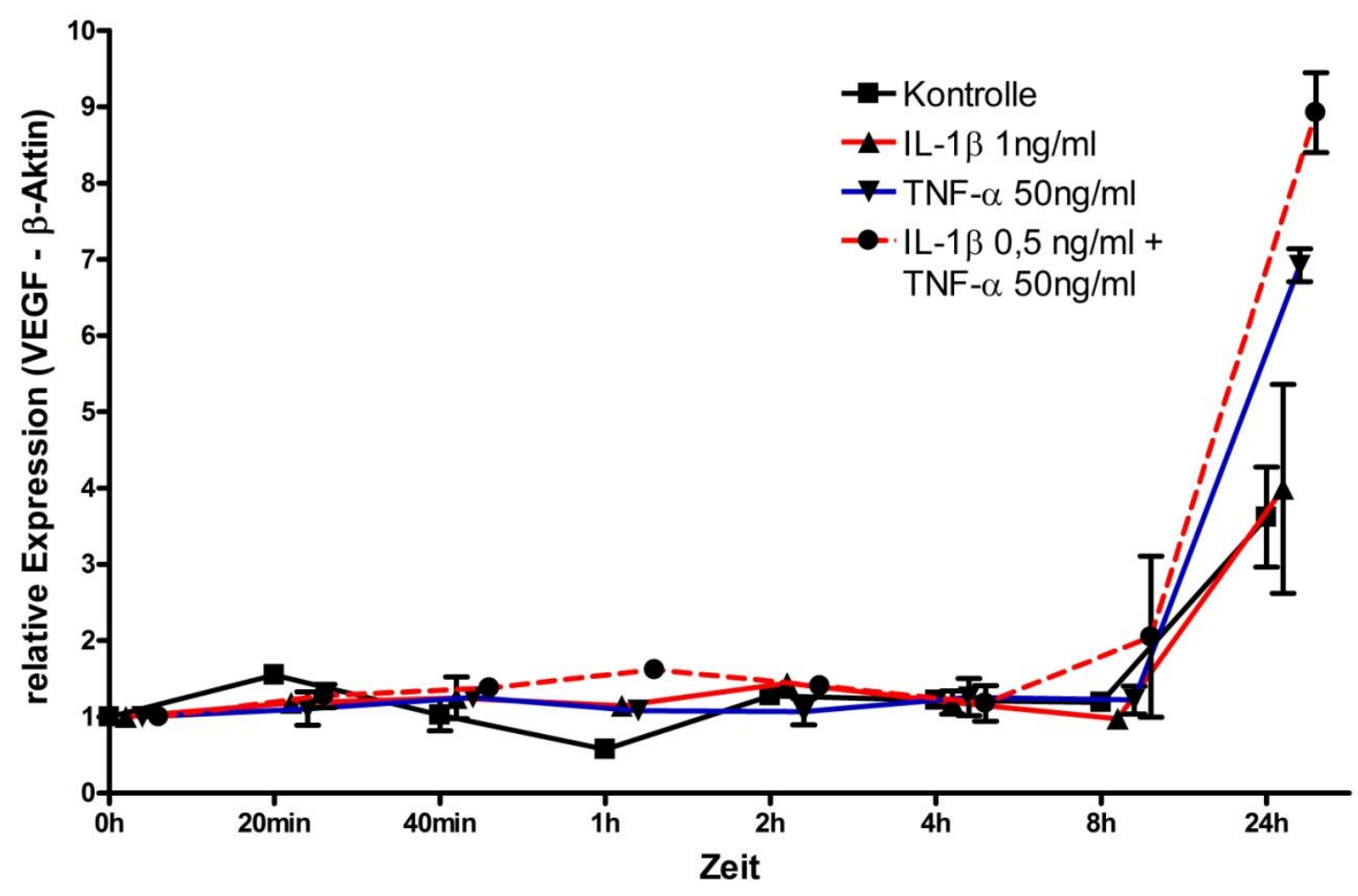

Abb. 32: Expression von VEGF in DLD-1-Zellen

Tab. 27: Signifikant veränderte Expression $(p \leq 0,05)$ von VEGF in DLD-1-Zellen

\begin{tabular}{|c|c|}
\hline $\mathrm{IL}-1 \beta \succsim$ vs. Kontrolle $\rightarrow-$ & $1 \mathrm{~h}$ \\
\hline TNF- $\alpha \rightarrow$ vs. Kontrolle $\rightarrow-$ & $1 \mathrm{~h} ; 24 \mathrm{~h}$ \\
\hline$I L-1 \beta+T N F-\alpha \rightarrow$ vs. Kontrolle $\rightarrow-$ & $1 \mathrm{~h} ; 2 \mathrm{~h} ; 24 \mathrm{~h}$ \\
\hline 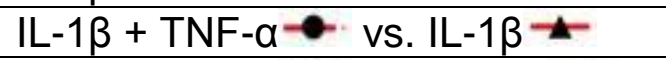 & $1 \mathrm{~h} ; 24 \mathrm{~h}$ \\
\hline $\mathrm{IL}-1 \beta+\mathrm{TNF}-\alpha \rightarrow$ vs. TNF- $\alpha \rightarrow$ & $1 \mathrm{~h} ; 24 \mathrm{~h}$ \\
\hline
\end{tabular}

Inkubation der DLD-1-Zellen mit TNF- $\alpha$ bewirkte einen geringfügigen Anstieg der VEGF-Genexpression ab dem Zeitpunkt 8h. Kombinierte Inkubation der Zellen mit IL$1 \beta$ und TNF- $\alpha$ führte zu einer zusätzlichen Expressionssteigerung. 
3.2.4) Regulation der VEGFR-1 mRNA-Expression in DLD-1-Zellen

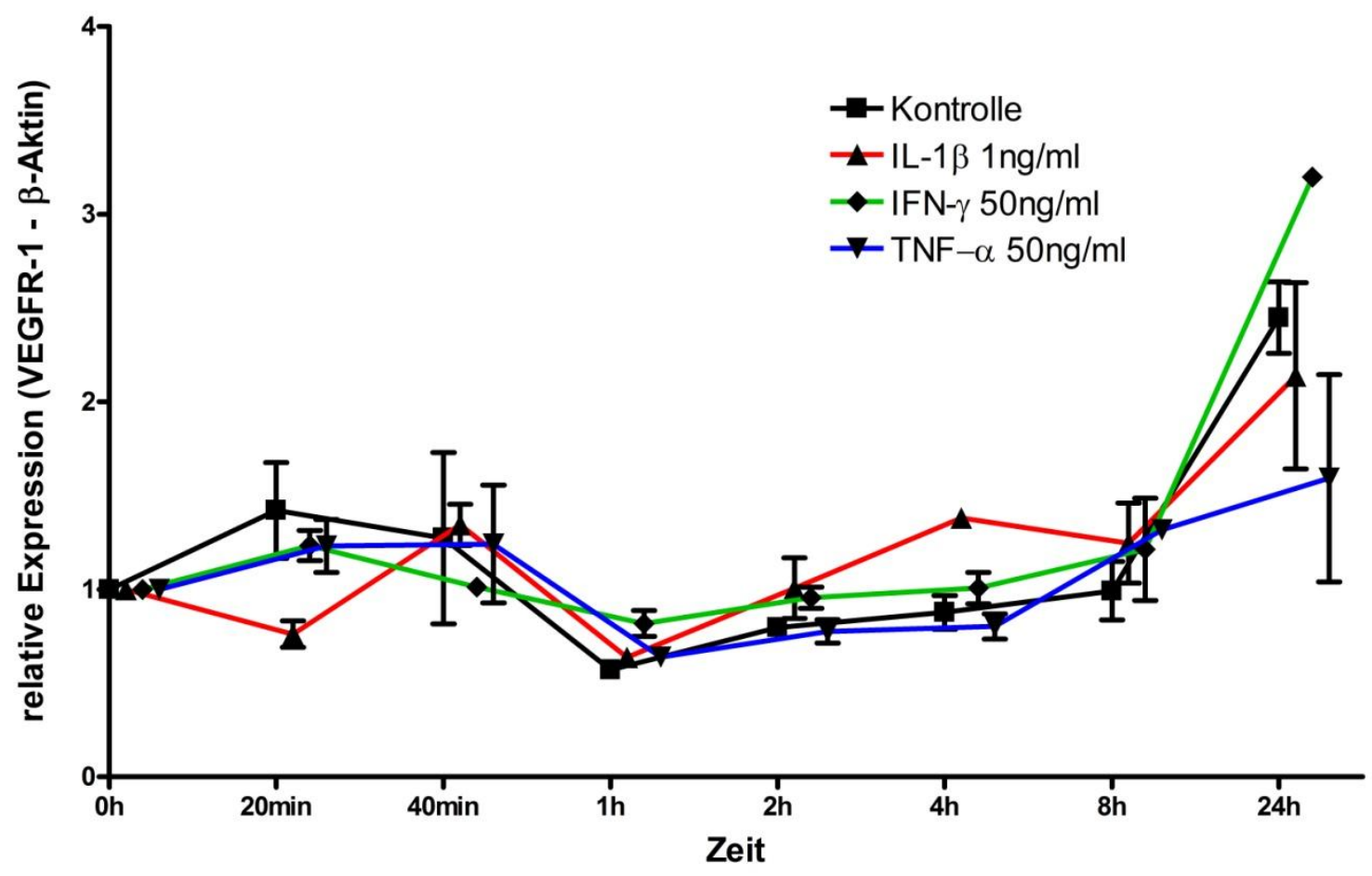

Abb. 33: Expression von VEGFR-1 in DLD-1-Zellen

Tab. 28: Signifikant veränderte Expression $(p \leq 0,05)$ von VEGFR-1 in DLD-1Zellen

\begin{tabular}{|l|l|}
\hline $\mathrm{IL}-1 \beta \rightarrow$ vs. Kontrolle $\rightarrow-$ & $4 \mathrm{~h}$ \\
\hline $\mathrm{IFN}-\mathrm{-} \bullet$ vs. Kontrolle $\rightarrow-$ & $1 \mathrm{~h} ; 24 \mathrm{~h}$ \\
\hline TNF- $\alpha \rightarrow$ vs. Kontrolle $\bullet-$ & - \\
\hline
\end{tabular}

DLD-1-Zellen exprimieren VEGFR-1, dabei zeigte sich ab dem Zeitpunkt 8h tendenziell eine Expressionszunahme auch in der Kontrolle. Einzelinkubation jeweils mit IL-1 $\beta$, IFN- $\gamma$ oder TNF- $\alpha$ führte zu keiner nennenswerten Änderung der Genexpression. 


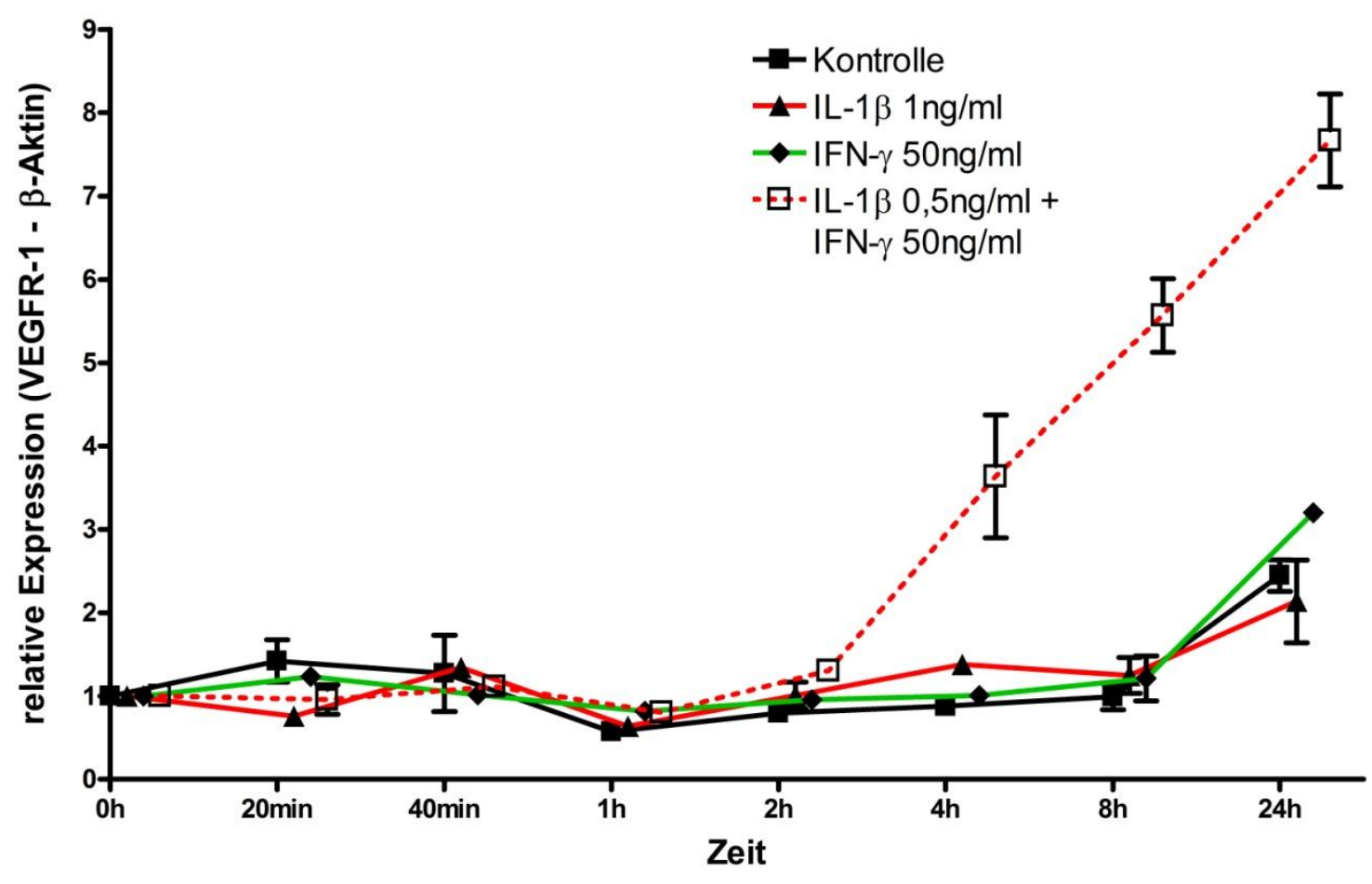

Abb. 34: Expression von VEGFR-1 in DLD-1-Zellen

Tab. 29: Signifikant veränderte Expression $(p \leq 0,05)$ von VEGFR-1 in DLD-1Zellen

\begin{tabular}{|c|c|}
\hline $\mathrm{IL}-1 \beta \succsim$ vs. Kontrolle $₫-$ & $4 \mathrm{~h}$ \\
\hline IFN- $\gamma^{-} \bullet-$ vs. Kontrolle $\rightarrow-$ & $1 \mathrm{~h} ; 24 \mathrm{~h}$ \\
\hline IL-1 $\beta+$ IFN- - - vs. Kontrolle - & $2 \mathrm{~h} ; 4 \mathrm{~h} ; 8 \mathrm{~h} ; 24 \mathrm{~h}$ \\
\hline 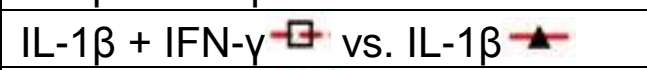 & 4h; 8h; 24h \\
\hline $\mathrm{IL}-1 \beta+\mathrm{IFN}-\gamma-\mathrm{-}$ vs. & $2 h ; 4 h ; 8 h ; 24 h$ \\
\hline
\end{tabular}

Kombinierte Inkubation der DLD-1-Zellen mit IL-1 $\beta$ und IFN- $\gamma$ führte zu einer deutlichen Zunahme der VEGFR-1-Expression ab dem Zeitpunkt $2 \mathrm{~h}$. 


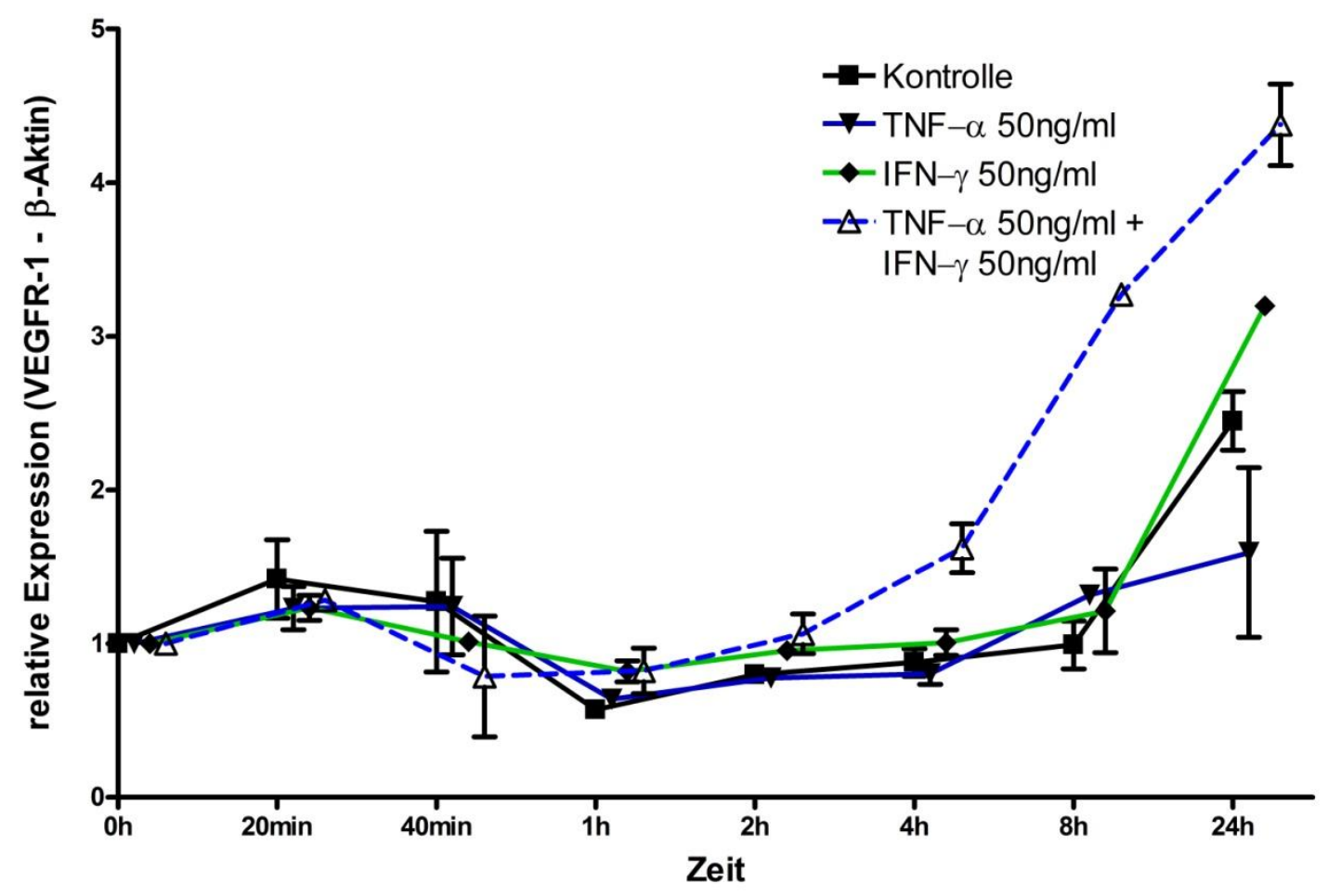

Abb. 35: Expression von VEGFR-1 in DLD-1-Zellen

Tab. 30: Signifikant veränderte Expression $(p \leq 0,05)$ von VEGFR-1 in DLD-1Zellen

\begin{tabular}{|c|c|}
\hline TNF- $\alpha \rightarrow$ vs. Kontrolle $\rightarrow-$ & \\
\hline IFN- $\gamma^{\bullet} \bullet$ vs. Kontrolle $\rightarrow-$ & $1 \mathrm{~h} ; 24 \mathrm{~h}$ \\
\hline TNF- $\alpha+$ IFN-y $-\Delta \cdot$ vs. Kontrolle $=-$ & $4 \mathrm{~h} ; 8 \mathrm{~h} ; 24 \mathrm{~h}$ \\
\hline TNF- $\alpha+$ IFN- $\gamma^{-\Delta \cdot}$ vs. TNF- $\alpha \rightarrow$ & 4h; 8h; 24h \\
\hline TNF- $\alpha+$ IFN-y $\boldsymbol{\Delta}^{*} \cdot$ vs. IFN-y־- & $4 h ; 8 h ; 24 h$ \\
\hline
\end{tabular}

Kombinierte Inkubation der DLD-1-Zellen mit TNF- $\alpha$ und IFN-y führte zu einer Zunahme der VEGFR-1-Genexpression ab dem Zeitpunkt $2 \mathrm{~h}$. 


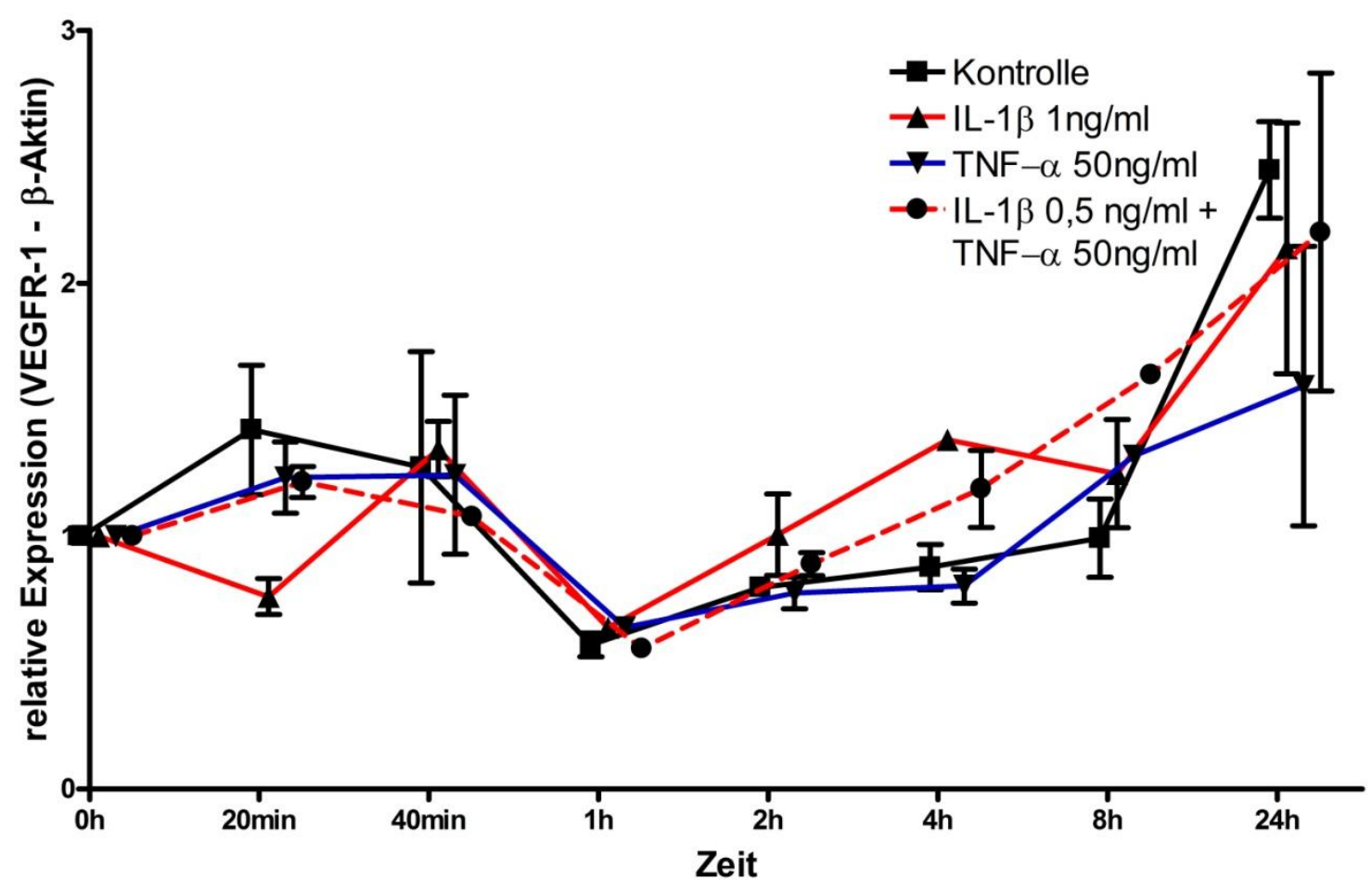

Abb. 36: Expression von VEGFR-1 in DLD-1-Zellen

Tab. 31: Signifikant veränderte Expression $(p \leq 0,05)$ von VEGFR-1 in DLD-1Zellen

\begin{tabular}{|c|c|}
\hline vs. Kontrolle $\rightarrow$ & $4 \mathrm{~h}$ \\
\hline TNF- $\alpha \rightarrow$ vs. Kontrolle $\rightarrow$ & \\
\hline $\mathrm{IL}-1 \beta+$ TNF- $\alpha \bullet$ vs. Kontrolle $\rightarrow$ & $8 \mathrm{~h}$ \\
\hline$I L-1 \beta+$ TNF- $\alpha \rightarrow$ vs. IL-1 $1 \beta \succsim$ & $20 \mathrm{~min}$ \\
\hline$I L-1 \beta+$ TNF- $\alpha \rightarrow$ vs. TNF- $\alpha \rightarrow$ & $4 \mathrm{~h}$; \\
\hline
\end{tabular}

Kombination von IL-1 $\beta$ und TNF- $\alpha$ hatte keinen nennenswerten Effekt auf die Expression von VEGFR-1 in DLD-1-Zellen. 


\subsection{5) Regulation der EGF mRNA-Expression in HT-29-Zellen}

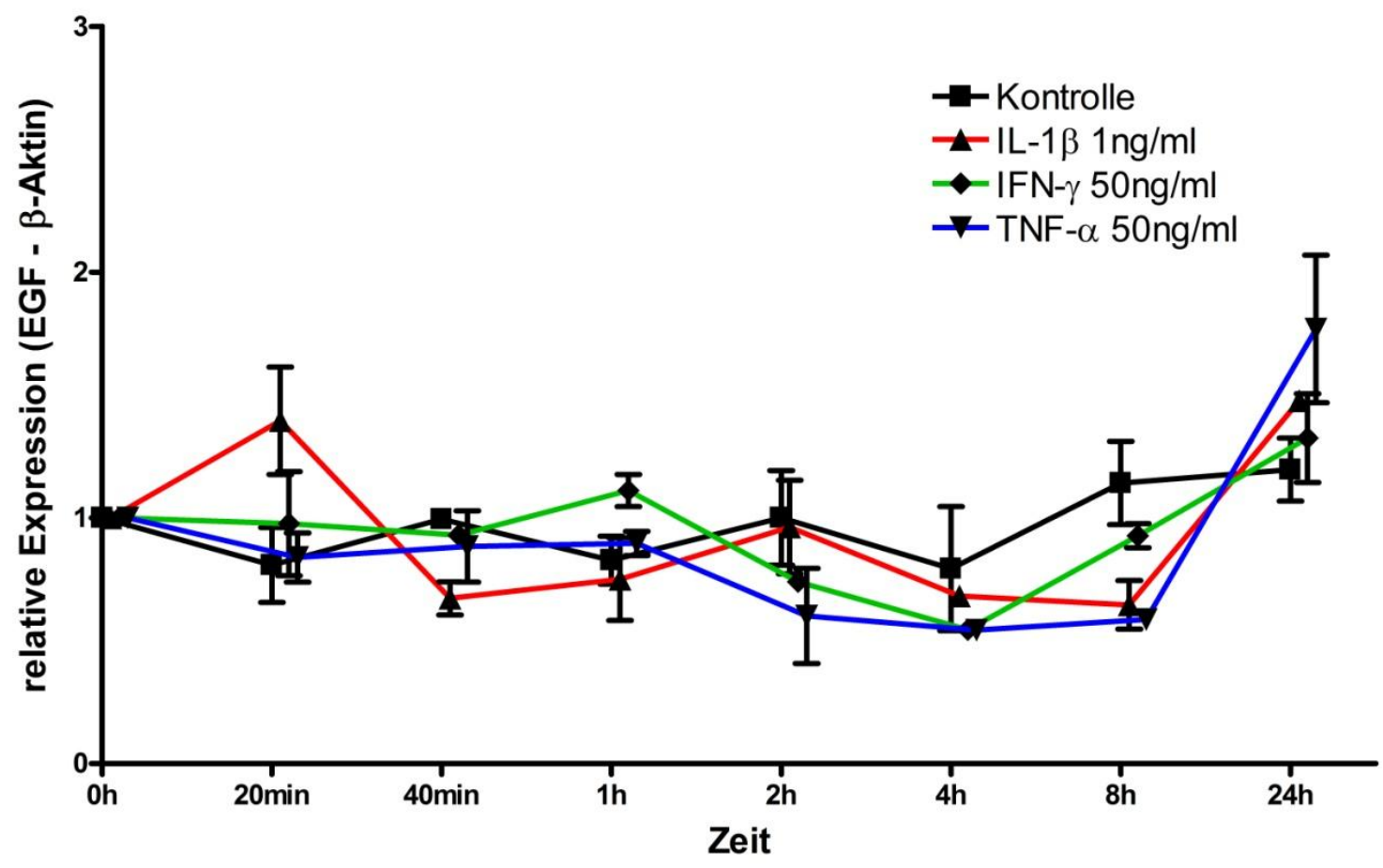

Abb. 37: Expression von EGF in HT-29-Zellen

Tab. 32: Signifikant veränderte Expression $(p \leq 0,05)$ von EGF in HT-29-Zellen $\mathrm{IL}-1 \beta \rightarrow$ vs. Kontrolle $\rightarrow-2 \mathrm{~min} ; 40 \mathrm{~min}$ IFN- $-\leftarrow$ vs. Kontrolle $\rightarrow$ TNF- $\alpha \rightarrow$ vs. Kontrolle $\rightarrow-8 \mathrm{~h}$

HT-29-Zellen exprimieren EGF. Einzelinkubation der Zellen mit IL-1 $\beta$, IFN- $\gamma$ oder TNF- $\alpha$ hatte keinen nennenswerten Effekt auf die Genexpression. 


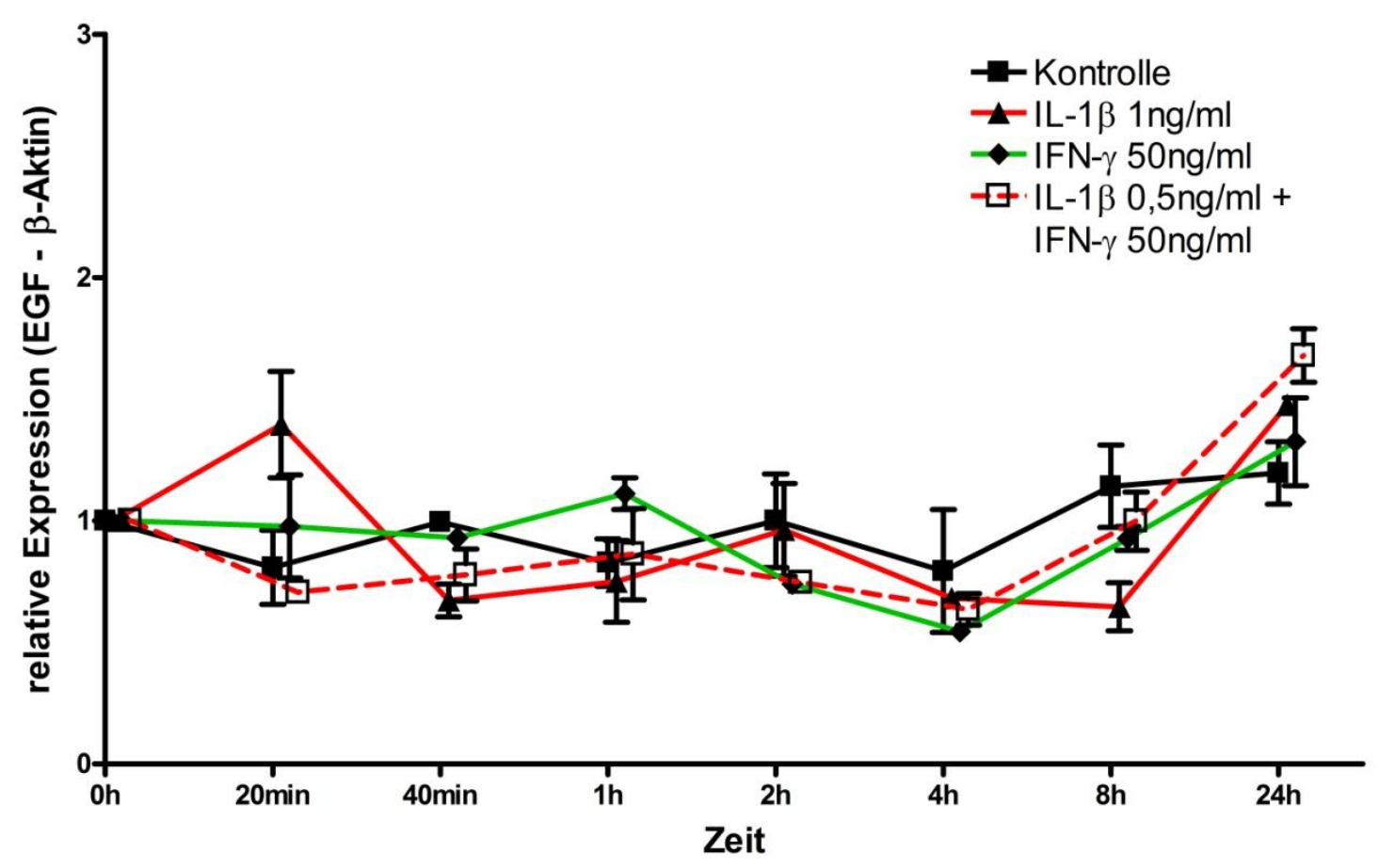

Abb. 38: Expression von EGF in HT-29-Zellen

Tab. 33: Signifikant veränderte Expression $(p \leq 0,05)$ von EGF in HT-29-Zellen

\begin{tabular}{|c|c|}
\hline 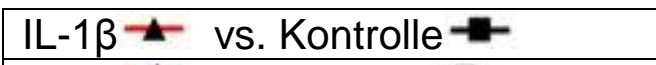 & $20 \mathrm{~min} ; 40 \mathrm{~min}$ \\
\hline IFN- $\gamma^{\bullet-}$ vs. Kontrolle $\rightarrow-$ & - \\
\hline IL-1 $\beta+$ IFN- $\gamma^{-G}$ vs. Kontrolle - & - \\
\hline 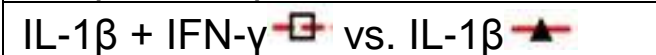 & - \\
\hline 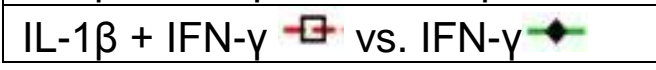 & - \\
\hline
\end{tabular}

Kombination von IL-1 $\beta$ und IFN- $\gamma$ führte zu keiner nennenswerten Veränderung der EGF-Expression in HT-29-Zellen. 


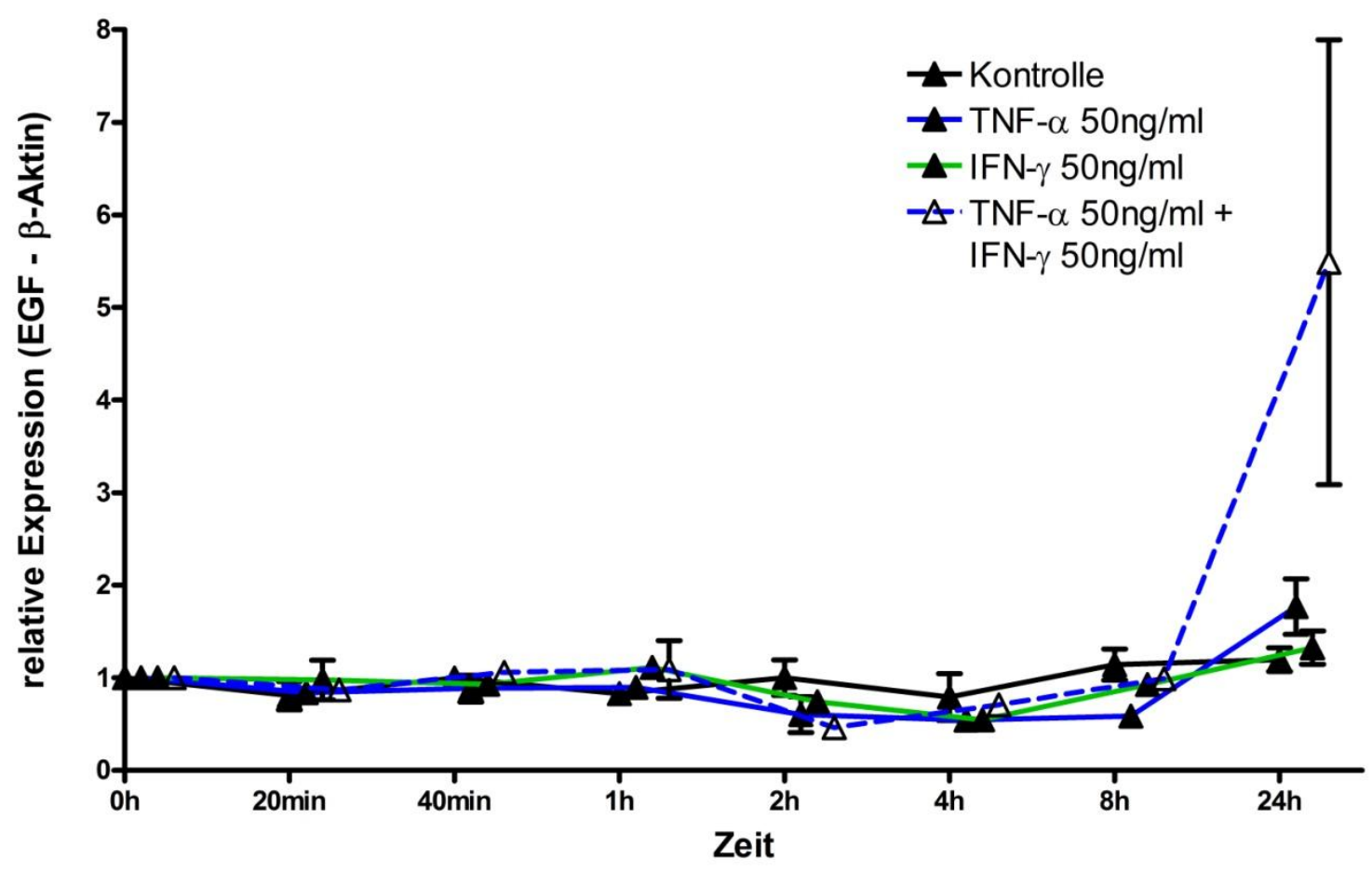

Abb. 39: Expression von EGF in HT-29-Zellen

Tab. 34: Signifikant veränderte Expression $(p \leq 0,05)$ von EGF in HT-29-Zellen

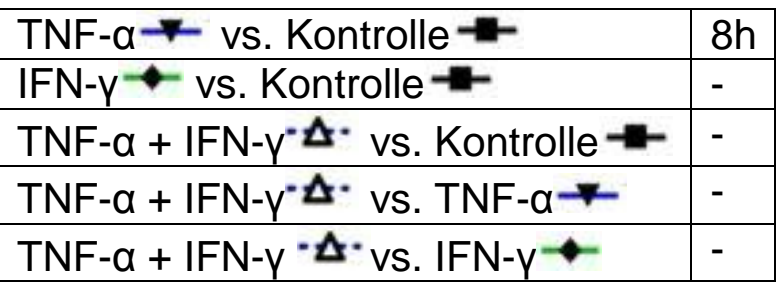

Kombinierte Inkubation der HT-29-Zellen mit TNF- $\alpha$ und IFN-y führte zu einer Zunahme EGF-Genexpression ab dem Zeitpunkt 8h. 


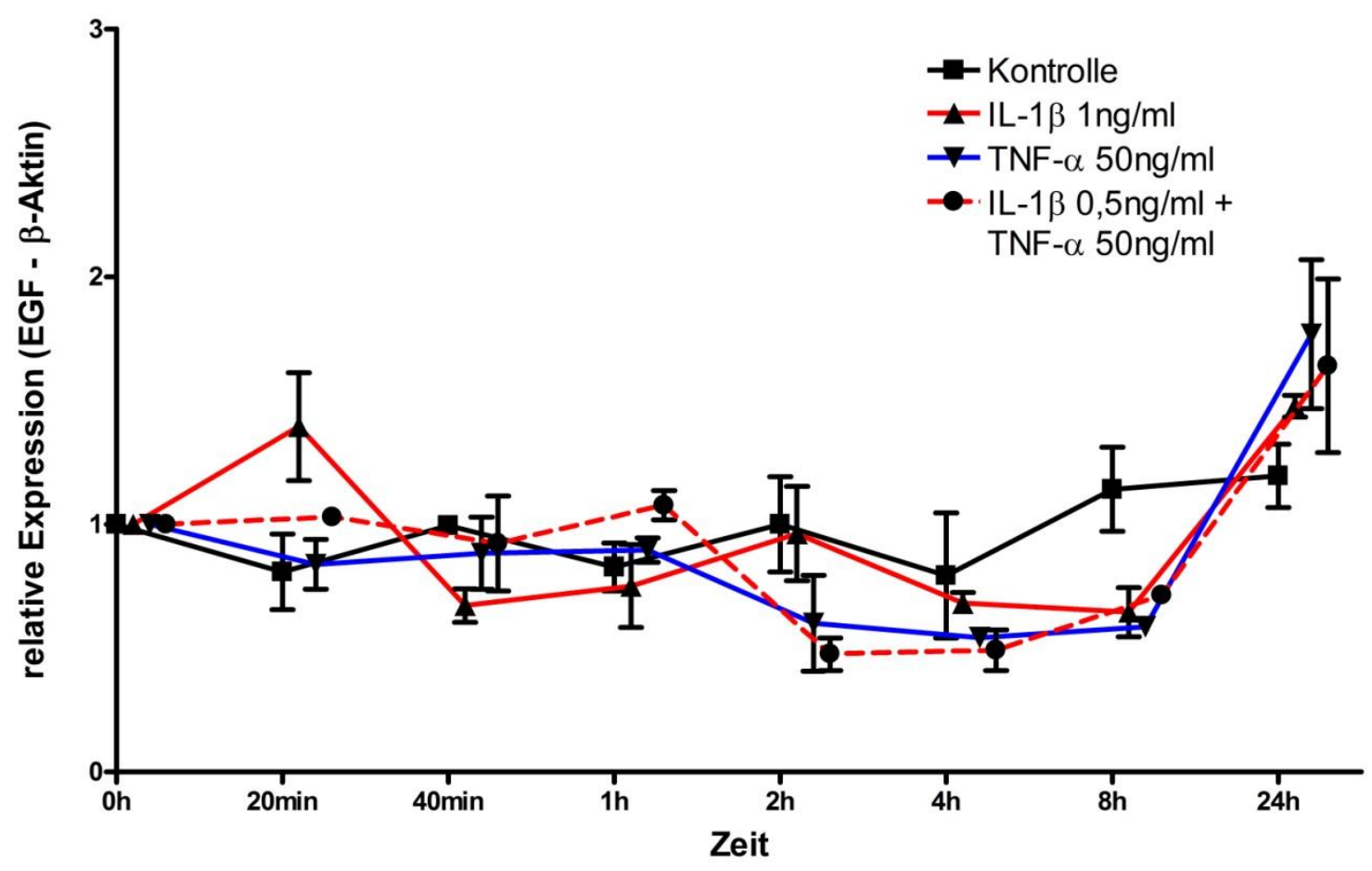

Abb. 40: Expression von EGF in HT-29-Zellen

Tab. 35: Signifikant veränderte Expression $(p \leq 0,05)$ von EGF in HT-29-Zellen

\begin{tabular}{|l|l|}
\hline $\mathrm{IL}-1 \beta \star$ vs. Kontrolle $\rightarrow-$ & $20 \mathrm{~min} ; 40 \mathrm{~min}$ \\
\hline TNF- $\alpha \rightarrow$ vs. Kontrolle $\rightarrow-$ & $8 \mathrm{~h}$ \\
\hline $\mathrm{IL}-1 \beta+$ TNF- $\alpha \bullet-$ vs. Kontrolle $\rightarrow-$ & $2 \mathrm{~h}$ \\
\hline $\mathrm{IL}-1 \beta+$ TNF- $\alpha \bullet$ vs. IL-1 $\beta \star-$ & $2 \mathrm{~h}$ \\
\hline $\mathrm{IL}-1 \beta+$ TNF- $\alpha \bullet$ vs. TNF- $\alpha \rightarrow-$ & $8 \mathrm{~h}$ \\
\hline
\end{tabular}

Kombinierte Inkubation der HT-29-Zellen mit IL-1 $\beta$ und TNF- $\alpha$ führte zu keiner Veränderung der Genexpression von EGF. 
3.2.6) Regulation der EGFR mRNA-Expression in HT-29-Zellen

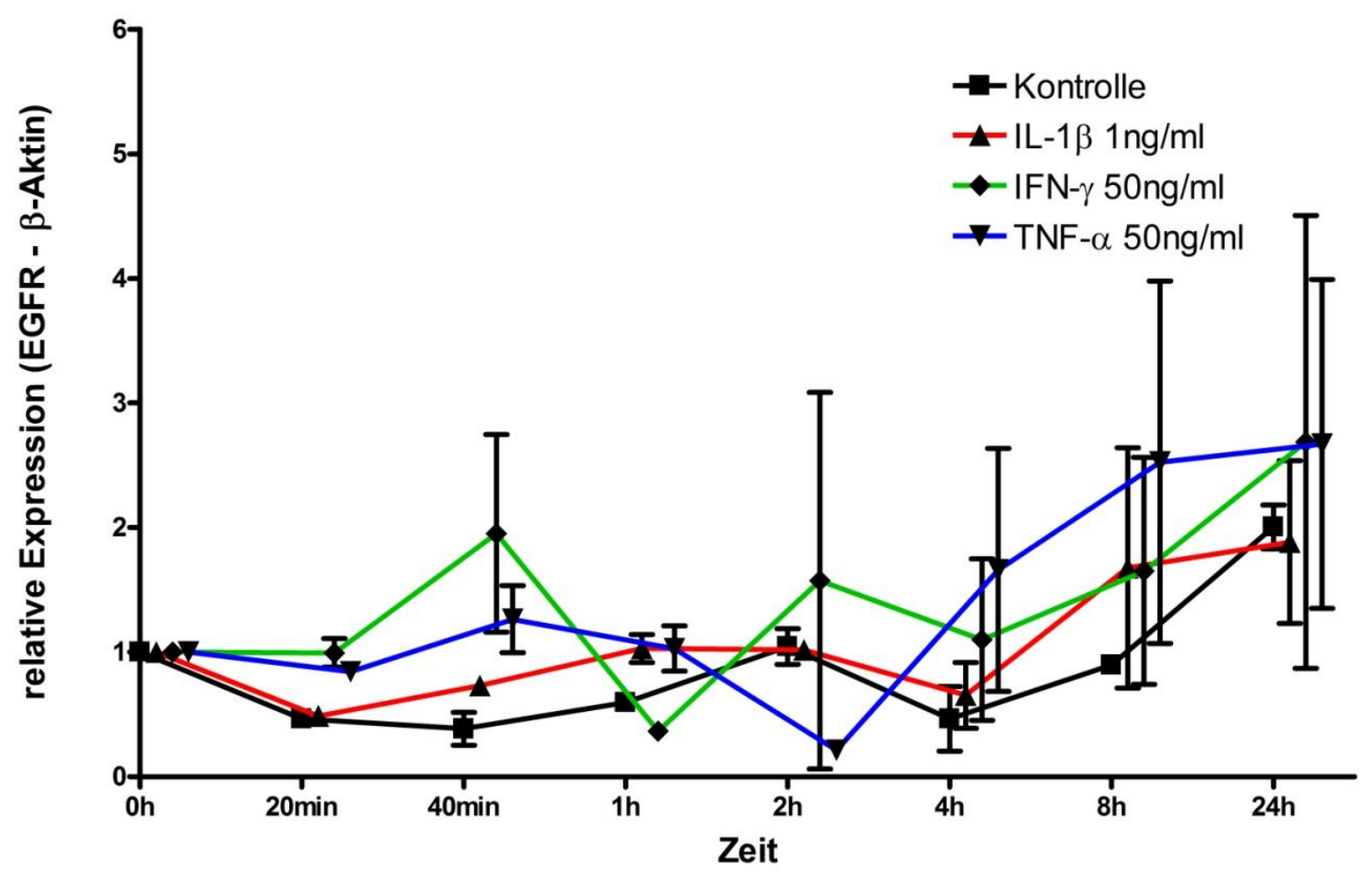

Abb. 41: Expression von EGFR in HT-29-Zellen

Tab. 36: Signifikant veränderte Expression $(p \leq 0,05)$ von EGFR in HT-29-Zellen

\begin{tabular}{|l|l|}
\hline $\mathrm{IL}-1 \beta \star$ vs. Kontrolle $\rightarrow-$ & $40 \mathrm{~min} ; 1 \mathrm{~h}$ \\
\hline $\mathrm{IFN}-\mathrm{\gamma} \bullet$ vs. Kontrolle $\rightarrow-$ & $20 \mathrm{~min} ; 1 \mathrm{~h}$ \\
\hline TNF- $\alpha \rightarrow$ vs. Kontrolle $\bullet-$ & $20 \mathrm{~min} ; 40 \mathrm{~min} ; 1 \mathrm{~h} ; 2 \mathrm{~h}$ \\
\hline
\end{tabular}

HT-29-Zellen exprimieren EGFR, ab dem Zeitpunkt 4h zeigte sich tendenziell eine Zunahme der Genexpression auch in der Kontrolle. Einzelinkubation der Zellen mit IL-1 $\beta$, IFN- $\gamma$ oder TNF- $\alpha$ hatte darauf keinen nennenswerten Effekt. 


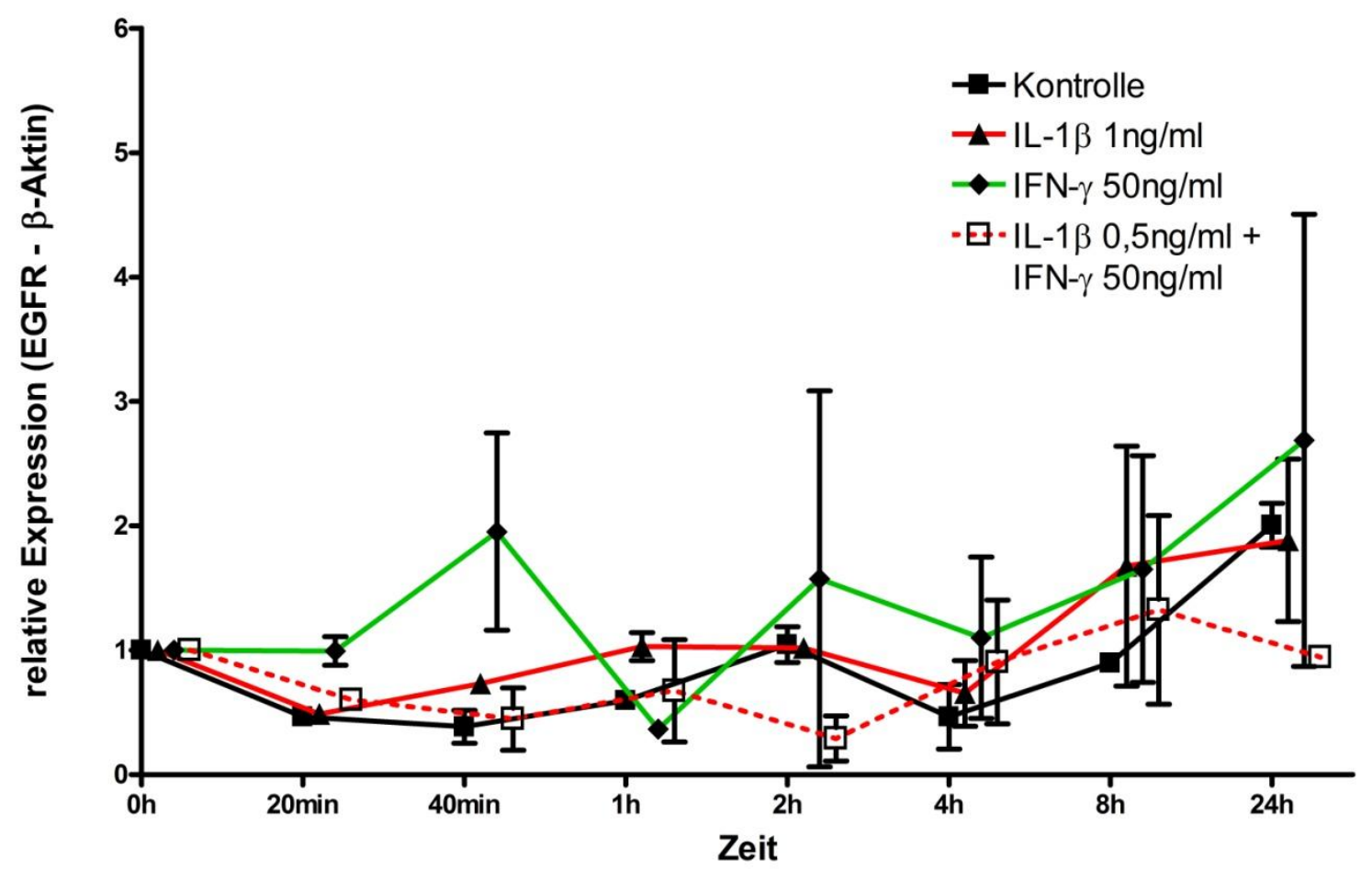

Abb. 42: Expression von EGFR in HT-29-Zellen

Tab. 37: Signifikant veränderte Expression $(p \leq 0,05)$ von EGFR in HT-29-Zellen

\begin{tabular}{|c|c|}
\hline $\mathrm{IL}-1 \beta \rightarrow$ vs. Kontrolle $\rightarrow$ & $40 \mathrm{~min} ; 1 \mathrm{~h}$ \\
\hline IFN- $\gamma^{\bullet-}$ vs. Kontrolle $\rightarrow-$ & $20 \mathrm{~min} ; 1 \mathrm{~h}$ \\
\hline IL-1 $1 \beta+$ IFN- $\gamma^{-\square}$ vs. Kontrolle $\rightarrow-$ & $2 \mathrm{~h} ; 24 \mathrm{~h}$ \\
\hline IL-1 $\beta+$ IFN- $\gamma^{-G}$ vs. IL-1 $1 \beta \star$ & $2 \mathrm{~h}$ \\
\hline IL-1 $1 \beta+$ IFN- $\gamma^{-G}$ vs. IFN- $\gamma^{-\bullet}$ & $20 \mathrm{~min}$ \\
\hline
\end{tabular}

Kombinierte Inkubation der HT-29-Zellen mit IL-1 $\beta$ und IFN-y führte zu einem geringgradigen Absinken der Genexpression von EGFR zum Zeitpunkt 24h. 


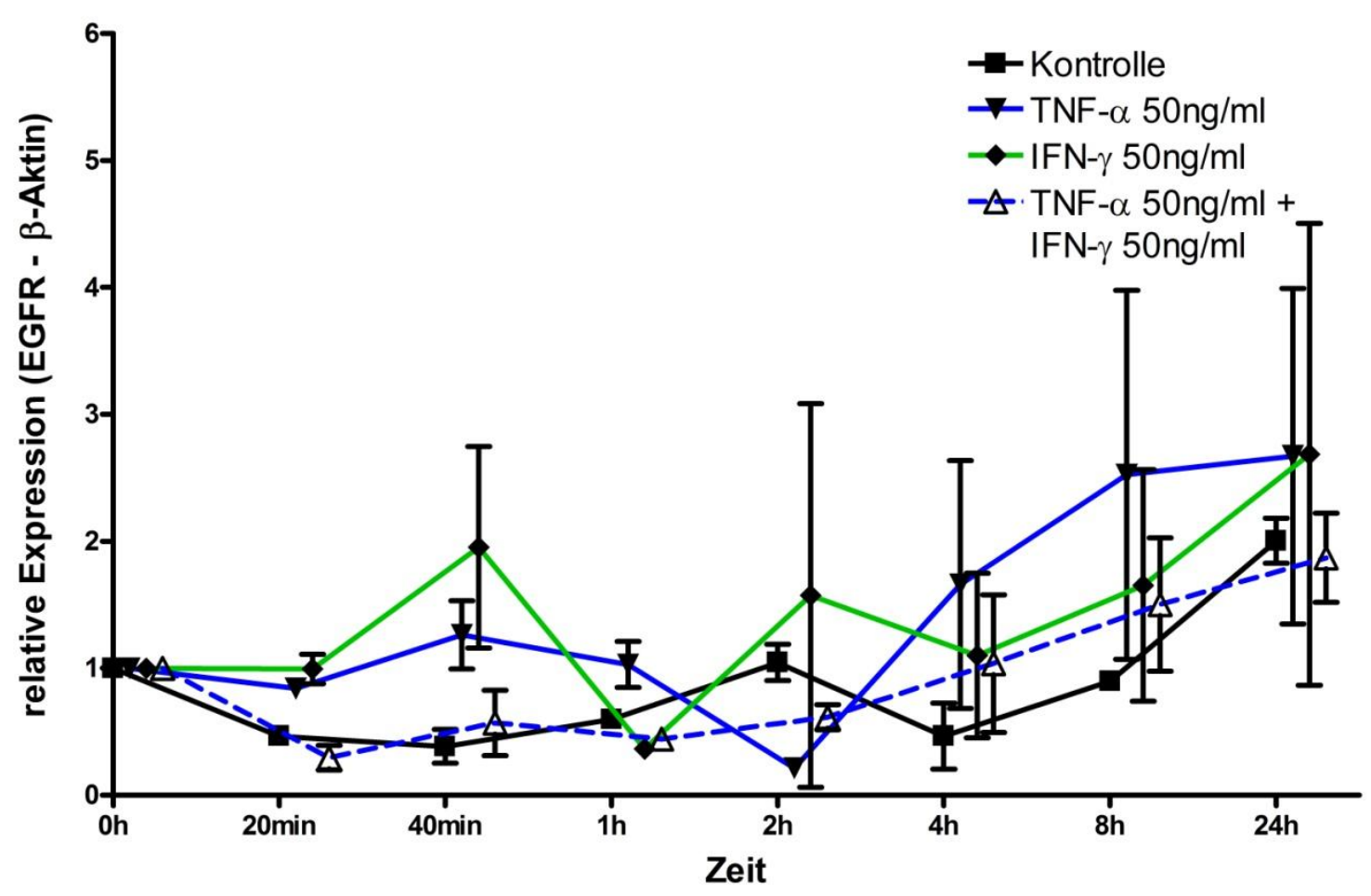

Abb. 43: Expression von EGFR in HT-29-Zellen

Tab. 38: Signifikant $(p \leq 0,05)$ veränderte Expression von EGFR in HT-29-Zellen

\begin{tabular}{|c|c|}
\hline TNF- $a \rightarrow$ vs. Kontrolle $\rightarrow$ & 20min; 40min; 1h; 2h \\
\hline IFN- $\gamma^{\bullet-}$ vs. Kontrolle $\rightarrow$ & $20 \mathrm{~min} ; 1 \mathrm{~h}$ \\
\hline TNF- $\alpha+$ IFN- $\gamma^{-\Delta} \cdot$ vs. Kontrolle $=-$ & \\
\hline TNF- $\alpha+$ IFN-y $\cdot \Delta \cdot v s$. TNF- $\alpha-$ & 20min; $1 \mathrm{~h} ; 2 \mathrm{~h}$ \\
\hline TNF- $\alpha+$ IFN- $\gamma^{-\Delta \cdot}$ vs. IFN- $\gamma^{-\bullet}$ & \\
\hline
\end{tabular}

Kombinierte Inkubation mit TNF- $\alpha$ und IFN- $\gamma$ bewirkte keine eindeutige Veränderung der EGFR-Genexpression in HT-29-Zellen. 


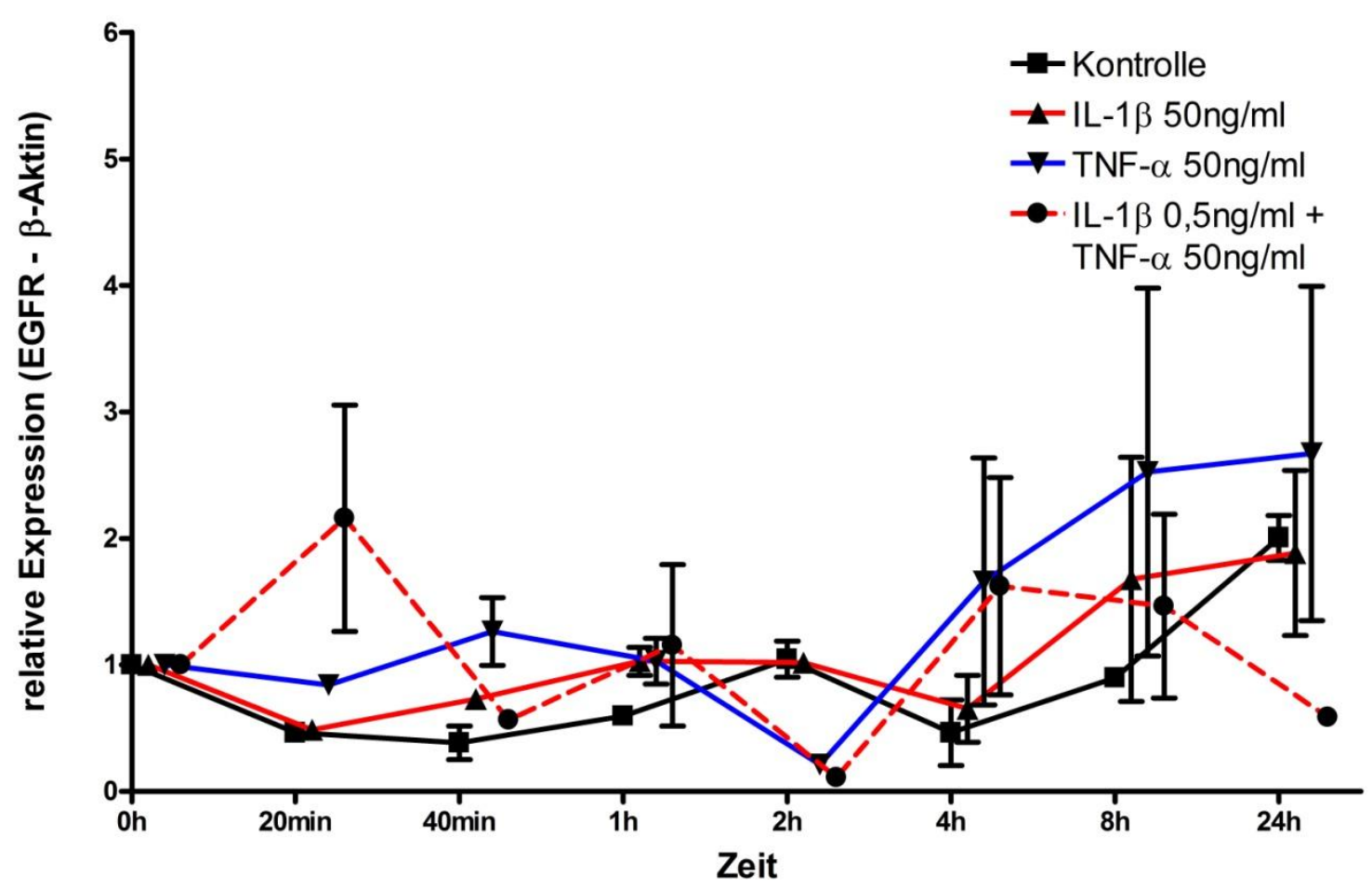

Abb. 44: Expression von EGFR in HT-29-Zellen

Tab. 39: Signifikant veränderte Expression $(p \leq 0,05)$ von EGFR in HT-29-Zellen

\begin{tabular}{|c|c|}
\hline$I L-1 \beta-$ vs. Kontrolle - \pm & 40min; $1 \mathrm{~h}$ \\
\hline TNF- $a \rightarrow$ vs. Kontrolle $\rightarrow-$ & 20min; 40min; 1h; 2h \\
\hline$I L-1 \beta+$ TNF- $\alpha \rightarrow$ vs. Kontrolle $\rightarrow-$ & $2 h ; 24 h$ \\
\hline$I L-1 \beta+$ TNF- $\alpha-\bullet$ vs. IL-1 $\beta-$ & $1 \mathrm{~h}$ \\
\hline IL-1 $\beta+$ TNF- $\alpha-\bullet$ vs. TNF- $\alpha \rightarrow$ & $2 \mathrm{~h}$ \\
\hline
\end{tabular}

Kombinierte Inkubation der HT-29-Zellen mit IL-1 $\beta$ und TNF- $\alpha$ hatte keinen eindeutigen Effekt auf die EGFR-Genexpression. 


\subsection{7) Regulation der VEGF-mRNA-Expression in HT-29-Zellen}

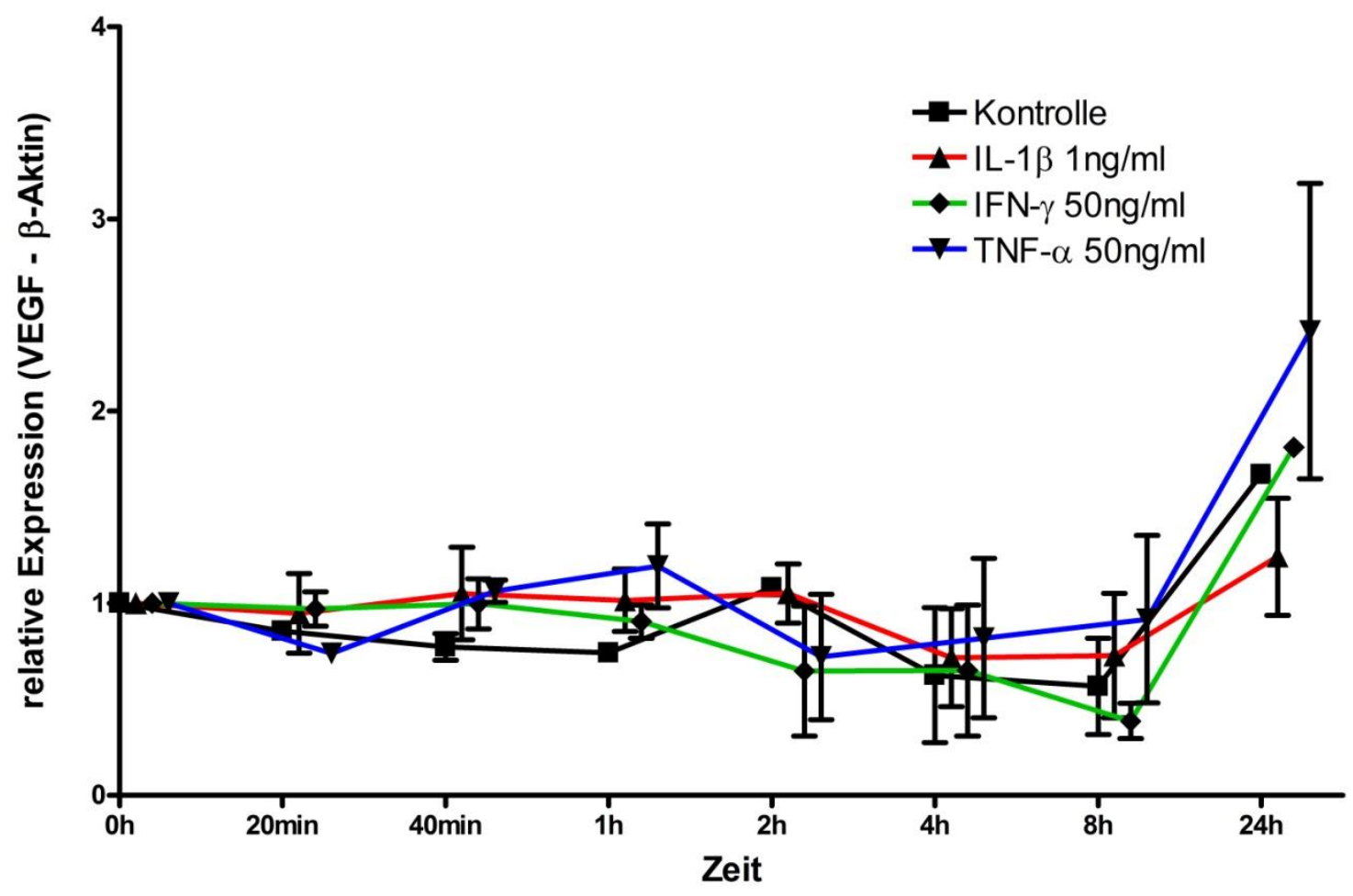

Abb. 45: Expression von VEGF in HT-29-Zellen

Tab. 40: Signifikant veränderte Expression $(p \leq 0,05)$ von VEGF in HT-29-Zellen

\begin{tabular}{|c|c|}
\hline $\mathrm{IL}-1 \beta \succsim$ vs. Kontrolle $\rightarrow-$ & \\
\hline IFN- $\gamma^{\bullet}-$ vs. Kontrolle $\bullet$ & $24 \mathrm{~h}$ \\
\hline TNF- $\alpha \rightarrow$ vs. Kontrolle $\rightarrow-$ & $40 \mathrm{~min}$ \\
\hline
\end{tabular}

HT-29-Zellen exprimieren VEGF, ab dem Zeitpunkt 8h zeigte sich tendenziell eine Zunahme der Genexpression, auch in der Kontrolle. Einzelinkubation der Zellen mit IL-1 $\beta$, TNF- $\alpha$ oder IFN- $\gamma$ hatte darauf keinen nennenswerten Effekt. 


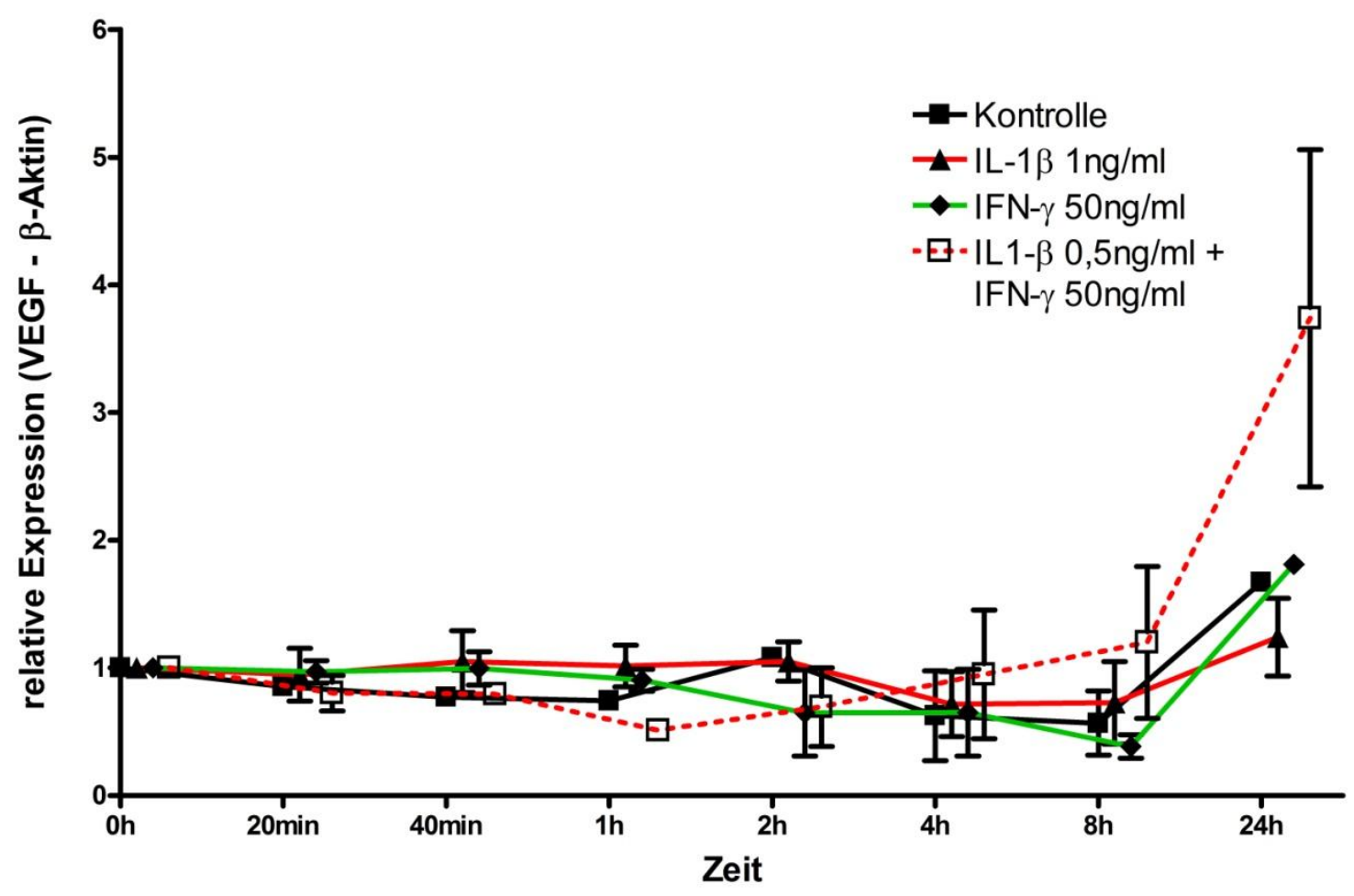

Abb. 46: Expression von VEGF in HT-29-Zellen

Tab. 41: Signifikant veränderte Expression $(p \leq 0,05)$ von VEGF in HT-29-Zellen

\begin{tabular}{|c|c|}
\hline$-1 \beta \neg$ vs. Kontrolle $\rightarrow-$ & \\
\hline IFN- $\gamma^{-\bullet-v s . I}$ & $24 \mathrm{~h}$ \\
\hline 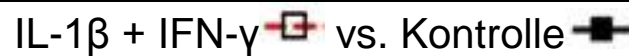 & $1 \mathrm{~h}$ \\
\hline 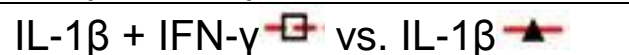 & $1 \mathrm{~h}$ \\
\hline $\mathrm{IL}-1 \beta+\mathrm{IFN}-\gamma^{-\square}$ vs. IFN- $\gamma^{-} \leftarrow$ & $1 \mathrm{~h}$ \\
\hline
\end{tabular}

Kombinierte Inkubation der HT-29-Zellen mit IL-1 $\beta$ und IFN- $\gamma$ führte zu einer Zunahme der VEGF-Genexpression gegenüber dem Kontrollwert bzw. gegenüber der Einzelinkubation mit IL-1 $\beta$ oder IFN-y. 


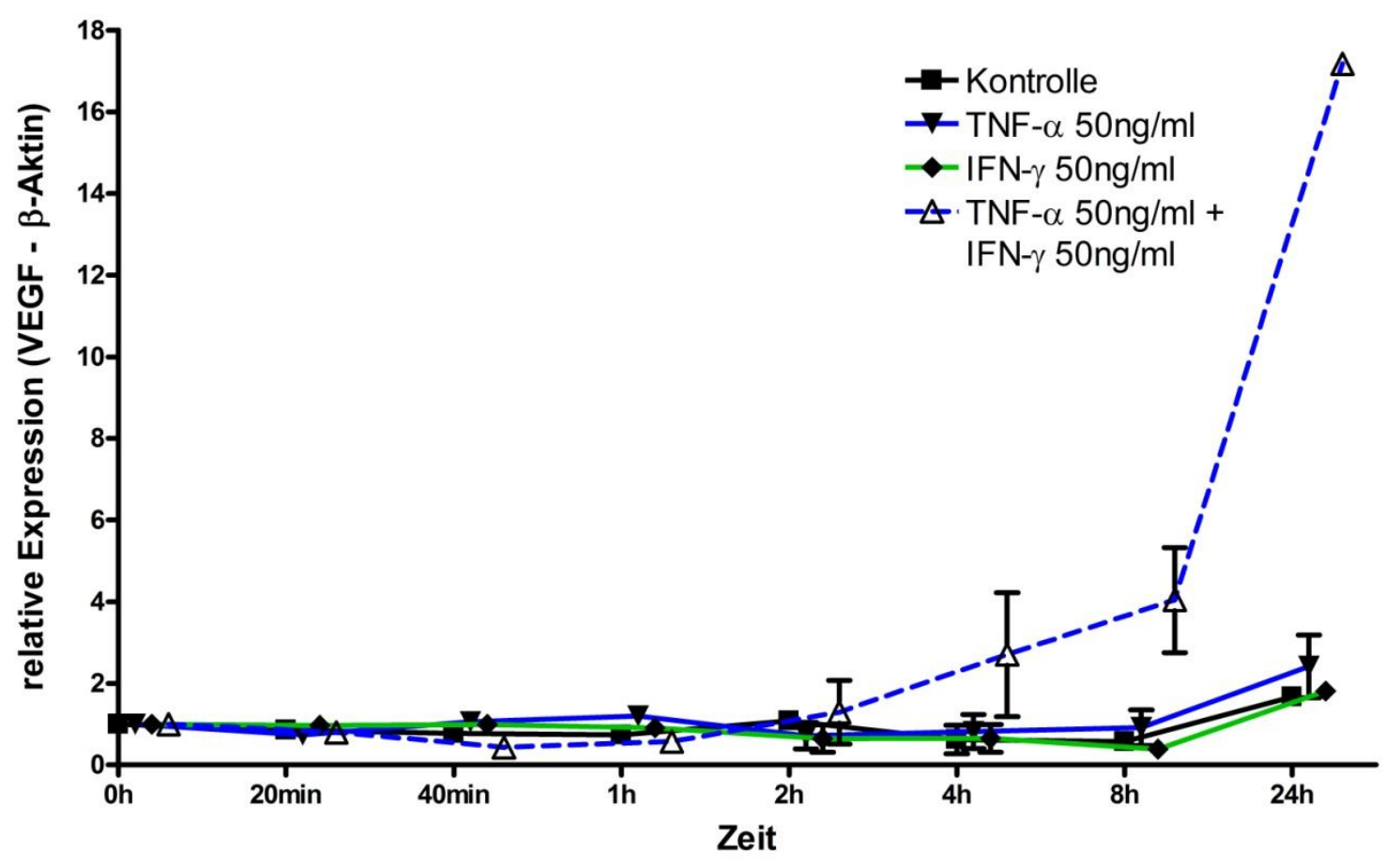

Abb. 47: Expression von VEGF in HT-29-Zellen

Tab. 42: Signifikant veränderte Expression $(p \leq 0,05)$ von VEGF in HT-29-Zellen

\begin{tabular}{|c|c|}
\hline TNF- $\alpha \rightarrow$ vs. Kontrolle $\rightarrow-$ & $40 \mathrm{~min}$ \\
\hline IFN- $-\vdash-$ vs. Kontrolle $\rightarrow-$ & $24 \mathrm{~h}$ \\
\hline TNF- $\alpha+$ IFN- $\gamma^{-\Delta^{*}}$ vs. Kontrolle & $8 \mathrm{~h} ; 24 \mathrm{~h}$ \\
\hline TNF- $\alpha+$ IFN- $\gamma^{-\Delta \cdot}$ vs. TNF- $\alpha \rightarrow$ & $40 \mathrm{~min} ; 8 \mathrm{~h} ; 24 \mathrm{~h}$ \\
\hline TNF- $\alpha+I F N-\gamma^{-\Delta \cdot}$ vs. II & \\
\hline
\end{tabular}

Kombinierte Inkubation der Zellen mit TNF- $\alpha$ und IFN-y führte zu einer deutlichen Zunahme der VEGF-Genexpression ab dem Zeitpunkt $2 \mathrm{~h}$ gegenüber Inkubation mit den beiden Zytokinen allein. 


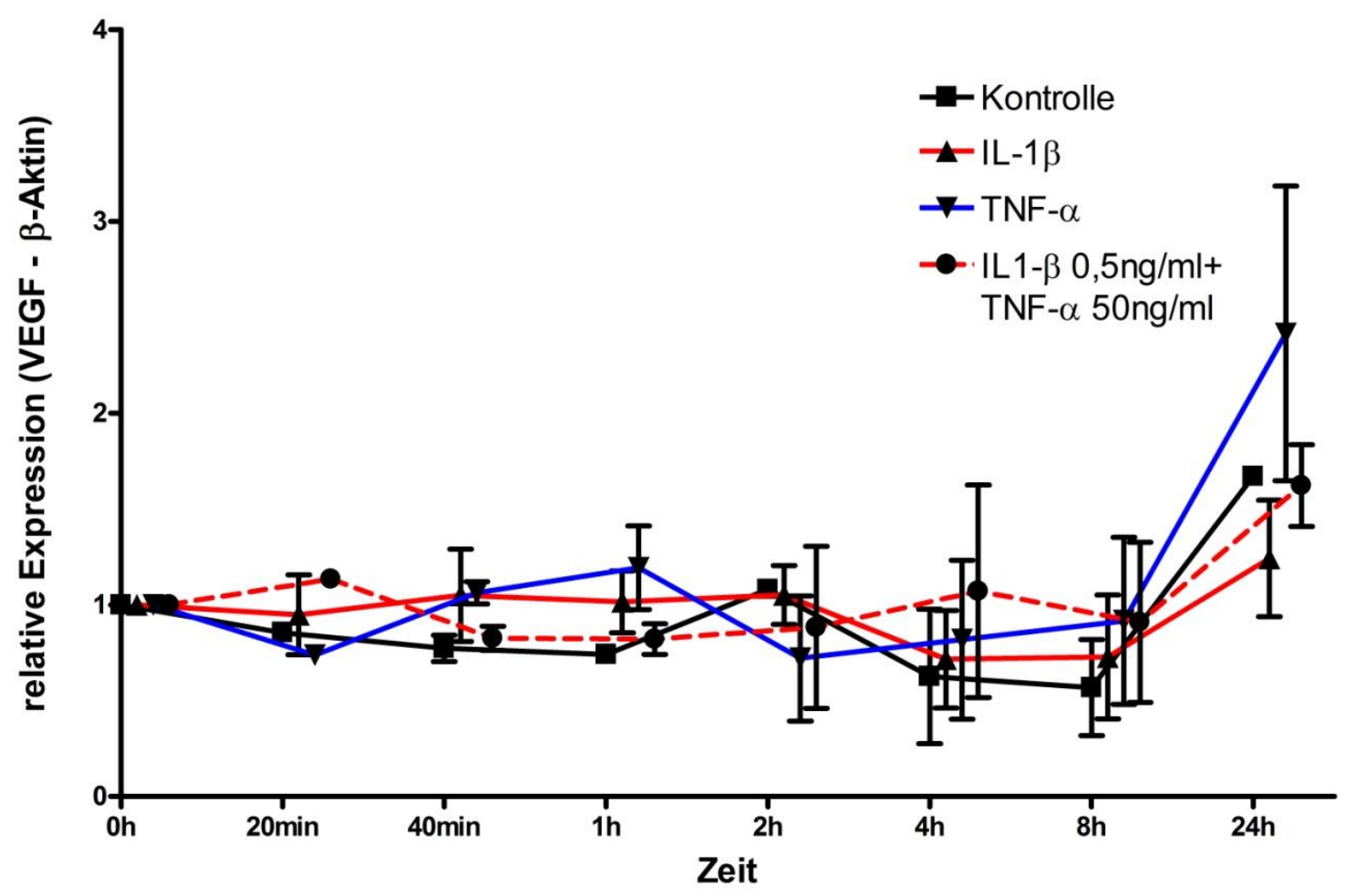

Abb. 48: Expression von VEGF in HT-29-Zellen

Tab. 43: Signifikant veränderte Expression $(p \leq 0,05)$ von VEGF in HT-29-Zellen

\begin{tabular}{|c|c|}
\hline $\mathrm{L}-1 \beta \succsim$ vs. Kontrolle $₫-$ & \\
\hline TNF- $\alpha \rightarrow$ vs. Kontrolle $\rightarrow-$ & $40 \mathrm{~min}$ \\
\hline IL-1 $1 \beta+$ TNF $-\alpha \rightarrow$ vs. Kontrolle $\rightarrow-$ & $20 \mathrm{~min}$ \\
\hline 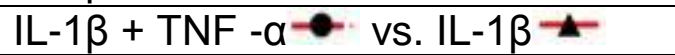 & \\
\hline$I L-1 \beta+$ TNF- $\alpha \rightarrow$ vs. TNF- $\alpha \rightarrow$ & $20 \mathrm{~min} ; 40 \mathrm{~min}$ \\
\hline
\end{tabular}

Inkubation der Zellen mit TNF- $\alpha$ allein bewirkte einen geringfügigen Anstieg der VEGF-Expression. Kombinierte Inkubation der HT-29-Zellen mit IL-1 $\beta$ und TNF- $\alpha$ hatte keinen zusätzlichen Effekt. 


\subsection{8) Regulation der VEGFR-1 mRNA-Expression in HT-29-Zellen}

Für VEGFR-1 konnte in HT-29-Kolonkarzinomzellen nur eine sehr niedrige Expression nachgewiesen werden, es werden deshalb die CT-Rohwerte tabellarisch aufgeführt.

Tab. 44: Expression von VEGFR in HT-29-Zellen, CT-Rohwerte

\begin{tabular}{|c|c|c|c|c|c|c|c|}
\hline $\begin{array}{l}\text { Beh. / } \\
\text { Zeitpunkt }\end{array}$ & $\begin{array}{l}\bar{x} \\
C T\end{array}$ & $\begin{array}{l}\text { Beh. / } \\
\text { Zeitpunkt }\end{array}$ & $\begin{array}{l}\bar{x} \\
\text { CT }\end{array}$ & $\begin{array}{l}\text { Beh. / } \\
\text { Zeitpunkt }\end{array}$ & $\begin{array}{l}\bar{x} \\
\text { CT }\end{array}$ & $\begin{array}{l}\text { Beh. / } \\
\text { Zeitpunkt }\end{array}$ & $\begin{array}{l}\bar{x} \\
\text { CT }\end{array}$ \\
\hline Ko Oh & 35,3 & IL-1及 Oh & 35,3 & TNF- $\alpha$ Oh & 35,3 & IFN-y Oh & 35,3 \\
\hline Ko 20min & 34,6 & IL-1ß 20min & 36,3 & TNF- $\alpha$ 20min & 34,4 & IFN-y 20min & 35,4 \\
\hline Ko 40min & 34,9 & IL-1 $1 \beta$ 40min & 37,5 & TNF- $\alpha$ 40min & 35,0 & IFN-y 40min & 35,4 \\
\hline Ko 1h & 35,3 & IL-1ß 1h & 34,9 & TNF- $\alpha 1 \mathrm{~h}$ & 35,3 & IFN-Y 1h & 34,2 \\
\hline Ko $2 \mathrm{~h}$ & 33,6 & 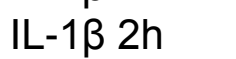 & 34,1 & TNF- $\alpha 2 h$ & 34,4 & IFN-Y $2 \mathrm{~h}$ & 36,4 \\
\hline Ko 4h & 35,0 & IL-1 $4 \mathrm{~h}$ & 34,7 & TNF- $\alpha 4 h$ & 35,6 & IFN-Y 4h & 35,1 \\
\hline Ko 8h & 35,9 & IL-1 $8 \mathrm{~h}$ & 35,0 & TNF- $\alpha 8 \mathrm{~h}$ & 35,1 & IFN-y 8h & 34,8 \\
\hline Ko 24h & 35,8 & $\mathrm{IL}-1 \beta 24 \mathrm{~h}$ & 35,3 & TNF- $\alpha 24 h$ & 34,9 & IFN- $\gamma 24 h$ & 33,7 \\
\hline
\end{tabular}

\begin{tabular}{|c|c|c|c|c|c|}
\hline $\begin{array}{l}\text { Behandlung / } \\
\text { Zeitpunkt }\end{array}$ & $\begin{array}{l}\bar{x} \\
\text { CT }\end{array}$ & $\begin{array}{l}\text { Behandlung / } \\
\text { Zeitpunkt }\end{array}$ & $\begin{array}{l}\bar{x} \\
\text { CT }\end{array}$ & $\begin{array}{l}\text { Behandlung / } \\
\text { Zeitpunkt }\end{array}$ & $\bar{x} C T$ \\
\hline IL-1 $\beta+T N F-\alpha 0 h$ & 35,3 & $11 \mathrm{I}+\mathrm{IEN} \times \mathrm{Ob}$ & 35,3 & TNF- $\alpha+I F N-\gamma$ Oh & 35,3 \\
\hline Omin & & $20 \mathrm{~min}$ & 36,3 & $\mathrm{~N}-\mathrm{y} 20 \mathrm{~min}$ & 36,2 \\
\hline $\mathrm{IL}-1 \beta+\mathrm{TNF}-\alpha$ 40min & 35,6 & IL-1 $1 \beta+I F N-\gamma 40 \min$ & 35,6 & TNF- $\alpha+I F N-\gamma 40 \min$ & 38,4 \\
\hline $\mathrm{IL}-1 \beta+T N F-\alpha 1 \mathrm{~h}$ & 36,1 & & 36,3 & TNF- $\alpha+I F N-\gamma 1 \mathrm{~h}$ & 36,0 \\
\hline IL-1 $\beta+T N F$ & 35,2 & IL-1 $\beta+I F N-\gamma 2 h$ & 35,4 & TNF- $\alpha+I F N-y 2 h$ & 34,6 \\
\hline IL-1 $\beta+T N F-\alpha 4 h$ & 36,2 & IL-1 $\beta+I F N-\gamma 4 h$ & 33,4 & TNF- $\alpha+I F N-y 4 h$ & 38,4 \\
\hline IL-1 $\beta+T N F-\alpha 8 h$ & 35,5 & IL-1 $1 \beta+I F N-\gamma 8 h$ & 33,1 & TNF- $\alpha+I F N-y 8 h$ & 33,4 \\
\hline$I L-1 \beta+T N F-\alpha 24 h$ & 35,3 & IL-1 $1 \beta+I F N-\gamma 24 h$ & 34,3 & TNF- $\alpha+I F N-y 24 h$ & 34,7 \\
\hline
\end{tabular}

Abkürzungen: Beh.: Behandlung, CT: Comparative Threshold, IFN- $\gamma$ : Interferon gamma, IL-1 $\beta$ : Interleukin-1 beta, Ko: Kontrolle, SD: Standard Deviation, TNF- $\alpha$ : Tumor-Nekrose-Faktor alpha, $\overline{\mathbf{x}}$ : Mittelwert

Die VEGFR-Expression nahm unter Inkubation mit den Zytokinen IL-1 $\beta$, IFN-y oder TNF- $\alpha$ über den Beobachtungszeitraum geringfügig zu. 


\section{4) Diskussion}

\section{1) PBMCs}

Wachstumsfaktoren spielen eine große Rolle für Zellproliferation und -differenzierung und sichern dadurch unter physiologischen Bedingungen Wachstum und Wundheilung. In malignen Erkrankungen tragen durch stromale Zellen, Endothel-, Immunund Tumorzellen gebildete Wachstumsfaktoren zur Tumorpromotion und -progression bei. In der vorliegenden Arbeit wurde untersucht, inwieweit aktivierte PBMCs an der Bildung der Wachstumsfaktoren EGF und VEGF beteiligt sind und wie sich die Expression der Gene für sowohl die Wachstumsfaktoren selbst als auch für ihre Rezeptoren durch den Einsatz von Antikörpern gegen EGF, VEGF und TNF- $\alpha$ beeinflussen lässt. Aufgrund der interindividuellen Unterschiede der Genexpression zeigte sich ein relativ großer Standardfehler. Die Ergebnisse werden deshalb vorrangig in Abhängigkeit der quantitativen Expressionsänderung interpretiert.

\subsection{1) Expression von EGF und seinem Rezeptor EGFR-1 in PBMCs}

\section{EGF}

Die durchgeführten Versuche zeigten, dass PBMCs EGF exprimieren, wenn auch auf niedrigem Niveau (Ergebnisse ohne Abbildung). Stimulation der Zellen mit PHA, LPS oder TNF- $\alpha$ ergab über den gesamten Beobachtungszeitraum keine eindeutige Änderung der EGF-Expression, auch zusätzliche Inkubation mit anti-VEGF- oder anti-TNF- $\alpha$-Antikörper ergaben keinen eindeutigen Effekt. Dieses Ergebnis steht im Widerspruch zu den Beobachtungen von Jendraschak et al., die - ebenfalls mittels PCR - keine Expression des EGF-Gens in humanen mononukleären Zellen des peripheren Blutes nachweisen konnten (Jendraschak et al. 1993). Es ist jedoch bekannt, dass Monozyten nach dem Übertritt ins Gewebe und der Transformation zu Makrophagen EGF bilden, wenn sie durch Tumorzellen mittels colony stimulating factor-1 (CSF-1) dazu angeregt werden. Im Sinne einer parakrinen Rückkopplung stimuliert das freigesetzte EGF die Tumorzellen wiederum zur Migration und 
Gefäßinvasion und begünstigt dadurch die Streuung von Tumorzellen (Qian und Pollard 2010).

\section{EGFR}

Der EGF-Rezeptor wurde in den hier durchgeführten Versuchen von den PBMCs weder mit noch ohne Stimulation durch PHA, LPS oder TNF- $\alpha$ exprimiert (Ergebnisse ohne Abbildung). In vorangegangenen Studien konnte der EGFR zumindest auf Bund T-Lymphozyten ebenfalls nicht nachgewiesen werden. Derweil zeigte sich seine Expression auf mononukleären Zellen des peripheren Blutes, insbesondere auf CD14+-Monozyten (Eales-Reynolds et al. 2001, Chan et al. 2009). Der Nachweis geschah jeweils auf Proteinebene an isolierten Monozyten. Die uneinheitlichen Ergebnisse zur EGFR-Expression auf PBMCs ergeben sich demnach am ehesten durch die Unterschiede in Untersuchungsmaterial und -methode. So beträgt der Anteil an CD14+-Monozyten an einer gemischten Kultur mononukleärer Zellen des peripheren Blutes - wie hier verwendet - nur ca. 5\% (Slipka et al. 2001), wodurch der Nachweis insbesondere bei niedriger Genexpression möglicherweise erschwert wird. Zudem ist $\mathrm{zu}$ diskutieren, inwieweit die Ergebnisse zu Untersuchungen auf Proteinebene mit den Ergebnissen auf mRNA-Ebene vergleichbar sind.

Die Ergebnisse lassen darauf schließen, dass EGF und der EGFR-Signalweg in Immunzellen, die das Tumorgewebe noch nicht infiltriert haben, eine untergeordnete Rolle für das Tumorwachstum spielen. Der therapeutische Einsatz eines EGFAntikörpers ist - unter Berücksichtigung der Ergebnisse von Qian und Pollard eventuell eine therapeutische Option zur Senkung der Metastasenbildung durch Hemmung des von Gewebsmakrophagen gebildeten EGF. Der Einsatz von Antikörpern gegen den in Tumorzellen häufig überexprimierten EGF-Rezeptor - wie Cetuximab - bleibt vorerst die wirkungsvollere Therapiemethode.

\subsection{2) Expression von VEGF und seinem Rezeptor VEGFR-1 in PBMCs}

\section{Expression von VEGF}

Verschiedene Subtypen von Leukozyten produzieren VEGF: Makrophagen (McLaren et al. 1996), Neutrophile (Taichman et al. 1997; Webb et al. 1998), Basophile (de 
Paulis et al. 2006) und T-Zellen (Freeman et al. 1995). Die VEGF-Expression in mononukleären Zellen des Blutes wird durch von Tumorzellen freigesetzte Zytokine gesteigert (França et al. 2011). Auch die vorliegende Arbeit zeigt, dass in Immunzellen des Blutes VEGF produziert wird (Abb. 7, Abb. 8). Durch Anregung der PBMCs mit LPS nahm die VEGF-Expression zu, kombinierte Inkubation mit LPS und anti-VEGF-Antikörper bewirkte eine geringfügige Abnahme der VEGF-Expression gegenüber der Inkubation mit LPS allein (Abb. 9, Abb. 10). Dies deckt sich mit den Untersuchungsergebnissen von Kiriakidis et al., die eine LPS-vermittelte VEGFInduktion via NF-KB nachweisen konnten, welche unter gleichzeitiger Inkubation mit anti-VEGF-Antikörper niedriger ausfiel (Kiriakidis et al. 2003). Diese Beobachtung lässt vermuten, dass die durch LPS-Inkubation bewirkte Expressionszunahme von VEGF teilweise auf einen auto- oder parakrinen Rückkopplungsmechanismus zurückzuführen ist: durch LPS stimulierte PBMCs bilden VEGF, welches - entweder direkt über den auf den PBMCs ebenfalls exprimierten VEGFR-1 (s. u.) oder via Induktion weiterer Entzündungsmediatoren - wiederum eine zusätzliche Steigerung der VEGF-Expression bewirkt. Wird das gebildete VEGF mittels eines Antikörpers neutralisiert, lässt die VEGF-Expression nach.

Inkubation der PBMCs mit TNF- $\alpha$ hatte keinen nennenswerten Effekt auf die VEGFExpression (Abb. 11). Dieses Ergebnis ist insofern überraschend, als TNF- $\alpha$ genauso wie LPS ein Aktivator der NF-KB-Kaskade ist. Auch Kiriakidis et al. konnten über eine Inkubation der Zellen mit TNF- $\alpha$ keine Expressionssteigerung von VEGF erreichen, sie erklären die unterschiedliche Wirkung der beiden Agenzien mit einer unterschiedlichen Signalvermittlung in der frühen NF-KB-Kaskade.

Inkubation der PBMCs mit Infliximab allein oder in Kombination mit LPS führte zu einer Hemmung der basalen (Abb. 11) bzw. der LPS-induzierten VEGF-Expression (Abb. 10), ein Zusammenhang der VEGF-Expression mit TNF- $\alpha$ liegt also in jeden Fall nahe. Für neutrophile Granulozyten wurde eine VEGF-Expressionssteigerung durch TNF- $\alpha$ derweil bereits bewiesen (Webb et al. 1998). In klinischen Studien wurde zudem ein hemmender Effekt von Infliximab auf die Expression von VEGF in Immunzellen in Synovialbiopsien von Patienten mit Psoriasisarthritis nachgewiesen (Cañete et al. 2004). Auch fiel der VEGF-Serumspiegel von Patienten mit chronisch entzündlichen Darmerkrankungen unter Therapie mit Infliximab signifikant ab 
(Koutroubakis et al. 2006). Verschiedene Studien ergaben darüber hinaus eine niedrigere Rate an CED-assoziierten kolorektalen Karzinomen bei CED-Patienten, die eine antientzündliche Therapie mit Infliximab erhielten (Biancone et al. 2009). Auseinandergehende Untersuchungsergebnisse zur TNF- $\alpha$-Wirkung auf die VEGFExpression sind wahrscheinlich auch durch die unterschiedliche Wirkung von endogenem und exogenem bzw. membrangebundenem (mTNF- $\alpha$ ) und löslichem (sTNF- $\alpha$ ) TNF- $\alpha$ bedingt. Eine Steigerung der Zytokinexpression wird dabei bevorzugt über die membrangebundene Form und den TNFR2 ausgelöst (Holtmann und Neurath 2004), in unseren Experimenten wurde jedoch lösliches TNF- $\alpha$ eingesetzt. Zudem ist zu berücksichtigen, welche Leukozyten-Subpopulation untersucht wurde, und ob es sich dabei um im Blut zirkulierende oder Gewebsimmunzellen handelt. Letztlich bleibt die Frage, ob die hier verwendeten Dosen von LPS und Infliximab im Ausmaß inrer Wirkung äquivalent sind, gegebenenfalls sollten die Experimente mit verschiedenen Konzentrationen der beiden Agenzien und mit längeren Inkubationszeiten wiederholt werden.

Inkubation mit PHA hatte - auch in Kombination mit anti-VEGF-Antikörper (Abb. 12) oder Infliximab (Abb. 13) - keinen eindeutigen Effekt auf die VEGF-Expression. Dies lässt vermuten, dass die PHA-Zielzellen - wie eingangs erwähnt im wesentlichen Lymphozyten - nicht im selben Ausmaß an der VEGF-Bildung im Blut beteiligt sind, wie das Monozyten-Makrophagen-System.

\section{Expression von VEGFR-1}

VEGFR-1 wurde bereits auf verschiedenen Immunzellen nachgewiesen: Zellen des Monozyten-Makrophagen-Systems (Sawano et al. 2001), NK-Zellen (Chen et al. 2002), Neutrophile (Ancelin et al. 2004) Eosinophile (Feistritzer et al. 2004) und TLymphozyten (Shin et al. 2009, Basu et al. 2010) exprimieren den Rezeptor, nicht aber Basophile (de Paulis et al. 2010). Für die B-Zelllinie wurde eine VEGFR-1Expression zumindest in Vorläuferzellen (Fragoso et al. 2008) und Zellen der B-CLL (Kay et al. 2002) gezeigt. Erwartungsgemäß exprimierten die PBMCs in den hier durchgeführten Versuchen den VEGFR-1, die größte Steigerung der VEGFR-1Expression bewirkte die Stimulation mit LPS (Abb. 14, Abb. 15). Dieser Effekt wurde im Mausexperiment bereits beobachtet und wird demzufolge über die Notch1- 
Kaskade reguliert (Outtz et al. 2010), welche wiederum mit dem NF-KB-Signalweg interagiert. Tendenziell bewirkte kombinierte Inkubation mit LPS und anti-VEGFAntikörper eine zusätzliche Steigerung der VEGFR-1-Expression (Abb. 16). Eine denkbare Erklärung wäre hier eine Rezeptorhochregulation als Reaktion auf eine geringere Verfügbarkeit des Liganden. Angesichts mangelnder Hinweise auf einen solchen Mechanismus sowie die sehr kurze Zeitspanne innerhalb derer diese Veränderung beobachtet wurde, bleibt dieser Ansatz jedoch rein spekulativ. Barleon et al. zeigten in Versuchen mit HUVEC-Endothelzellen, dass Behandlung der Zellen mit VEGF im Gegenteil zu einer Steigerung der VEGFR-1-Expression führten, was vielmehr für einen positiven Rückkopplungs-Mechanismus von VEGF auf die VEGFR-1-Expression spricht (Barleon et al. 1997). Vor dem Hintergrund dieser uneinheitlichen Ergebnisse steht im klinischen Einsatz von VEGF-Blockern wie Bevacizumab vorerst die antiangiogenetische Wirkung auf Endothelzellen im Vordergrund.

Auch Inkubation der PBMCs mit TNF- $\alpha$ bewirkte in unseren Experimenten einen geringgradigen Anstieg der VEGFR-1-Expression, unter Kombination von TNF-a mit Infliximab wurde die TNF- $\alpha-W i r k u n g$ erwartungsgemäß neutralisiert (Abb. 17). Behandlung der Zellen mit Infliximab allein oder zusätzlich zu LPS führte zu einer geringgradigen Hemmung der basalen (Abb. 17) bzw. LPS-vermittelten (Abb. 18) VEGFR-1-Induktion. Die vielfach beobachtete antientzündliche Wirkung von Infliximab kommt somit zum Teil über eine Reduktion der VEGFR-1-Expression auf Immunzellen zustande, die genauen Zusammenhänge dieser Wirkungsweise bedürfen jedoch weiterer Untersuchungen. Bisher gilt lediglich eine hypoxieinduzierte Zunahme der VEGFR-1-Expression in HUVEC-Zellen (Gerber et al. 1997) als gesichert, eine Beteiligung von TNF- $\alpha$ und weiteren, TNF- $\alpha$-getriggerten Mediatoren wäre hier denkbar.

Anders als für VEGF zeigte sich für VEGFR-1 auch unter Inkubation mit PHA tendenziell eine Zunahme der Genexpression (Abb. 14, Abb. 15). Zugabe von antiVEGF-Antikörper hatte darauf keinen Effekt (Abb. 19) Derweil zeigte sich unter kombinierter Inkubation mit PHA und Infliximab überraschenderweise eine Hemmung der PHA-vermittelten VEGFR-1-Induktion (Abb. 20). Demnach führt Aktivierung von Lymphozyten zu einer gesteigerten VEGFR-1-Expression in PBMCs, die Hemmung 
dieser Wirkung durch den anti-TNF- $\alpha$-Antikörper Infliximab weist auf einen TNF- $\alpha$ vermittelten Effekt hin. Da jedoch Inkubation mit rekombinantem TNF- $\alpha$ in den hier durchgeführten Experimenten nur einen geringgradig steigernden Effekt auf die VEGFR-1-Expression hatte, sollte diese Vermutung in nachfolgenden Experimenten mit einer Messung des sezernierten endogenen TNF- $\alpha$ auf Proteinebene - z. B. mittels ELISA für sTNF-a oder mittels Durchflußzytometrie für die membrangebundene Form mTNF- $\alpha$ - überprüft werden. Im Übrigen wird VEGFR-1 auch auf T-Lymphozyten exprimiert (s. o.), Shin et al. zeigten zudem, dass Stimulation von T-Lymphozyten mit VEGF diese wiederum zu einer gesteigerten Bildung von IL-10 und INF-y anregt (Shin et al. 2009). T-Lymphozyten tragen zu einer VEGF-vermittelten Entzündung also einerseits durch die Produktion von VEGF bei, andererseits beeinflussen sie das Tumormikromilieu durch Freisetzung von Zytokinen und Beeinflussung der VEGFR-1-Expression.

Zusammenfassend zeigt die vorliegende Arbeit eine entzündungsbedingte Zunahme der VEGF- und VEGFR-1-Expression in aktivierten PBMCs des peripheren Blutes, dabei ergeben sich Hinweise auf eine Beteiligung der Lymphozyten sowie des Monozyten-Makrophagen-Systems. Eine Blockade von VEGF- wie sie mit dem Antikörper Bevacizumab bereits zur Hemmung der Tumorangiogenese eingesetzt wird - ist vor diesem Hintergrund auch auf immunologischer Ebene eine wirkungsvolle Methode zur Hemmung des Tumorwachstums. VEGFR-1 rückt in diesem Zusammenhang in den Focus der zielgerichteten Tumortherapie. Die Reifung und Mobilisation von Immunzellvorläufern im bzw. aus dem Knochenmark kann durch seine Blockade wirkungsvoll gehemmt werden (Abb. 49). So führte Applikation eines monoklonalen Antikörpers (mAb) gegen VEGFR-1 zu einem reduzierten Einwandern von Entzündungszellen in atherosklerotische Läsionen (Luttun et al. 2002). In einem Mausmodell zur Rheumatoiden Arthritis zeigte sich in der Synovia von mit anti-VEGFR-1 mAb behandelten Mäusen ebenfalls eine geringere Anzahl an Immunzellen, die mit einer Minderung der arthritischen Gelenkzerstörung einherging (Lee und Weinblatt 2001). 


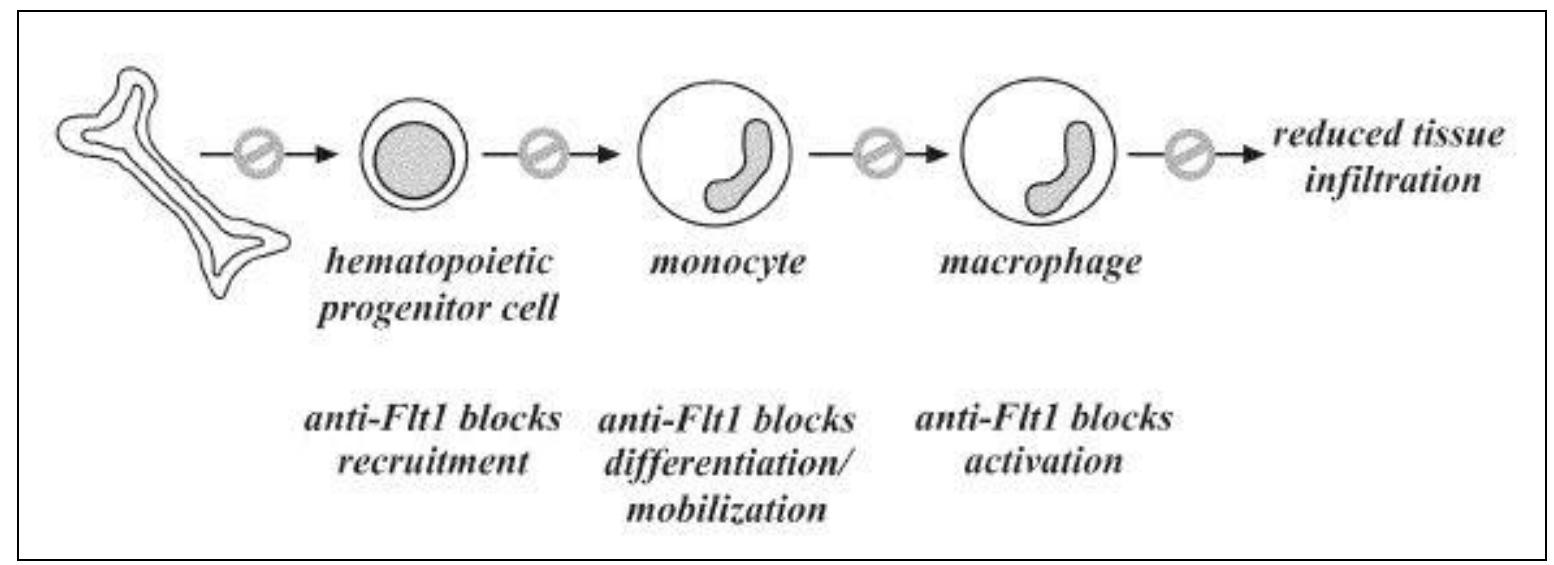

Abb. 49: Mobilisierung und Reifung von Immunzellen unter VEGFR-1-Blockade, aus: Luttun A, Tjwa M, Carmeliet P (2002): Placental growth factor (PIGF) and its receptor FIt-1 (VEGFR-1): novel therapeutic targets for angiogenic disorders. Ann N Y Acad Sci 979, 90

Am Ort der Entzündung wird die durch VEGFR-1 vermittelte Induktion der Bildung von TNF- $\alpha$ und verschiedenen Proteasen in reifen Immunzellen verhindert (Clauss 1998). Gleichzeitig bewirkt eine Blockade des VEGFR-1 die Hemmung der entzündlichen Eigenschaften von PIGF und VEGF-B. Einer Resistenzentwicklung durch PIGF-Überexpression im Rahmen einer anti-VEGF-Therapie kann dadurch entgegengewirkt werden (Ebos et al. 2007). Der Einsatz einer VEGFR-1-Blockade stellt durch diese multiplen Effekte eine wirkungsvolle Therapieoption bei chronischen Entzündungen und Tumorerkrankungen dar.

\section{2) Kolonkarzinomzellen}

\subsection{1) Expression von EGF und seinem Rezeptor EGFR-1 in unstimulierten HT-} 29- und DLD-1-Zellen

EGF

Obwohl EGF als Mitogen für Zellen des Darmepithels bekannt ist, ist seine Rolle in Karzinomen des menschlichen Kolons nicht vollständig geklärt. Dabei weisen Gewebeproben aus Kolonkarzinomen häufig EGF-Expression auf (Rajagopal et al. 
1995). Ito et al. konnten in Experimenten zur Expression verschiedener Wachstumsfaktoren in Kolonkarzinomzelllinien mittels Northern Blot keine EGFExpression in DLD-1-Zellen nachweisen (Ito et al. 1990). In unseren Experimenten gelang der Nachweis von EGF-mRNA mittels Real-Time-PCR in dieser Zellinie (Abb. 21). Die Expression von EGF durch HT-29-Zellen wurde in der Vergangenheit bereits nachgewiesen (Wu et al. 2009) und wird durch diese Arbeit bestätigt (Abb. 38). Klinisch korrelierte eine erhöhte Expression von EGF in Magenkarzinomen mit einer größeren Wachstumstiefe und einer erhöhten Proliferationsaktivität der Tumoren (Vondereck 2005). In in-vitro-Experimenten mit Kolonkarzinomzellen zeigte sich eine stimulierende Wirkung von EGF auf die Proliferation der mäßig differenzierten Moser-Zellen, während die stark metastasierenden KM12SM-Zellen durch EGF in ihrem Wachstum gehemmt wurden (Huang et al. 1992). Die Wirkung von EGF auf Tumorzellen ist demnach abhängig vom Tumortyp bzw. vom Differenzierungsgrad der Zellen. Im Tumormikromilieu kommt EGF als potenter Aktivator von VEGF zum Tragen: in einem Mausmodell zu Hauttumoren zeigte sich eine Phosphorylierung des VEGFR-1 nach Behandlung der Zellen mit EGF, wahrscheinlich ausgelöst über einen autokrinen VEGFMechanismus (Lichtenberger et al. 2010).

Zusamenfassend stellt eine gegen EGF gerichtete Antikörpertherapie zumindest keine optimale Therapieoption kolorektaler Karzinome dar, auch unter Berücksichtigung der hier gezeigten fehlenden EGF-Expression in PBMCS (s. o.) sowie der zu erwartenden Nebenwirkungen insbesondere auf den Gastrointestinaltrakt.

\section{EGFR}

Klinisch überexprimieren die meisten kolorektalen Karzinome auch EGFR, und sein Nachweis geht mit einer schlechten Prognose einher (Van Cutsem et al. 2004). In den hier durchgeführten Experimenten zeigte sich in den Kolonkarzinomzellinien DLD-1 Abb. 25) und HT-29 (Abb. 41) eine Expression des EGF-Rezeptors. Damit decken sich die hier gemachten Beobachtungen mit Untersuchungen aus der Vergangenheit: die EGFR/ErbB1-Expression auf DLD-1-Zellen wurde 2006 durch Mori et al. nachgewiesen (Mori et al. 2006), während die Expression von EGFR 
durch HT-29-Zellen von Wu et al. dokumentiert wurde (Wu et al. 2009). Die Blockade des EGFR mittels Tyrosinkinase-Inhibitoren oder Antikörpern hat sich fest in der heutigen Therapie von kolokrektalen Karzinomen etabliert. Dabei kommt die Wirkung der EGFR-Antagonisten zum einen über die Hemmung der EGFR-eigenen Wirkungen Zellproliferation und Antiapoptose zustande. Zum anderen wird auf diesem Wege auch die EGFR-vermittelte Bildung verschiedener tumor survival factors - wie die von VEGF - durch die Tumorzellen gemindert (Tabernero 2007, Abb. 50).

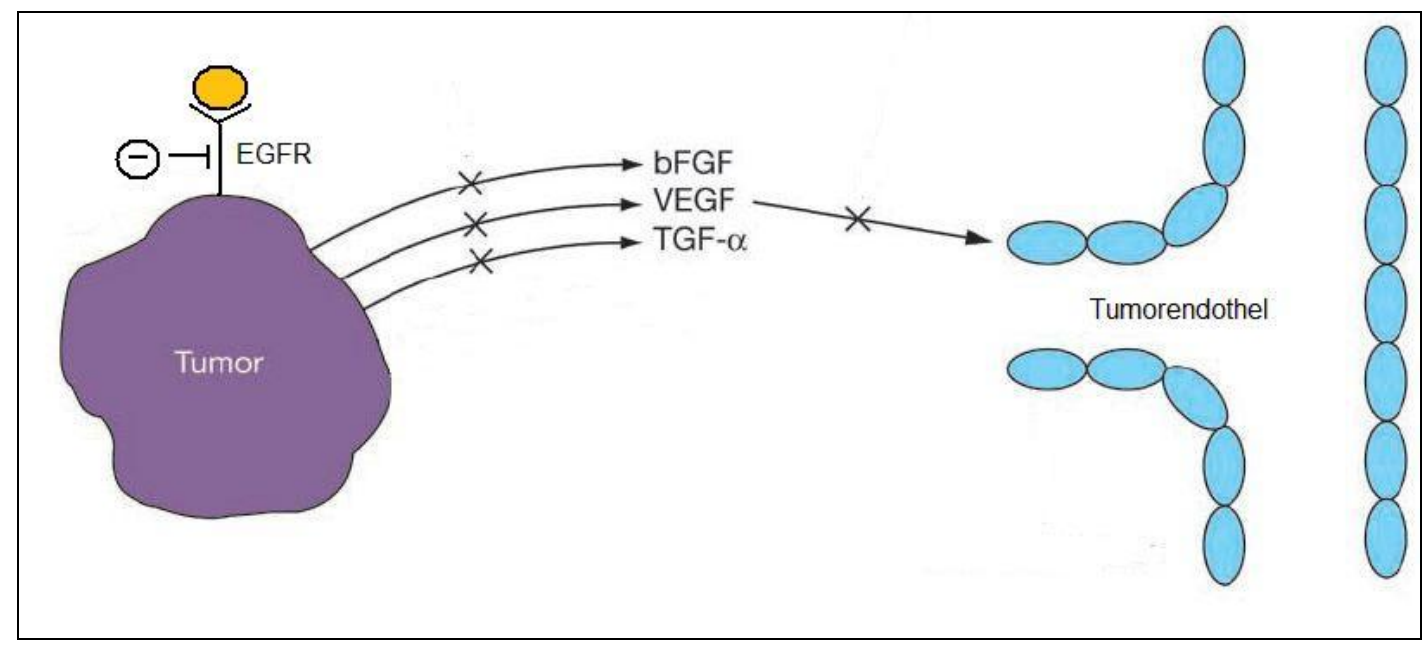

Abb. 50: Direkte und indirekte Antitumorwirkung einer EGFR-Blockade, aus: Tabernero J (2007): The role of VEGF and EGFR inhibition: implications for combining anti-VEGF and anti-EGFR agents. Mol Cancer Res 5(3), 213

\subsection{2) Expression von VEGF und seinem Rezeptor VEGFR-1 in unstimulierten} HT-29- und DLD-1-Zellen

VEGF wurde sowohl von DLD-1- (Abb. 29) als auch von den HT-29-Zellen (Abb. 45) exprimiert. Damit werden die Ergebnisse zu vorangegangenen Arbeiten zur Expression dieser Gene in der jeweiligen Zelllinie bestätigt (Shibata et al. 2008, Calvani et al. 2008). Die chemotaktische Wirkung von in Tumoren gebildetem VEGF führt zur Rekrutierung von Monozyten und Makrophagen, im Mausmodell auch von T-Zellen in Richtung des pathologisch veränderten Gewebes (Reinders et al. 2003). VEGF-vermittelte Einsprossung von Gefäßen und Vasodilatation begünstigen den 
Transport dieser Immunzellen zum Entzündungsherd. Die ebenfalls durch VEGF hervorgerufene Steigerung der Gefäßpermeabilität sowie eine VEGF-vermittelte Zunahme der Adhäsionsmoleküle ICAM-1, VCAM-1 und E-Selectin auf dem Tumorendothel begünstigen die Diapedese der Immunzellen durch die Gefäßwand ins Gewebe (Kim et al. 2001). Yoo et al. wiesen nach, dass durch VEGF außerdem die Freisetzung verschiedener Zytokine wie TNF- $\alpha$ und IL-6 aus benachbarten Monozyten angeregt und dadurch ein entzündliches Milieu geschaffen wird (Yoo et al. 2005). Bedingt durch die angiogenetischen und damit auch die Metastasierungfördernden Eigenschaften von VEGF gilt sie als negativer Prognoseparameter bezüglich Migration, Invasion und Gesamtüberleben bei Patienten mit kolorektalem Karzinom (Cao et al. 2009).

Auch VEGFR-1 wurde in den DLD-1-Zellen exprimiert (Abb. 33). VEGFR-1Expression in HT-29-Zellen konnte nachgewiesen werden, hier fiel sie jedoch sehr niedrig aus (Tab. 44). Für HT-29-Zellen wurde VEGFR-1-Expression in der Vergangenheit bereits beschrieben (Fan et al. 2005). Möglicherweise ist das Ausmaß der VEGFR-1-Expression abhängig vom Differenzierungsgrad der HT-29-Zellen, analog zu den von Cameron et al. gemachten Beobachtungen in Immunzellen c-kitpositiver GIST-Tumoren (Cameron et al. 2008). Die hier verwendeten HT-29 Zellen waren undifferenziert.

Es gibt Hinweise, dass Aktivierung von VEGFR-1 auf Kolonkarzinomzellen zu verstärkter Migration, Invasion und Koloniebildung der Zellen zu führt. Dabei konnte dieser Effekt nicht nur durch VEGF-A, sondern auch durch den VEGFR-1-Liganden VEGF-B ausgelöst werden (Fan et al. 2005). Klinisch wurde der Zusammenhang zwischen VEGFR-1-Expression und Metastasierungsgrad von kolorektalen Karzinomen indirekt bestätigt: es zeigte sich, dass eine niedrige VEGFR-1-Expression in Gewebeproben aus kolorektalen Karzinomen mit einer geringeren hämatogenen und lymphogenen Metastasierung korreliert (Simiantonaki et al. 2007). VEGFR-1 scheint in Kolonkarzinomzellen außerdem ein antiapoptotisches Signal zu vermitteln (Bates et al. 2003).

Das hier gezeigte gleichzeitige Vorkommen von VEGF und VEGFR-1 auf demselben Zelltyp (DLD-1) lässt vermuten, dass ein autokriner Rückkopplungsmechanismus aus 
VEGFR-1-Aktivierung und VEGF-Sekretion besteht, der es den Tumorzellen ermöglicht, ihre eigene Apoptose zu verhindern. Auf molekularer Ebene wird dieser Mechanismus zusätzlich getriggert: VEGFR-1-Aktivierung führt zur Induktion der zytosolischen Tyrosinkinase Src, die vor allem unter hypoxischen Bedingungen eine gesteigerte VEGF-Expression in Kolonkarzinomzellen zur Folge hat (Ellis et al. 1998). Zusammenfassend ist nicht nur das von Tumorzellen gebildete VEGF, sondern auch der VEGFR-1 - sofern exprimiert - auf der Tumorzelle ein geeignetes Ziel zur therapeutischen Beeinflussung von malignen Erkrankungen. Die bisherigen Ergebnisse zur VEGFR-1-Funktion in Kolonkarzinomen lassen vermuten, dass durch seine Blockade nicht nur das Zellüberleben in bereits bestehenden Tumoren, sondern auch deren Fähigkeit zur Bildung von Fernmetastasen beeinflusst werden kann.

\subsection{3) Regulation der Expression von EGF und VEGF sowie ihrer Rezeptoren in Kolonkarzinomzellen durch die Zytokine IL-1 $\beta$, TNF- $\alpha$ und IFN- $\gamma$}

Ein eindeutiger Effekt auf die Expression von EGF/R und VEGF/R- in den Tumorzellen konnte durch die Einzelinkubation mit den Zytokinen TNF- $\alpha$, IL-1 $1 \beta$ und IFN-y nicht erreicht werden, in DLD-1-Zellen zeigte sich jedoch nach Inkubation mit TNF- $\alpha$ oder mit IFN-y (Abb. 29) tendenziell ein Expressionsanstieg für VEGF zum Zeitpunkt 24h. Dabei ist der Effekt von TNF- $\alpha$ - wie in der Einleitung dargestellt - am ehesten auf Aktivierung des NF-KB-Signalwegs zurückzuführen. Der Effekt von IFN-Y ist unter Berücksichtigung des hohen Standardfehlers nur eingeschränkt beurteilbar.

In beiden Tumorzellinien führte kombinierte Inkubation mit TNF- $\alpha$ und IFN- $\gamma$ zu einem Anstieg der VEGF-Expression (Abb. 31, Abb. 47). In den DLD-1-Zellen zeigte sich dieser Effekt auch in der Expression von VEGFR-1 (Abb. 35), in den HT29-Zellen in der EGF-Expression (Abb. 39). Auch kombinierte Inkubation mit IL-1 $\beta$ plus IFN-y führte zu einem Anstieg der Expression von VEGF in beiden Zelllinien (Abb. 31, bzw. Abb. 47), in DLD-1-Zellen zeigte sich dieser expressionssteigernde Effekt auch für EGFR (Abb. 26). Die synergistische Wirkung von TNF- $\alpha$ bzw. IL-1 $\beta$ und IFN-y wurde bereits von Yeruva et al. für die Expression des Zytokins IP10/CXCL10 in DLD-1- und in HT-29-Zellen gezeigt (Yeruva et al. 2008). Der 
Synergismus zwischen TNF- $\alpha$ und IFN-y bzw. zwischen IL-1 $1 \beta$ und IFNy lässt sich demnach am ehesten durch eine frühe Konvergenz von Signalwegen erklären, die wiederum zur Aktivierung von Transkriptionsfaktoren wie NF-kB, IRF-1 und STAT1 führen (Yeruva et al. 2008), eine weitere denkbare Ursache ist die gleichzeitige Existenz von Bindungsstellen für sowohl TNF- $\alpha / N F-k B$ als auch für IFN- $\mathrm{Y} / \mathrm{IRF}-1 \mathrm{bzw}$. STAT1 in der Promotorregion des Zielgens (Lee et al. 2000). Zudem bewirkt IFN-y in HT-29-Zellen eine gesteigerte Produktion des TNF-Rezeptor (TNFR) 2, sodass TNF$\alpha$ in der Folge stärker wirken kann (Yeruva et al. 2008). Auffällig war, dass die synergistische Wirkung von IL-1 $\beta$ plus IFN- $\gamma$ in den HT-29-Zellen schwächer ausfiel als in den DLD-1-Zellen: in HT-29-Zellen zeigte sich unter Inkubation mit IL-1 $\beta$ plus IFN-y ein ca. zweifacher Anstieg der VEGF-Expression (Abb. 46), in DLD-1-Zellen derweil ein ca. sechsfacher Anstieg (Abb. 30). Dies liegt am wahrscheinlichsten darin begründet, dass HT-29-Zellen den IL-1 $\beta$-Rezeptor schwächer exprimieren als die DLD-1-Zellen (Panja et al. 1998).

Auffällig ist, dass sich in unseren Experimenten eindeutige Änderungen der Genexpression zum Teil frühestens nach einer Inkubationsdauer von $2 \mathrm{~h}$ zeigten, und auch dann nur unter kombinierter Inkubation mit zwei Zytokinen. Yeruva et al. erzielten messbare Veränderungen der Expression von CXCL10 in ihren Zellinien unter Inkubation mit TNF- $\alpha$ oder IFN-y einzeln bereits nach $40 \mathrm{~min}$. Offenbar folgt die Expression der Wachstumsfaktoren EGF und VEGF sowie die ihrer Rezeptoren jedoch einer langsameren Kinetik: Yang et al. beispielsweise bestimmten die maximale Expression des EGF-Rezeptors in DLD-1-Zellen nach Stimulation mit IFNa nach erst 72 Stunden bei einem Gesamtbeobachtungszeitraum von 96 Stunden (Yang et al. 2004). Der Beobachtungszeitraum für zukünftige Experimente dieser Art sollte demnach länger gewählt werden.

In der Zusammenschau haben die in vivo von aktivierten Immunzellen freigesetzten Zytokine TNF- $\alpha, \quad I L-1 \beta$ und IFN- $\gamma$ einzeln nur einen geringen Effekt auf die Genexpression der Wachstumsfaktoren EGF und VEGF und ihrer Rezeptoren. Erst die Kombination der Mediatoren führt zu einer deutlichen Veränderung der Expression des jeweiligen Gens. Für eine gegen EGF/R beziehungsweise VEGF/R gerichtete Tumortherapie mittels Modulation der Immunreaktion im entarteten Gewebe oder dem gesamten Organismus bieten sich somit multiple Ansätze. Dass 
der Einsatz des TNF- $\alpha$-Blockers Infliximab die Entstehung von kolorektalen Karzinomen auf dem Boden chronisch-entzündlicher Darmerkrankungen beeinflussen kann, wurde bereits erwähnt. Weiterhin laufen Studien zur Blockade von IFN- $y$ in CED. Patienten mit Morbus Crohn profitierten von zweimaliger Gabe des IFN- $\gamma$-Blockers Fontolizumab bei einem geringen Nebenwirkungsprofil (Hommes et al. 2006). In Anbetracht des von uns gezeigten Synergismus von TNF- $\alpha$ und IFN- $\gamma$ auf die Expression von VEGF und VEGFR in Zellen des Kolonkarzinoms erscheint eine Kombination der beiden Antikörper Infliximab und Fontolizumab als denkbare Option zur antientzündlichen und gleichzeitig antiangiogenetischen Tumortherapie. Auch eine kombinierte Therapie mit einem IL-1 $\beta$-Antagonisten und Fontolizumab wäre demnach sinnvoll. Wirkstoffe zur therapeutischen IL-1 $\beta$-Blockade wären beispielsweise der rekombinante IL-1 $\beta$-Rezeptorantagonist Anakinra, der in der Therapie der Rheumatoiden Arthritis angewendet wird, oder der monoklonale IL-1 $\beta$ Antikörper Canatimumab, der in der Behandlung des seltenen Cryoporin-assoziierten periodischen Syndroms (CAPS), eines Gendefekts, der mit einer chronischen IL-1Überproduktion einhergeht, Anwendung findet. 


\section{5) Zusammenfassung}

Verschiedene Erkrankungen gehen mit einer chronischen Entzündungsreaktion einher und begünstigen dadurch Tumorentstehung und -wachstum. Beispiele dafür sind der gastroösophageale Reflux und die Infektion mit Helicobacter pylori. Auch die chronische (Gastro-)Enteritis im Rahmen der sog. chronisch-entzündlichen Darmerkrankungen (CED) ist mit einem erhöhten Risiko der Tumorentwicklung assoziiert. Ein lokaler Reiz - bzw. im Rahmen der CED eine Kombination aus lokal wirksamen endo- und exogenen Faktoren - führt zum Zelluntergang und zur regenerativen Zellteilung. Dabei entstehen Mutationen, und Zellen mit fehlerhaftem Erbgut vermehren sich unkontrolliert. Gleichzeitig werden Immunzellen aus dem Blut angelockt, die Zytokine wie TNF- $\alpha$, IL-1 $\beta$ und IFN- $\gamma$ freisetzen und dadurch die Bildung von Wachstumsfaktoren wie dem epidermalen Wachstumsfaktor (EGF) und dem vaskulären endothelialen Wachstumsfaktor (VEGF) sowohl in Tumorzellen als auch in umliegenden Entzündungszellen bewirken. Das Zusammenspiel dieser sogenannten tumor survival factors bewirkt die Entwicklung eines das Tumorwachstum begünstigenden Mikromilieus.

Diese Arbeit diente der Untersuchung der Bildung der beiden Wachstumsfaktoren EGF und VEGF sowie ihrer Rezeptoren EGFR und VEGFR-1 in Immun- und Tumorzellen auf Ebene der mRNA. Es sollte gezeigt werden, inwieweit die jeweiligen Gene vom jeweiligen Zelltyp exprimiert werden und wie ihre Expression durch entzündliche Mediatoren beeinflusst wird. Weiterhin wird untersucht, ob Applikation spezifischer Antikörper - im speziellen anti-VEGF-Antikörper, anti-EGF-Antikörper und anti-TNF-a-Antikörper - die Genexpression verändert und ob eine solche zielgerichtete Antikörpertherapie somit als therapeutische Option von Tumorerkrankungen in Frage kommt. Zu diesem Zweck wurden Immunzellen aus dem Blut männlicher, gesunder Probanden isoliert und jeweils durch Zugabe von Phytohämagglutinin (PHA) oder Lipopolysaccharid (LPS) stimuliert. Kolonkarzinomzellen (DLD1- und HT-29) wurden mit den Zytokinen TNF- $\alpha$, IL-1 $\beta$ oder IFN- $y$ inkubiert. Die RNA wurde isoliert und in cDNA transkribiert. Anschließend wurde die Expression der Wachstumsfaktoren EGF und VEGF per Real-Time-PCR gemessen. 
Es zeigte sich, dass PBMCs EGF auf niedrigem Niveau exprimieren, Expression von EGFR konnte in innen nicht nachgewiesen werden. Derweil zeigte sich die Expression von VEGF, die nach Stimulierung des Monozyten-Makrophagen-Systems mit LPS anstieg. Behandlung der Zellen mit Infliximab führte zu einer Hemmung sowohl der LPS-induzierten als auch der basalen VEGF-Expression. Inkubation der Zellen mit TNF- $\alpha$ oder PHA hatte derweil keinen nennenswerten Effekt auf die Expression von VEGF.

VEGFR-1 wurde durch PBMCs exprimiert und seine Expression stieg durch Stimulierung mit LPS an. Auch hier fiel die LPS-induzierte Expressionssteigerung durch Zugabe von Infliximab geringer aus, ebenso wie die basale VEGF-Expression. Zugabe von anti-VEGF-Antikörper bewirkte im Gegenteil eine zusätzliche Steigerung der Genexpression. Auch Inkubation der Zellen mit PHA und TNF- $\alpha$ führte zu einem Anstieg der VEGFR-1-Expression, in beiden Fällen bewirkte Zugabe von Infliximab eine Hemmung dieses Effekts.

Die Kolonkarzinomzellen DLD-1 und HT-29 bildeten sowohl EGF und EGFR als auch VEGF. Die DLD-1-Zellen bildeten außerdem auf niedrigem Niveau VEGFR-1. Die Genexpression von EGF/R und VEGF/R-1 konnte zwar in beiden Zelllinien durch Behandlung mit den Zytokinen TNF- $\alpha$, IL-1 $\beta$ oder IFN- $\gamma$ - jeweils einzeln appliziert während des Beobachtungseitraums nicht wesentlich beeinflusst werden, es zeigte sich jedoch eine stark stimulierende Wirkung der Kombination aus IL-1- $\beta$ und IFN- $\gamma$ auf die Expression von VEGF in beiden Zelllinien, in den DLD-1-Zellen außerdem auf die Expression von EGFR. Die Kombination von TNF- $\alpha$ mit IFN-y bewirkte ebenfalls in beiden Zelllinien einen Anstieg der Expression von VEGF, in DLD-1-Zellen zeigte sich dieser Effekt auch in der Expression von VEGFR-1.

Eine antientzündliche Therapie mit Infliximab wirkt somit der Expression von VEGF in bestimmten Leukozytensubpopulationen und dadurch möglicherweise auch dem durch VEGF vermittelten Tumorwachstum entgegen. Die Wirksamkeit eines antiVEGF-Antikörpers zur Modulation der tumorinduzierten Immunreaktion bedarf weiterer Untersuchungen. Im Rahmen der Tumortherapie kommt eine VEGFBlockade offenbar vielmehr über eine Hemmung der VEGF-Wirkung auf Endothelzellen als auf Immunzellen zustande. Zusätzlich ergibt sich die Möglichkeit 
der Blockade von VEGFR-1, der von Immunzellen des peripheren Blutes und von bestimmten Tumorzelllinien exprimiert wird und dessen Expression unter Stimulation zunehmen kann. Auch der Einsatz von Antikörpern gegen Zytokine - z. B. Infliximab gegen TNF- $\alpha$, aber auch von Antikörpern gegen IL-1 $\beta$ und IFN- - - könnte demnach Tumorwachstum bremsen. Der praktische Nutzen dieser Option bedarf weiterer Untersuchungen, insbesondere auf klinischer Ebene. 


\section{6) Anhang: Abbildungsverzeichnis}

Abb. 1: Karzinogene Wirkung von TNF- $\alpha$ via NF-KB, nach: Burstein E, Fearon ER (2008): Colitis and cancer: a tale of inflammatory cells and their cytokines. J Clin Invest 118(2), 465.

Abb. 2: Effekte der EGFR-Aktivierung,

http://en.wikibooks.org/wiki/Structural_Biochemistry/Cell_Signaling_Pathways/Epidermal_Growth_Fac

tor_Signaling......

Abb. 3: VEGFR-1-Aktivierung auf Monozyten, aus: Tchaikovski V, Fellbrich G, Waltenberger J (2008): The molecular basis of VEGFR-1 signal transduction pathways in primary human monocytes.

Arterioscler Thromb Vasc Biol 28(2), 327

Abb. 4: EGFR-Blockade mittels Antikörpertherapie, nach: Krejsa C, Rogge M, Sadee W (2006):

Protein therapeutics: new applications for pharmacogenetics. Nat Rev Drug Discov 5(6), 516 ......

Abb. 5: Effekte von Bevacizumab, aus: Muhsin M, Graham J, Kirkpatrick P (2004): Bevacizumab. Nat

Rev Drug Discov 3(12), 995 20

Abb. 6: Wechselwirkungen zwischen Tumor- und Immunzellen .23

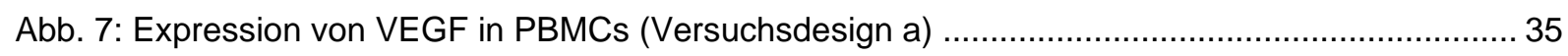

Abb. 8: Expression von VEGF in PBMCs (Versuchsdesign b) ....................................................... 36

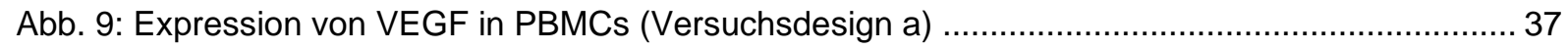

Abb. 10: Expression von VEGF in PBMCs (Versuchsdesign b) .................................................... 38

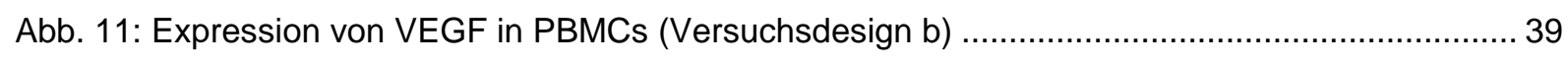

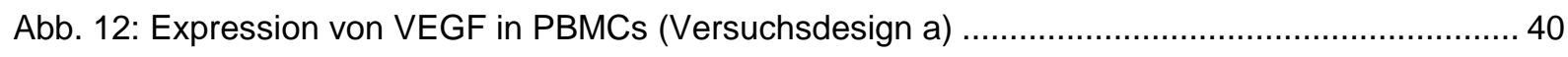

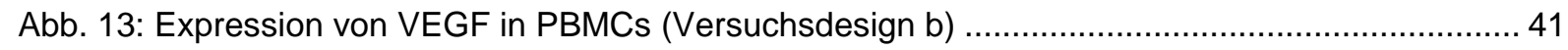

Abb. 14: Expression von VEGFR-1 in PBMCs (Versuchsdesign a) ................................................. 42

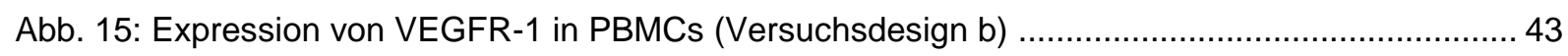

Abb. 16: Expression von VEGFR-1 in PBMCs (Versuchsdesign a) .................................................. 44

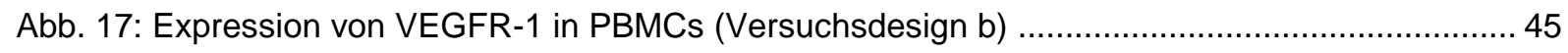

Abb. 18: Expression von VEGFR-1 in PBMCs (Versuchsdesign b) .................................................. 46

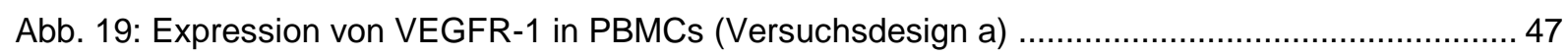

Abb. 20: Expression von VEGFR-1 in PBMCs (Versuchsdesign b) …............................................. 48

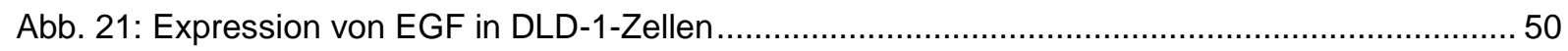

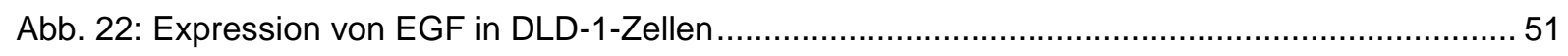

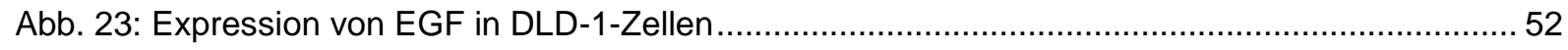

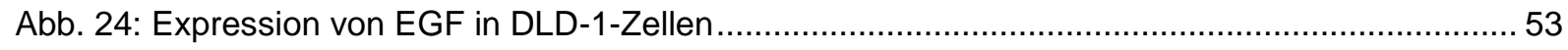

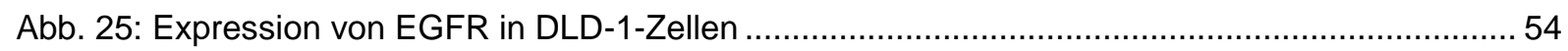

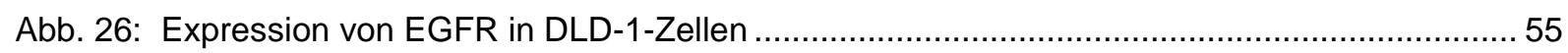




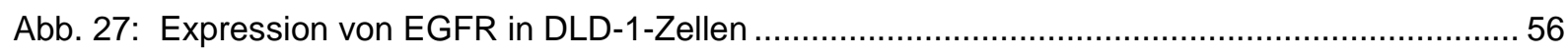

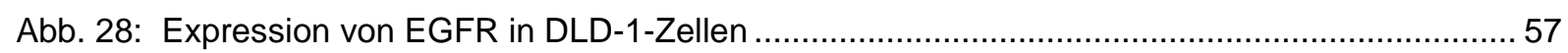

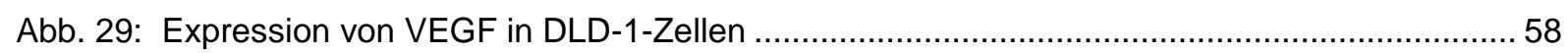

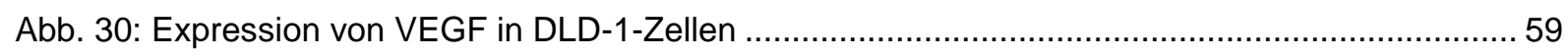

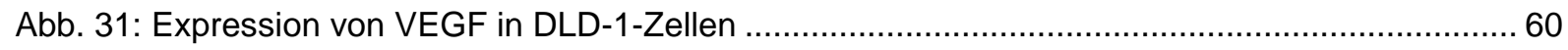

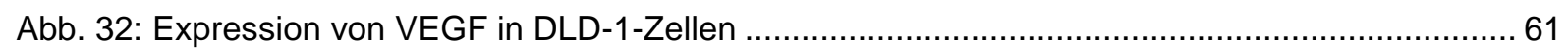

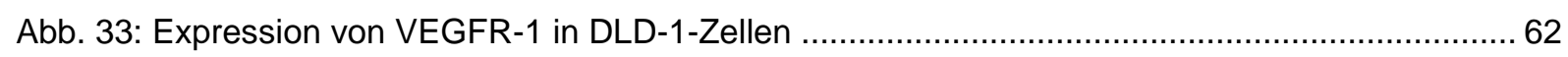

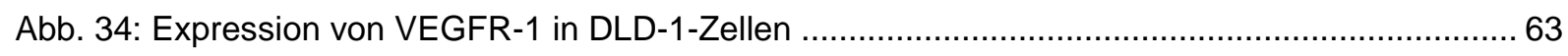

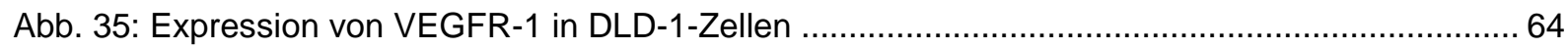

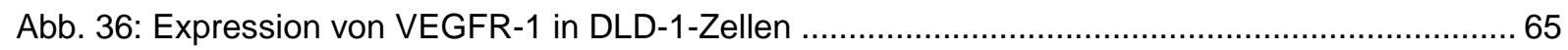

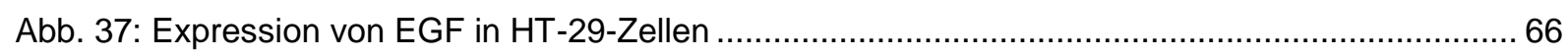

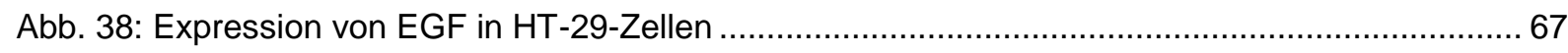

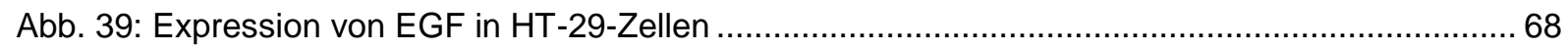

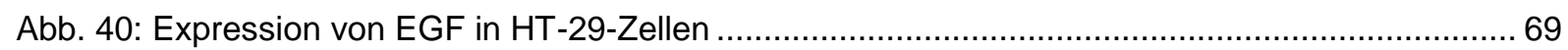

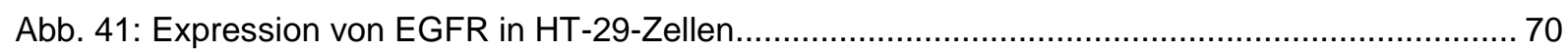

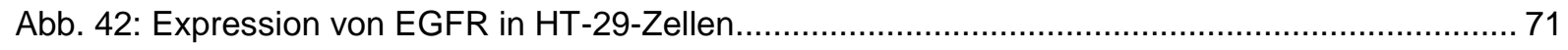

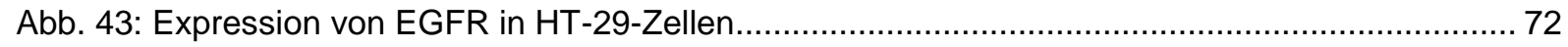

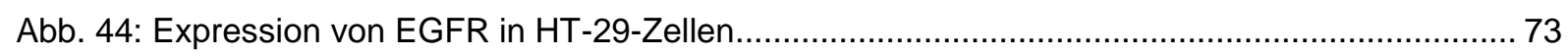

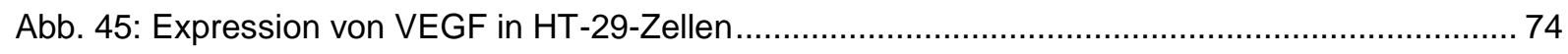

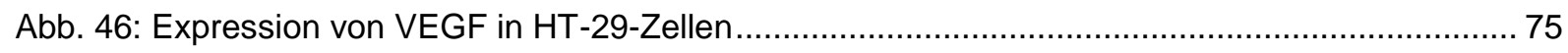

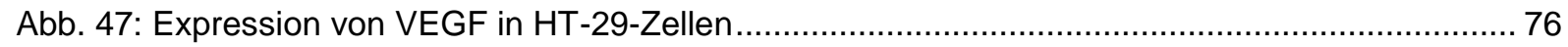

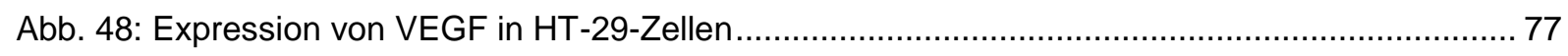

Abb. 49: Mobilisierung und Reifung von Immunzellen unter VEGFR-1-Blockade, aus: Luttun A, Tjwa M, Carmeliet P (2002): Placental growth factor (PIGF) and its receptor Flt-1 (VEGFR-1): novel therapeutic targets for angiogenic disorders. Ann N Y Acad Sci 979, 90

Abb. 50: Direkte und indirekte Antitumorwirkung einer EGFR-Blockade, aus: Tabernero J (2007): The role of VEGF and EGFR inhibition: implications for combining anti-VEGF and anti-EGFR agents. Mol Cancer Res 5(3), 213. 


\section{7) Literaturverzeichnis}

Adini A, Kornaga T, Firoozbakht F, Benjamin LE (2002): Placental growth factor is a survival factor for tumor endothelial cells and macrophages. Cancer Res. $\underline{62}(10), 2749-52$

Alitalo K, Carmeliet P (2002): Molecular mechanisms of lymphangiogenesis in health and disease. Cancer Cell 1 (3), 219-27

Ancelin M, Chollet-Martin S, Hervé MA, Legrand C, El Benna J, Perrot-Applanat M (2004): Vascular endothelial growth factor VEGF189 induces human neutrophil chemotaxis in extravascular tissue via an autocrine amplification mechanism. Lab Invest 84(4), 502-12.

Andus T, Daig R, Vogl D, Aschenbrenner E, Lock G, Hollerbach S, Köllinger M, Schölmerich J, Gross V (1997): Imbalance of the interleukin 1 system in colonic mucosa-association with intestinal inflammation and interleukin 1 receptor antagonist genotype 2. Gut 41(5), 651-7

Balkwill F, Mantovani A (2001): Inflammation and cancer: back to Virchow? Lancet 357(9255), 539-45

Bando H, Weich HA, Brokelmann M, Horiguchi S, Funata N, Ogawa T, Toi M. (2005): Association between intratumoral free and total VEGF, soluble VEGFR-1, VEGFR-2 and prognosis in breast cancer. Br J Cancer. 92(3), 553-61.

Barleon B, Siemeister G, Martiny-Baron G, Weindel K, Herzog C, Marmé D (1997): Vascular endothelial growth factor up-regulates its receptor fms-like tyrosine kinase 1 (FLT-1) and a soluble variant of FLT-1 in human vascular endothelial cells. Cancer Res $\underline{57}(23), 5421-5$

Basu A, Hoerning A, Datta D, Edelbauer M, Stack MP, Calzadilla K, Pal S, Briscoe DM (2010): Cutting edge: Vascular endothelial growth factor-mediated signaling in human $\mathrm{CD} 45 \mathrm{RO}+\mathrm{CD} 4+\mathrm{T}$ cells promotes Akt and ERK activation and costimulates IFN-gamma production. J Immunol 184(2), 545-9

Bates RC, Goldsmith JD, Bachelder RE, Brown C, Shibuya M, Oettgen P, Mercurio AM (2003): Flt-1dependent survival characterizes the epithelial-mesenchymal transition of colonic organoids. Curr Biol $\underline{13}(19), 1721-7$

Biancone L, Petruzziello C, Calabrese E, Zorzi F, Naccarato P, Onali S, Pallone F (2009): Long-term safety of Infliximab for the treatment of inflammatory bowel disease: does blocking TNFalpha reduce colitis-associated colorectal carcinogenesis? Gut $\underline{58}(12), 1703$

Böcker U, Schottelius A, Watson JM, Holt L, Licato LL, Brenner DA, Sartor RB, Jobin C (2000): Cellular differentiation causes a selective down-regulation of interleukin (IL)-1beta-mediated NFkappaB activation and IL-8 gene expression in intestinal epithelial cells. J Biol Chem $\underline{275}(16), 12207-$ 13

Bosani M, Ardizzone S, Porro GB (2009): Biologic targeting in the treatment of inflammatory bowel diseases. Biologics $\underline{3}, 77-97$

Burstein E, Fearon ER (2008): Colitis and cancer: a tale of inflammatory cells and their cytokines. J Clin Invest 118(2), 464-7

Calvani M, Trisciuoglio D, Bergamaschi C, Shoemaker RH, Melillo G (2008): Differential involvement of vascular endothelial growth factor in the survival of hypoxic colon cancer cells. Cancer Res $\underline{68}(1)$, 285-91

Cameron S, Haller F, Dudas J, Moriconi F, Gunawan B, Armbrust T, Langer C, Füzesi L, Ramadori G (2008): Immune cells in primary gastrointestinal stromal tumors. Eur J Gastroenterol Hepatol 20(4), 327-34 
Cañete JD, Pablos JL, Sanmartí R, Mallofré C, Marsal S, Maymó J, Gratacós J, Mezquita J, Mezquita $\mathrm{C}$, Cid MC (2004): Antiangiogenic effects of anti-tumor necrosis factor alpha therapy with infliximab in psoriatic arthritis. Arthritis Rheum 50(5), 1636-41

Cao D, Hou M, Guan, Jiang M, Yang Y, Gou H (2009): Expression of HIF-1alpha and VEGF in colorectal cancer: association with clinical outcomes and prognostic implications. BMC Cancer $\underline{9}, 432$

Chan G, Nogalski MT, Yurochko AD (2009): Activation of EGFR on monocytes is required for human cytomegalovirus entry and mediates cellular motility. Proc Natl Acad Sci USA 106(52):22369-74

Chen WS, Kitson RP, Goldfarb RH (2002): Modulation of human NK cell lines by vascular endothelial growth factor and receptor VEGFR-1 (FLT-1). In Vivo 16(6), 439-45

Clauss M (1998): Functions of the VEGF receptor-1 (FLT-1) in the vasculature. Trends Cardiovasc Med $\underline{8}(6), 241-5$

Cohen E (2006): Role of Epidermal Growth Factor Receptor Pathway-Targeted Therapy in Patients With Recurrent and/or Metastatic Squamous Cell Carcinoma of the Head and Neck. J Clin Oncol 24 , 2659-2665

Csiszár A, Szentes T, Haraszti B, Balázs A, Petrányi GG, Pócsik E (2004). The pattern of cytokine gene expression in human colorectal carcinoma. Pathol Oncol Res 10(2), 109-16

Cunningham D, Humblet $Y$, Siena S, Khayat D, Bleiberg H, Santoro A, Bets D, Mueser M, Harstrick A, Verslype C, Chau I, Van Cutsem EJD (2004): Cetuximab monotherapy and cetuximab plus irinotecan in irinotecan-refractory metastatic colorectal cancer. N Engl J Med 351(4), 337-45

de Paulis A, Prevete N, Fiorentino I, Rossi FW, Staibano S, Montuori N, Ragno P, Longobardi A, Liccardo B, Genovese A, Ribatti D, Walls AF, Marone G (2006): Expression and functions of the vascular endothelial growth factors and their receptors in human basophils. J Immunol 177(10), 732231

Deschoolmeester V, Baay M, Specenier P, Lardon F, Vermorken JB (2010): A Review of the Most Promising Biomarkers in Colorectal Cancer: One Step Closer to Targeted Therapy. The Oncologist $\underline{15}, 699-731$

Dratviman-Storobinsky O, Lubin BC, Hasanreisoglu M, Goldenberg-Cohen N (2009): Effect of subconjuctival and intraocular bevacizumab injection on angiogenic gene expression levels in a mouse model of corneal neovascularization. Mol Vis $\underline{15}, 2326-38$

Eales-Reynolds LJ, Laver H, Modjtahedi H (2001): Evidence for the expression of the EGF receptor on human monocytic cells. Cytokine $\underline{16}(5), 169-72$

Ebos JM, Lee CR, Christensen JG, Mutsaers AJ, Kerbel RS (2007): Multiple circulating proangiogenic factors induced by sunitinib malate are tumor-independent and correlate with antitumor efficacy. Proc Natl Acad Sci U S A 104(43), 17069-74

Ellis LM (2004): Epidermal growth factor receptor in tumor angiogenesis. Hematol Oncol Clin North Am. 18(5), 1007-21

Ellis LM, Staley CA, Liu W, Fleming RY, Parikh NU, Bucana CD, Gallick GE (1998): Down-regulation of vascular endothelial growth factor in a human colon carcinoma cell line transfected with an antisense expression vector specific for c-src. Eur J Cancer 34(3), 337-40

Fan F, Wey JS, McCarty MF, Belcheva A, Liu W, Bauer TW, Somcio RJ, Wu Y, Hooper A, Hicklin DJ, Ellis LM (2005): Expression and function of vascular endothelial growth factor receptor-1 on human colorectal cancer cells. Oncogene 24(16), 2647-53

Feistritzer C, Kaneider NC, Sturn DH, Mosheimer BA, Kähler CM, Wiedermann CJ (2004): Expression and function of the vascular endothelial growth factor receptor FLT-1 in human eosinophils. Am J Respir Cell Mol Biol 30(5), 729-35 
Feldmann M, Maini RN (2010): Anti-TNF therapy, from rationale to standard of care: what lessons has it taught us? J Immunol $\underline{185(2), 791-4}$

Ferrara N, Gerber HP, LeCouter J (2003): The biology of VEGF and its Receptors. Nat Med $\underline{9}(6), 669-$ 76

Fickova M (2002): Structure and activation of EGF-receptor: Minireview. Endocrine Regulations $\underline{36}$, 87-93

Fischer C, Jonckx B, Mazzone M, Zacchigna S, Loges S, Pattarini L, Chorianopoulos E, Liesenborghs L, Koch M, De Mol M (2007): Anti-PIGF inhibits growth of VEGF(R)-inhibitor-resistant tumors without affecting healthy vessels. Cell $131(3), 463-75$

Fragoso R, Igreja C, Clode N, Henriques A, Appleton C, Zhu Z, Wu Y, Dias S (2008): VEGF signaling on hematopoietic precursors restricts B-lymphoid commitment in vitro and in vivo. Exp Hematol $\underline{36}(10), 1329-1336$

França CM, Barros FM, Lotufo MA, Fernandes KP, Borra RC (2011): Response of peripheral blood mononuclear cells to conditioned medium from cultured oral squamous cell carcinomas. Braz Oral Res 25 (5), 414-20

Freeman MR, Schneck FX, Gagnon ML, Corless C, Soker S, Niknejad K, Peoples GE, Klagsbrun M (1995): Peripheral blood T lymphocytes and lymphocytes infiltrating human cancers express vascular endothelial growth factor: a potential role for T cells in angiogenesis. Cancer Res 55(18), 4140-5

Gerber HP, Condorelli F, Park J, Ferrara N (1997): Differential transcriptional regulation of the two vascular endothelial growth factor receptor genes. Flt-1, but not Flk-1/KDR, is up-regulated by hypoxia. J Biol Chem 272(38), 23659-67

Griga T, Gutzeit A, Sommerkamp C, May B (1999): Increased production of vascular endothelial growth factor by peripheral blood mononuclear cells in patients with inflammatory bowel disease. Eur $\mathrm{J}$ Gastroenterol Hepatol 11(2), 175-9

Guha M, Mackman N (2001): LPS induction of gene expression in human monocytes. Cell Signal. $\underline{13}(2), 85-94$

Hanauer SB, Feagan BG, Lichtenstein GR, Mayer LF, Schreiber S, Colombel JF, Rachmilewitz D, Wolf DC, Olson A, Bao W, Rutgeerts $P$ (2002): Maintenance infliximab for Crohn's disease: the ACCENT I randomised trial. Lancet 359(9317), 1541-9

Holtmann MH, Neurath MF (2004): Differential TNF-signaling in chronic inflammatory disorders. Curr Mol Med. $4(4), 439-44$

Hommes DW, Mikhajlova TL, Stoinov S, Stimac D, Vucelic B, Lonovics J, Zákuciová M, D'Haens G, Van Assche G, Ba S, Lee S, Pearce T (2006): Fontolizumab, a humanised anti-interferon gamma antibody, demonstrates safety and clinical activity in patients with moderate to severe Crohn's disease. Gut $\underline{55}(8), 1131-7$

Huang S, Trujillo JM, Chakrabarty S (1992): Proliferation of human colon cancer cells: role of epidermal growth factor and transforming growth factor alpha. Int J Cancer $\underline{52}(6), 978-86$

Hurwitz H, Fehrenbacher L, Novotny W, Cartwright T, Hainsworth J, Heim W, Berlin J, Baron A, Griffing S, Holmgren E, Ferrara N, Fyfe G, Rogers B, Ross R, Kabbinavar F (2004): Bevacizumab plus irinotecan, fluorouracil, and leucovorin for metastatic colorectal cancer. N Engl J Med 350(23), 233542

Ito M, Yoshida K, Kyo E, Ayhan A, Nakayama H, Yasui W, Ito H, Tahara E (1990): Expression of several growth factors and their receptor genes in human colon carcinomas. Virchows Arch B Cell Pathol Incl Mol Pathol 59 (3), 173-8 
Jelkmann W (2001): Pitfalls in the measurement of circulating vascular endothelial growth factor. Clin Chem $\underline{47}(4), 617-23$

Jendraschak E, Kaminski WE, Hessel F, Kiefl R, von Schacky C (1993): Growth factor mRNA profiles in unstimulated human mononuclear cells: identification of genes which are constitutively and variably expressed. Biochem Biophys Res Commun 196(1), 25-31.

Kaplan RN, Riba RD, Zacharoulis S, Bramley AH, Vincent L, Costa C, MacDonald DD, Jin DK, Shido K, Kerns SA, Zhu Z, Hicklin D, Wu Y, Port JL, Altorki N, Port ER, Ruggero D, Shmelkov SV, Jensen KK, Rafii S, Lyden D (2005): VEGFR1-positive haematopoietic bone marrow progenitors initiate the pre-metastatic niche. Nature $\underline{438}(7069), 820-7$

Karin M, Greten FR (2005): NF-kappaB: linking inflammation and immunity to cancer development and progression. Nat Rev Immunol $\underline{5}(10)$, 749-59

Kawakami M, Furuhata T, Kimura Y, Yamaguchi K, Hata F, Sasaki K, Hirata K. (2003): Expression analysis of vascular endothelial growth factors and their relationships to lymph node metastasis in human colorectal cancer. J Exp Clin Cancer Res 22(2), 229-37

Kay NE, Bone ND, Tschumper RC, Howell KH, Geyer SM, Dewald GW, Hanson CA, Jelinek DF (2002): B-CLL cells are capable of synthesis and secretion of both pro- and anti-angiogenic molecules. Leukemia $\underline{16}(5), 911-9$

Kim I, Moon SO, Kim SH, Kim HJ, Koh YS, Koh GY (2001): Vascular endothelial growth factor expression of intercellular adhesion molecule 1 (ICAM-1), vascular cell adhesion molecule 1 (VCAM1), and E-selectin through nuclear factor-kappa B activation in endothelial cells. J Biol Chem 276(10), $7614-20$

Kiriakidis S, Andreakos E, Monaco C, Foxwell B, Feldmann M, Paleolog E J (2003): VEGF expression in human macrophages is NF-kappaB-dependent: studies using adenoviruses expressing the endogenous NF-kappaB inhibitor IkappaBalpha and a kinase-defective form of the IkappaB kinase 2. Cell Sci 116(4), 665-74

Koutroubakis IE, Tsiolakidou G, Karmiris K, Kouroumalis EA (2006): Role of angiogenesis in inflammatory bowel disease. Inflamm Bowel Dis 12(6), 515-23.

Krejsa C, Rogge M, Sadee W (2006): Protein therapeutics: new applications for pharmacogenetics. Nat Rev Drug Discov 5(6):507-2

Lee AH, Hong JH, Seo YS (2000): Tumour necrosis factor-alpha and interferon-gamma synergistically activate the RANTES promoter through nuclear factor kappaB and interferon regulatory factor 1 (IRF1) transcription factors. Biochem J $\underline{350}(1), 131-8$

Lee DM, Weinblatt ME (2001): Rheumatoid arthritis. Lancet. 358(9285), 903-11

Lee SS, Joo YS, Kim WU, Min DJ, Min JK, Park SH, Cho CS, Kim HY (2001): Vascular endothelial growth factor levels in the serum and synovial fluid of patients with rheumatoid arthritis. Clin Exp Rheumatol 19(3), 321-4

Lichtenberger BM, Tan PK, Niederleithner H, Ferrara N, Petzelbauer P, Sibilia M (2010): Autocrine VEGF signaling synergizes with EGFR in tumor cells to promote epithelial cancer development. Cell $\underline{140}(2), 268-79$

Luttun A, Tjwa M, Carmeliet P (2002): Placental growth factor (PIGF) and its receptor Flt-1 (VEGFR1): novel therapeutic targets for angiogenic disorders. Ann N Y Acad Sci $\underline{979}, 80-93$

Matsumoto T, Mugishima H (2006): Signal Transduction via Vascular Endothelial Growth Factor (VEGF) Receptors and Their Roles in Atherogenesis. J Atheroscler Thromb $\underline{13}(3), 130-5$ 
McLaren J, Prentice A, Charnock-Jones DS, Millican SA, Müller KH, Sharkey AM, Smith SK (1996): Vascular endothelial growth factor is produced by peritoneal fluid macrophages in endometriosis and is regulated by ovarian steroids. $\mathrm{J}$ Clin Invest $\underline{98}(2), 482-9$

Mendelsohn J, Baselga J (2000): The EGF receptor family as targets for cancer therapy. Oncogene $\underline{19}, 6550-65$

Mor F, Quintana FJ, Cohen IR (2004): Angiogenesis-inflammation cross-talk: vascular endothelial growth factor is secreted by activated T cells and induces Th1 polarization. J Immunol 172(7), 4618-23

Mori K, Kitayama J, Shida D, Yamashita H, Watanabe T, Nagawa H (2006): Lysophosphatidic acidinduced effects in human colon carcinoma DLD-1 cells are partially dependent on transactivation of epidermal growth factor receptor. J Surg Res 132(1), 56-61

Moriconi F, Raddatz D, Ho NA, Yeruva S, Dudas J, Ramadori G (2007): Quantitative gene expression of cytokines in peripheral blood leukocytes stimulated in vitro: modulation by the anti-tumor nerosis factor-alpha antibody infliximab and comparison with the mucosal cytokine expression in patients with ulcerative colitis. Transl Res 150(4), 223-32

Muhsin M, Graham J, Kirkpatrick P (2004): Bevacizumab. Nat Rev Drug Discov $\underline{3}$ (12), 995-6

Murakami M, Zheng Y, Hirashima M, Suda T, Morita Y, Ooehara J, Ema H, Fong GH, Shibuya M. (2008): VEGFR1 tyrosine kinase signaling promotes lymphangiogenesis as well as angiogenesis indirectly via macrophage recruitment. Arterioscler Thromb Vasc Biol 28 (4), 658-64

Numata A (1992): Detection of endogenous IFN-gamma and TNF-alpha in tumor-infiltrating mononuclear cells of human colorectal cancer. Hokkaido Igaku Zasshi $\underline{67}(1), 40-53$

Olofsson B, Pajusola K, Kaipainen A, von Euler G, Joukov V, Saksela O, Orpana A, Pettersson RF, Alitalo K, Eriksson U (1996): Vascular endothelial growth factor B, a novel growth factor for endothelial cells. Proc Natl Acad Sci USA 93(6), 2576-81

Outtz HH, Wu JK, Wang X, Kitajewski J (2010): Notch1 deficiency results in decreased inflammation during wound healing and regulates vascular endothelial growth factor receptor-1 and inflammatory cytokine expression in macrophages. J Immunol 185(7), 4363-73

Panja A, Goldberg S, Eckmann L, Krishen P, Mayer L (1998): The regulation and functional consequence of proinflammatory cytokine binding on human intestinal epithelial cells. J Immunol $\underline{161}(7), 3675-84$

Park JE, Chen HH, Winer J, Houck KA, Ferrara N. (1994): Placenta growth factor. Potentiation of vascular endothelial growth factor bioactivity, in vitro and in vivo, and high affinity binding to Flt-1 but not to Flk-1/KDR. J Biol Chem 269(41), 25646-54

Popivanova BK, Kitamura K, Wu Y, Kondo T, Kagaya T, Kaneko S, Oshima M, Fujii C, Mukaida N (2008): Blocking TNF- $\alpha$ in mice reduces colorectal carcinogenesis associated with chronic colitis. J Clin Invest $\underline{118}, 560-570$

Qian BZ, Pollard JW (2010): Macrophage diversity enhances tumor progression and metastasis. Cell 141(1), 39-51

Rajagopal S, Huang S, Moskal TL, Lee BN, el-Naggar AK, Chakrabarty S (1995): Epidermal growth factor expression in human colon and colon carcinomas: anti-sense epidermal growth factor receptor RNA down-regulates the proliferation of human colon cancer cells. Int J Cancer $\underline{62}(6), 661-7$

Reinders ME, Sho M, Izawa A, Wang P, Mukhopadhyay D, Koss KE, Geehan CS, Luster AD, Sayegh $\mathrm{MH}$, Briscoe DM (2003): Proinflammatory functions of vascular endothelial growth factor in alloimmunity. J Clin Invest 112(11), 1655-65 
Robak E, Sysa-Jedrzejewska A, Robak T. (2003): Vascular endothelial growth factor and its soluble receptors VEGFR-1 and VEGFR-2 in the serum of patients with systemic lupus erythematosus. Mediators Inflamm 12(5), 293-8

Rutgeerts P, Sandborn WJ, Feagan BG, Reinisch W, Olson A, Johanns J, Travers S, Rachmilewitz D, Hanauer SB, Lichtenstein GR, de Villiers WJ, Present D, Sands BE, Colombel JF (2005): Infliximab for induction and maintenance therapy for ulcerative colitis. N Engl J Med 353(23), 2462-76

Salven $P$, Lymboussaki A, Heikkilä $P$, Jääskela-Saari $H$, Enholm B, Aase $K$, von Euler $G$, Eriksson U, Alitalo K, Joensuu H (1998): Vascular endothelial growth factors VEGF-B and VEGF-C are expressed in human tumors. Am J Pathol 153(1), 103-8

Sawano A, Iwai S, Sakurai Y, Ito M, Shitara K, Nakahata T, Shibuya M. (2001): Flt-1, vascular endothelial growth factor receptor 1 , is a novel cell surface marker for the lineage of monocytemacrophages in humans. Blood $\underline{97}(3), 785-91$

Selvaraj SK, Giri RK, Perelman N, Johnson C, Malik P, Kalra VK. (2003): Mechanism of monocyte activation and expression of proinflammatory cytochemokines by placenta growth factor. Blood 102(4), $1515-24$

Shibata A, Nakagawa K, Sookwong P, Tsuduki T, Tomita S, Shirakawa H, Komai M, Miyazawa T (2008): Tocotrienol inhibits secretion of angiogenic factors from human colorectal adenocarcinoma cells by suppressing hypoxia-inducible factor-1alpha. J Nutr $\underline{138(11), 2136-42}$

Shin JY, Yoon IH, Kim JS, Kim B, Park CG (2009): Vascular endothelial growth factor-induced chemotaxis and IL-10 from T cells. Cell Immunol 256(1-2):72-8

Simiantonaki N, Taxeidis M, Jayasinghe C, Kirkpatrick CJ (2007): Epithelial expression of VEGF receptors in colorectal carcinomas and their relationship to metastatic status. Anticancer Res $27(5 \mathrm{~A})$, 3245-50

Slipka S, Szántó S, Szucs K, Kovács I, Kiss E, Antal-Szamás P, Lakos G, Aleksza M, Illés A, Gergely $P$, Szegedi G (2001): Decreased arachidonic acid release in peripheral blood monocytes of patients with systemic lupus erythematosus. J Rheumatol 28(9), 2012-7

Tabernero J (2007): The role of VEGF and EGFR inhibition: implications for combining anti-VEGF and anti-EGFR agents. Mol Cancer Res $\underline{5}(3), 203-20$

Taichman NS, Young S, Cruchley AT, Taylor P, Paleolog E (1997): Human neutrophils secrete vascular endothelial growth factor. J Leukoc Biol 62(3), 397-400

Takahashi H, Shibuya M (2005): The vascular endothelial growth factor (VEGF) receptor system and its role under physiological and pathological conditions. Clinical Science 109, 227-241

Tchaikovski V, Fellbrich G, Waltenberger J (2008): The molecular basis of VEGFR-1 signal transduction pathways in primary human monocytes. Arterioscler Thromb Vasc Biol 28(2), 322-8

Tjwa M, Luttun A, Autiero M, Carmeliet P (2003): VEGF and PIGF: two pleiotropic growth factors with distinct roles in development and homeostasis. Cell Tissue Res $\underline{314}(1), 5-14$

Van Cutsem EJD, Tabernero J, Dias-Rubio E, Chirivella TA, Humblet Y, Van Laethem J-L, Kisker O, Farrès O, de Gramont A (2004): An international phase II study of cetuximab in combination with FOLFOX-4 in the first-line treatment of patients with mCRC expressing EGFR. Ann Oncol 15(3), iii91

Vendramini-Costa DB, Carvalho JE (2012): Molecular link mechanisms between inflammation and cancer. Curr Pharm Des. 18(26):3831-52

Virchow R.: Die krankhaften Geschwülste. August Hirschwald-Verlag Berlin, 1867 
Vondereck B: Expression und prognostische Bedeutung des epidermalen Wachstumsfaktors (EGF), transformierenden Wachstumsfaktor alpha (TGFa), EGF-Rezeptor (EGF-R) und des erbB-2-Proteins beim Magenkarzinom. Med. Diss. Düsseldorf 2005

Voronov E, Shouval DS, Krelin Y, Cagnano E, Benharroch D, Iwakura Y, Dinarello CA, Apte RN (2003): IL-1 is required for tumor invasiveness and angiogenesis. Proc Natl Acad Sci USA 100(5), $2645-2650$

Webb NJ, Myers CR, Watson CJ, Bottomley MJ, Brenchley PE (1998): Activated human neutrophils express vascular endothelial growth factor (VEGF). Cytokine 10(4), 254-7

Wicki A, Herrmann R, Christofori G (2010): Kras in metastatic colorectal cancer. Swiss Med Wkly $\underline{140}$, 13112

Wu WK, Tse TT, Sung JJ, Li ZJ, Yu L, Cho CH (2009): Expression of ErbB receptors and their cognate ligands in gastric and colon cancer cell lines. Anticancer Res $\underline{29}(1), 229-34$

Wyckoff J, Wang W, Lin EY, Wang Y, Pixley F, Stanley ER, Graf T, Pollard JW, Segall J, Condeelis J (2004): A paracrine loop between tumor cells and macrophages is required for tumor cell migration in mammary tumors. Cancer Res 64(19), 7022-9

Yang JL, Qu XJ, Russell PJ, Goldstein D (2004): Regulation of epidermal growth factor receptor in human colon cancer cell lines by interferon alpha. Gut $\underline{53}(1), 123-9$

Yao L, Sgadari C, Furuke K, Bloom ET, Teruya-Feldstein J, Tosato G. (1999): Contribution of natural killer cells to inhibition of angiogenesis by interleukin-12. Blood 93(5), 1612-21.

Yarden Y, Sliwkowski MX (2001): Untangling the ErbB signalling network. Nat Rev Mol Cell Biol $2(2)$, $127-37$

Yeruva S, Ramadori G, Raddatz D (2008): NF-kappaB-dependent synergistic regulation of CXCL10 gene expression by IL-1beta and IFN-gamma in human intestinal epithelial cell lines. Int $\mathrm{J}$ Colorectal Dis $\underline{23}(3), 305-17$

Yoo SA, Bae DG, Ryoo JW, Kim HR, Park GS, Cho CS, Chae CB, Kim WU (2005): Arginine-rich antivascular endothelial growth factor (anti-VEGF) hexapeptide inhibits collagen-induced arthritis and VEGF-stimulated productions of TNF-alpha and IL-6 by human monocytes. J Immunol 174(9), 584655 